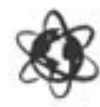

ISTITUTO ITALIANO DI

SCIENZE AMMINISTRATIVE

\section{PUBLIC ADMINISTRATION, COMPETITIVENESS AND SUSTAINABLE DEVELOPMENT}

\author{
Edited by \\ Gregorio Arena \& Mario P. Chiti
}




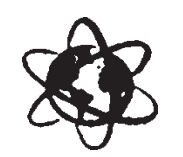

ISTITUTO ITALIANO DI

SCIENZE AMMINISTRATIVE

\title{
Public Administration, Competitiveness and Sustainable Development
}

\author{
Proceedings of the National Conference organized by \\ the Italian National Section of the IIAS \\ Trento, 23-24 May 2002
}

Edited by

Gregorio Arena \& Mario P. Chiti 
Public administration, competitiveness and sustainable development : proceedings of the national conference organized by the Italian national section of the IIAS : Trento,

23-24 May 2002 / edited by Gregorio Arena \& Mario P. Chiti . - Firenze : Firenze

University Press, 2003.

http://digital.casalini.it/fulltext is.asp?isbn=8884531004

Stampa a richiesta disponibile su http://epress.unifi.it

ISBN 88-8453-100-4 (online)

ISBN 88-8453-101-2 (print)

350.000945 (ed. 20)

Public administration - Italy - Congresses

Istituto italiano di scienze amministrative - IISA

Via Belmeloro 10

40126 Bologna (Italia)

www.iisa.it

Grafica e layout di Fulvio Guatelli

\section{(C) 2003 Firenze University Press}

Università degli Studi di Firenze

Firenze University Press

Borgo Albizi, 28, 50122 Firenze, Italy

http://epress.unifi.it/

Printed in Italy 


\section{INDEX}

MARIO P. CHITI

Introduction

Gregorio ARENA

Users, customers, allies: new perspectives

in relations between citizens and public administrations

Marco Bombardelli

Public Informatics, E-government and Sustainable Development ... 17

Bernardo Giorgio MatTarella

Control of administrative corruption and the rules of public ethics ......53

Alessandra Pioggia

The person as a strategic resource

in the administration of sustainable development

Stefano Battini

Policies for sustainable development:

economic globalisation and administrative globalisation

Giuseppe Cogliandro

Conclusions: Material on the Concept of Sustainability 



\section{Introduction}

Mario P. CHITI*

1. Upon its return to normal full-time operations this past decade, the Italian Section of the IIAS has engaged in carrying out an ambitious programme of initiatives on themes in the field of administrative law and the administrative sciences, thus restoring it to a leading role in the Italian legal and institutional community with an interest in such matters. Among them, I recall the study seminars on the administrative reforms in Italy, which became particularly important beginning in 1990; comparative law research on the administrative reforms in other European countries; the series of publications published in collaboration with the School of Administrative Sciences of the University of Bologna; and the active collaboration with other countries and National Sections of the Institute, in particular with Spain.

It was in part thanks to these initiatives that the IIAS decided to hold the first regional international conference in Bologna in 2000; the resulting work - which had the full support of our Section - has enjoyed remarkable success

A further advance in terms of initiatives undertaken by the Italian Section is the recent decision to participate in a more incisive way in the annual congresses organised by the Institute. To that end, each year the Section will hold its own national meeting for the purpose of discussing the theme of the following IIAS congress; the national meeting will revolve around a series of introductory reports which will be published in book form, along with the ensuing discussion and general conclusions.

In this way, the annual national meeting organised by the Italian Section will provide an important occasion for sensitising members of the group to the themes chosen by the Institute for consideration at the national congresses; for verifying how such themes - usually of a decidedly general nature and also designed with an eye to legal and institutional contexts quite different from those found in Italy - are relevant within the framework of our system; and, finally, for broadening the

* Università degli Studi di Firenze, Vice President of the Italian Section, Member of the IIAS Executive Committee.

Public administration, competitiveness and sustainable development, edited by Gregorio Arena \& Mario P. Chiti, ISBN 88-8453-100-4

(c) 2003, Firenze University Press 
ambit of the members of the Section, especially with reference to young scholars and to experts in European and comparative law.

The first meeting of this type was held in May 2002 in Trento, in collaboration with the University of Trento and thanks to the decisive contribution of Prof. Gregorio Arena, who teaches administrative law at the same university. The records of the meeting published in this volume demonstrate the coherence of the programme of the Section in terms of what was effectively accomplished. In fact, the theme of the International Congress "Towards Quality Governance for Sustainable Growth and Development" was in part nationalised, inasmuch as the theme of competitiveness was added to the topics for discussion in New Delhi; competitiveness is a crucial matter for our national system, which must measure itself against other administrative systems, especially within the European Union. In the matter of governance, emphasis was placed on the role of the public administration.

The task of treating the themes was assigned to young scholars distinguished for their research in these areas, whose reports were then discussed by leading authorities in the field. In addition to this volume, the results of the meeting appear in a monographic issue of Rivista italiana di diritto pubblico comunitario in order to reach a wider public and thus stimulate debate even among those who were unable to attend the meeting in Trento.

The next meeting of the Italian Section has been scheduled in keeping with the scheme indicated above, and therefore will have as its object the theme of the IIAS Congress to be held in Cameroon in 2003. The meeting will take place in Pavia, hosted by the University of Pavia, one of the oldest and most prestigious in Italy.

2. The theme of sustainable development is relatively new to Italy, at least from the standpoint of governance. As a matter of fact, for some time now debate over the question of the sustainability of development has been underway in relation to the environment and to public health, using technical notions devoid of legal relevance. More recently, however, attention has turned to other aspects of sustainability as well, now that a generally accepted meaning of the term has been reached which defines it as the sum total of policies for satisfying the needs of the present generation without compromising the capacity of future generations to satisfy their own needs.

Within this broader context the role of public administration is obvious, as the European Union has pointed out on the occasion of recent European Councils (in particular, the Gothenburg Council in 2002). More than any other factor, it is in fact the public administration that guarantees "a context able to influence innovation and encourage 
its spread, so that the solutions prevalent in the marketplace may become winning in terms of sustainable development as well" (so states the May 2002 advisory document of the European Commission in view of a Union strategy for sustainable development).

This entails a greater integration of public policies based on a systematic and transparent evaluation of the costs and effects; stable longterm management; and broad economic reform in order to create additional room for the market and to obtain "fair prices."

Can the European vision that inspires the Union's forthcoming initiatives hold true in the same terms for Italy as well? What margins exist for a balancing of national policies and Community policies according to the principle of subsidiarity? Are the Italian and European outlooks likewise relevant for developing countries, or countries in transition?

It is to these key questions - almost completely new to Italy - that the Trento meeting has attempted to provide an answer. The results which appear in this volume are now open to the critical gaze of the Institute and of the legal and administrative community. 



\title{
Users, customers, allies: new perspectives in relations between citizens and public administrations
}

\author{
Gregorio ArenA*
}

\author{
1. Introduction -2. The bipolar paradigm -2.1. Administration/the \\ administered -2.2. Administration/customers - 3. Citizens/allies
}

\section{Introduction}

Thanks to a radical change in the paradigm of reference a new phase is opening in thought on public administrations.

The first phase was based upon what an authoritative Italian scholar has called the "bipolar paradigm", according to the classic scheme of administration that realises the public interest by availing itself of the instruments typical of Administrative Law, and therefore ordering, authorising or prohibiting in its capacity of administration for the purpose of regulation, or else providing services and benefits in its capacity of administration for rendering the same. In this phase, the subjects to whom administrative action is directed are in a subordinate, passive position in the regards of the administration, as denoted by the very terms used to identify them: users, the administered, the assisted, patients and the like.

The second phase has been and still is marked by a business approach, the so-called New Public Management, based upon the three fateful "Es" (efficiency, effectiveness and economy), as well as upon the introduction into the public administration of management tools and methodologies borrowed from the world of private enterprise. The subjects to whom the administrations address themselves are no longer referred to as users, but as "customers" because it is thought that public administrations ought to entertain relations with citizens similar to those that entrepreneurs have with their customers.

Today a third phase is being entered, based upon a new pluralist, humanist paradigm which stands in contrast to the traditional bipolar paradigm, both in its authoritative version (first phase), and in its business approach version (second phase); the content of this new phase was ef-

*Università degli Studi di Trento.

Public administration, competitiveness and sustainable development, edited by Gregorio Arena \& Mario P. Chiti, ISBN 88-8453-100-4

(C) 2003, Firenze University Press 
fectively summed up in the opening remarks to participants at the IIAS 2002 Congress in New Delhi by the Vice Chairman of the Organising Committee, Dr V.K. Agnihotri, when he stated that "citizen-centric governance with a human touch is the aim of third-generation public administration".

The reference to "citizen-centric governance with a human touch", meaning a public administration that hinges on autonomous, responsible persons, and not on the administered or even on customers, is a familiar perspective for many Italian jurists both from the normative and scholarly standpoint; it is therefore from this outlook that the reflection contained in the pages to follow is developed.

As regards Italian norms in the subject matter, the reference is first and foremost to constitutional principles: Section 2, which recognises and guarantees the inviolable rights of man, but at the same time requires the fulfilment of duties in the area of political, economic and social solidarity; Section 3, which establishes the equality of citizens before the law, but likewise commits the public authorities to attending to the creation of conditions which make it possible for every person to fully realise himself (or herself), according to a conception that echoes Amartya Sen's theory of capabilities; and, finally, the last paragraph of the new Section 118 of the Constitution, which recognises to citizens the right to be sustained by the public authorities whenever they, the citizens, autonomously carry out initiatives which are in the general interest, based upon the principle of horizontal subsidiarity.

A second fundamental normative reference regards the law on administrative proceedings - Law n. 241/1990 - which has radically altered the arrangement of relations between the public administrations and the citizens in Italy, guaranteeing to the latter a whole series of rights to participation, to information, to interlocution, etc., which are incompatible with the preservation of the bipolar paradigm. Additional laws followed this one in the 1990s, introducing legal institutions tending under various profiles to place the relationship involving the public authorities and the citizenry on a more equal footing.

\section{The bipolar paradigm}

As instead regards Administrative Law scholarship, by this time the perception is widespread in Italy among more aware scholars of the crisis involving traditional analytical tools and of the necessity to find new interpretative methods.

\subsection{Administration/the administered}

Particularly significant in this respect is the position of one of the most authoritative Italian scholars, Sabino Cassese, who in a recent es- 
say uses the expression "bipolar paradigm" in order to indicate the dual elements upon which the relationship between the public administrations and citizens was based (and to a great extent still is based); and he cites two passages from the work of two illustrious Italian jurists of the century just ended, where the conception is expressed in an exemplary manner.

The first, Santi Romano, stated in his 1930 work Corso that "The subjects in the field of administrative law may be different in kind ... But the distinction which in our view appears fundamental and to which it is therefore necessary to subordinate all others, is the distinction between active subjects and passive subjects in relation to administrative power. It is thus necessary to make a distinction between, on the one hand, the subjects who administer, and who, taken together, constitute ... the public administration, and, on the other hand, the administered" ${ }^{1}$. The second, Massimo Severo Giannini, stated in turn in his 1950 work Lezioni that "In the present State communities (State community), on the one hand there are public authorities, who express themselves in the state organisation; while on the other hand, there are the persons, or private subjects, or citizens ... who possess certain fundamental rights. In the State communities there are, therefore, two forces, authority and freedom, which each have centres of support and of expression" 2 .

Cassese emphasises how, according to this traditional viewpoint "... the State and public law are dominated by the State/citizen conflict, two irreducible poles in contrast with one another. This paradigm has been slowly formed in the passage from systems, such as the medieval European system or extra-European systems, dominated by a power where there is no differentiation between State and civil society, to a system, such as the one we are living in, based upon the separation of State and community ..."”.

This is therefore "the fundamental paradigm of public law in the twentieth century: two separate poles, neither convergent, nor contracting, but in opposition owing to the superiority of one over the other; in order to compensate for such superiority, the stronger of the two is held to the observance of rules and duties, while the private one acts according to its own interest, in freedom, except for the external limits imposed by law. It is around this paradigm that the ways of legal study and knowl-

${ }^{1}$ S. Romano, Corso di diritto amministrativo, Padova, 1930, 83, op. cit. in S. Cassese, "L'arena pubblica. Nuovi paradigmi per lo Stato", Riv. trim. dir. pub., 3/2001, 602.

2 M.S. Giannini, Lezioni di diritto amministrativo, Milano, 1950, 71, op. cit. in S. Cassese, ibid.

3 S. Cassese, "L'arena pubblica. Nuovi paradigmi per lo Stato", Riv. trim. dir. pub., 3/2001, 602 . 
edge came to be formed and developed, for which reason it can be said that every nook and cranny is influenced by this basic contrast" 4 .

And in fact, as stated above, the usual modality of relations between administrations and citizens sees the latter only in the role of the administered, users, patients, the assisted - all of which are terms used by no mere happenstance to indicate that within the framework of the bipolar paradigm the administration can present itself as power, as well as a provider of services, but in any case the recipient of whatever administrative action is forever a passive subject merely on the receiving end of public intervention, whether it be an expropriation or a retirement benefit. Naturally, the administered person can make use of various instruments for safeguarding himself vis-à-vis the administration, ranging from the more traditional ones such as an appeal to the administrative judge to the more recent tool of resort to the ombudsman, but his position of subjection in the regards of the public administration remains unchanged.

\subsection{Administration/customers}

Within the framework of the bipolar paradigm recent years have witnessed the development of another modality of relations as well, one which casts the citizen no longer in the role of user, but rather that of "customer": this way of relating goes back to the early 1990s, with the introduction of Citizens' Charters in the United Kingdom and later other countries as well, among them Italy. Involved here is a modality of relationship that tends to explicitly reproduce the supplier/customer relation in the public sector, recognising to the customer the right to precise quality standards and to information about the same, as well as the right to be asked his opinion concerning the quality of the service.

As for the Italian experience in the application of the Carte dei servizi or Citizens' Charters, the impression is that on this occasion, as well as on many others, the reforms have been experienced by the administrations more as a mere bureaucratic requirement to be fulfilled than as an opportunity to change its modus operandi. As for the citizens, on the one hand the information on the existence of the standards provided by the Citizens' Charters has been and is skimpy indeed, while on the other hand the tools are lacking (but perhaps most of all the will is lacking) to make the opinion of users concerning the quality of services truly meaningful, so that it can produce effects similar to the effects that customer satisfaction or dissatisfaction produce in the private sector.

${ }^{4}$ S. Cassese, "L'arena pubblica. Nuovi paradigmi per lo Stato," Riv. trim. dir. pub., 3/2001, 604. 
In any event, above and beyond an assessment of the effectiveness of the Citizens' Charters and other comparable instruments, the positive aspect of the modality of the relationship based on a concept of the citizen as a customer lies in having made, at least in theory, the citizen emerge from the passive role of one who is administered and to have assigned him the role of sovereign: to attempt to introduce into the public services the approach defined as "customer-oriented" in fact means trying to break the traditional orientation of self-reference common to public bureaucracies in order that they be made aware that the very existence of the public services, in all sectors, is justified only insofar as they are effectively useful to the citizen.

In the relationship of the administration with the citizen/customer the role that can be played by what are defined as the "new rights" of citizens vis-à-vis the administration is made manifest particularly clearly; these range from the right to the efficiency and effectiveness of the public services to the right to the simplicity and economy of the administrative action, from the right to information to the right to participation, and so on. Besides, it is on this ground where the realisation of an administrative citizenship is being played out today in an attempt to make it able to take its place alongside and to integrate the other form of citizenship, which is political. The idea is to allow popular sovereignty to be fully realised, in appropriate forms, including in the area of relations between citizens and the institutions, which latter are represented by the public administrations.

However, there is also a negative aspect in considering the citizen as a "customer" of the administrations, which emerges above all when a mistaken spirit of emulation in the regards of the entrepreneurial model induces those operating in the public administrations to forget that the term "customer" applied to citizens is always just a metaphor, which is to say a way of soliciting public operators to devote to those who would otherwise be merely "the administered" the same care and attention that those who provide goods and services in a free market regime show their customers. Otherwise, the risk is that it will be forgotten that the customer is a subject who has the economic capacity to purchase goods and services on the market, while the citizen holds title to fundamental rights, constitutionally recognised and guaranteed, independent of the marketplace and not conditioned financially.

\section{Citizens/allies}

Finally, there is a third modality of relations, that which involves the relationship of the administration with a citizen/ally, wherein the basic approach is completely different: while the two modalities of re- 
lations discussed above are in fact both based upon the bipolar paradigm, meaning upon the separation of administrations and citizens (whether they be users or customers), this third type of relations instead hinges on the collaboration of the two, giving rise to a new model of administration, defined as "shared administration" .

This model is based on a very simple theory; that is, that persons are not only bearers of needs and demands, but also of capabilities and resources which, if appropriately taken advantage of by the public administrations, can contribute in a significant way to the satisfaction both of their exigencies and of interests of a general nature.

The fundamental reference, as previously stated, is first and foremost to the Constitution, as much as to the section on fundamental principles as to the new Title V. As regards the principles, reference can first of all be made to the "personalist" principle according to which the human being, with his exigencies as well as his capabilities, must always be at the centre of the activity of the public authorities: in fact, the Constitution assigns to the Republic the task of removing economic and social barriers which, by limiting de facto the freedom and equality of citizens, prevent the "full development" of the person (Section 3, par. 2). If the removal of the barriers is a condition sufficient for the full realisation of everyone, it can be inferred that the person is a bearer of latent capabilities that it is the task of the Republic, in various ways, to contribute to making develop.

Also Section 2, mentioned earlier, if read from the standpoint of shared administration, offers a constitutional footing for the request by the administration, addressed to the citizens, to contribute to the solutions of problems of general interest which the administration alone is unable to successfully deal with: such provision in fact states that "The Republic shall recognise and guarantee the fundamental rights of man ... and shall require the fulfilment of the inviolable duties of political, economic and social solidarity". The Founding Fathers, in drafting this provision, were thinking of such duties as participation in the political life of the country, the payment of taxes, the fulfilment of military obligations and the like; but today there is nothing that prevents, in a different perspective of the relations between administrations and citizens, also including among such duties of social solidarity that of the collaboration of citizens with the public administration for the solution of problems that interest their community of belonging, however large or small it may be.

${ }^{5}$ For a thorough examination of the characteristics of this model, cf. G. Arena, "Introduzione all'amministrazione condivisa", Studi parlamentari e di diritto costituzionale, n. 117/118, 1997, 29-65. 
But in today's Constitution there is an even more explicit reference to persons as bearers not only of exigencies, but also of capabilities and resources: it is contained in Section 118 of the new Title V, wherein it is stated that "State, Regions, Metropolitan Areas, Provinces and Communes shall encourage the autonomous initiative of citizens, individual and associated, for the carrying out of activities of general interest, based upon the principle of subsidiarity". The introduction into the Constitution of the principle of horizontal subsidiarity represents a radical departure in relations between citizens and public authorities, that thoroughly undermines the bipolar paradigm: if citizens are not only able to autonomously undertake initiatives in the general interest, but the public authorities must also sustain such initiatives, then the assumption so well put in the passage by Santi Romano quoted above falls by the wayside, according to which, "The subjects in the field of administrative law may be different in kind ... but the distinction which in our view appears fundamental and to which it is therefore necessary to subordinate all others, is the distinction between active subjects and passive subjects in relation to administrative power. It is thus necessary to make a distinction between, on the one hand, the subjects who administer, and who, taken together, constitute ... the public administration, and, on the other hand, the administered" 6 .

Such distinction of roles, with the consequent opposition between subjects who administer and subjects who are "administered", is no longer justified in view of the principle of horizontal subsidiarity; or rather, it is justified only in those sectors, typical of the administration of regulation, where the exercise of administrative power comes into play. But where instead the exercising of a function is involved, which is to say where the issue is no longer authority/freedom, but function/interest, the opposition between administration and the administered upon which the bipolar paradigm is based, no longer has a reason for being and, even more, considering the complexity of today's social problems, often risks constituting an obstacle to the solution of problems of the collectivity.

It must be emphasised that the overcoming of the bipolar paradigm and of the related contrast between administration/the administered does not at all signify a confusion of roles, nor of the related responsibilities; to the contrary, even in the specific application of the principle of horizontal subsidiarity represented by the model of shared administration the distinction between the respective roles of the administration and of the citizens is fundamental for the proper functioning of the model itself.

${ }^{6}$ S. Romano, Corso di diritto amministrativo, Padova, 1930, 83, op. cit. in S. Cassese, "L'arena pubblica. Nuovi paradigmi per lo Stato", Riv. trim. dir. pub., 3/2001, 602. 
Taking into account what has been said, as well as the energies and potentialities present to a greater or lesser extent in every society, it is therefore held that today it is possible to establish a relationship between administration and citizens in such a way as to make the latter become allies of the administration - active subjects who, by integrating the resources they bear with those with which the administration is endowed, assume part of the responsibility for resolving problems of general interest. In so doing, "citizen-centric governance" comes to be fully realised, where citizens are neither the administered nor customers, but rather at the heart of the administrative system, in that they are the leading actors in it.

In short, as Amartya Sen says, "Persons cannot be viewed just as passive beneficiaries of the process of development. Responsible adults must be responsible for their own well-being; it is up to them to decide how to use the capabilities they possess" $"$ 


\title{
Public Informatics, E-government and sustainable development"
}

\author{
MARCo BombardeLLi**
}

\begin{abstract}
1. Introductory remarks -2 . The basic conditions for the development of public informatics and e-government -3 . Public informatics and the introduction of e-government in the Italian public administrations -3.1. The design of the administrative reforms 3.2. The normative framework in the matter of public informatics -3.2.1. The evolution of the legal guidelines -3.2.2. The possibilities of using public informatics permitted under current legislation - 3.3. The level of development of public informatics in Italian administrations -3.4 . The overall attitude toward public informatics -4 . The potentialities of e-government for sustainable development -4.1. The impact on institutional profiles of development -4.2 . The impact on social profiles of development -4.3 . The impact on environmental profiles of development - 4.4. The impact on economic profiles of development -5 . The limits of public informatics and of e-government as factors for sustainable development -6. Co-operation with the developing countries for the expansion of public informatics and e-government
\end{abstract}

\section{Introductory remarks}

The purpose of the present work is to analyse how public informatics and e-government can contribute to sustainable development and to competitive growth. The analysis will be performed mainly with reference to the situation in Italy, moving on from there in an effort to understand how the conditions for development valid for Italy can be taken as a point of reference for co-operative ventures in developing countries.

As a preliminary step, it is necessary to define for present purposes the terms used in the title of this essay.

By public informatics is meant the entirety of the new technologies applied to the public administrations, understood as the complex of

* The present writing reproduces, with the addition of footnotes, the address delivered by the author on the occasion of the meeting "Pubblica amministrazione, competitività, sviluppo sostenibile”, held May 23-24, 2002 in Trento.

** Università degli Studi di Trento. 
information and communication technologies (henceforth referred to as ICT) which the public administrations avail themselves of in the fulfilment of their duties ${ }^{1}$.

By e-government is meant the use, as a substitute for traditionallyused instruments, of ICT in the work of government and in administrative activity, for the purpose of optimising, through a better and more transparent circulation of information, the internal and external relations of the administrative apparatus and to improve the supply of services to the citizenry through greater speed and flexibility in providing them².

By sustainable development is meant the entirety of the developments that pertain to conditions of human beings and their possibility of aspiring to a life worth living, where all may fully develop their capabilities in peaceful co-existence with others, with the natural environment and with the possibility for the existence and development of future generations ${ }^{3}$. Sustainable development thus defined is a model of development that has at its core the human being and is oriented toward a global improvement of the quality of the life of individuals and of society, where progress in economic terms represents a necessary but insufficient condition, and is to be pursued contemporaneously with the betterment of living conditions for the entire citizenry, social justice and the safeguarding of the environment, in a relation of interdependence and mutual reinforcement.

Having thus defined the above terms for further use, it must be remembered that, even if the meaning and the indicators of development are different depending on whether in reference to a developed country or a developing country, in both cases development depends in a significant way on the capacity of the public administration to operate in support of the society and economy of that country. Similarly, by now it is a generally accepted opinion that ICT are fundamental for

${ }^{1}$ On public informatics and the problems linked to its development in Italy, cf. G. Duni, "Teleamministrazione”, Enc. giur. Treccani, XXX, 1993, 1 and following; E. Zaffaroni, "L'informatica nella pubblica amministrazione", Foro amm., 1996, 2616 and following; P. Costanzo, "Aspetti e problemi dell'informatica pubblica", Studi in onore di V. Uckmar I, 1997, 291 and following.

${ }^{2}$ E-government is currently at the centre of attention in reflections on the reform and modernisation of the public administration both in Italy and in the other developed countries. For a recent overview of the theme, cf. G. Trauner, Le gouvernement électronique: les techniques d'information et de communication dans l'administration publique, Brussels, IISA, 2002, as well as the bibliography assembled by the same author available at <www.vwrecht.uni-linz.ac.at/ $>$ Concerning the experience of e-government in Italy, it is useful to consult <www.pianoegov.it $>$.

${ }^{3}$ For a definition of sustainable development, see the Declaration of Rio on the environment and development, adopted in Rio de Janeiro, January 3-14, 1992. 
assuring sustainable development, contributing to making it possible for all the entire citizenry, including the weaker social categories, to responsibly exercise their rights and duties, to develop the capabilities and skills of each, to develop the competitiveness of small and medium-sized enterprises, to reduce poverty, to increase popular participation in the public decision-making process, including through a greater flow of available information ${ }^{4}$.

The theme forming the topic of the present work thus is located in an area where two basic factors in development overlap, one being the presence of a modern, efficient public administration, and the other an evolved, dynamic ICT system. A great many implications are connected with these two factors, but the present report will limit itself to considering only what is included in this area of overlap, setting itself the twofold task of identifying how the use of ICT can improve the capacity of the public administration to play its role of providing support for development, and how intervention by the public administration can best orient ICT in their role of providing support for sustainable development.

Since reference will be prevalently be made to the situation in a developed country, Italy, an matter to which particular attention will be devoted is an understanding of how the use of ICT by the public authorities can contribute to an increased competitiveness of the national economy while at the same time respecting the need for social justice and environmental compatibility; to achieving a higher level of social and individual rights for the citizenry; to an increased participation of citizens in the life of the institutions and to the increased efficiency of the latter; to the search for systems for the production of goods and services with the least possible negative impact on the environment and which are therefore also respectful of the quality of the lives and development of future generations.

${ }^{4}$ Cf. Point 9 of the Declaration of Rio, and the even more specific Declaration E/ 2000/L9 by the Economic and Social Council of the United Nations, entitled "Development and International Cooperation in the 21st Century: The Role of Information Technology in the Context of a Knowledge-based Economy", where in particular it is stated that ICT “... can play an important role in accelerating growth, in promoting sustainable development and eradicating poverty in developing countries as well as countries with economies in transition...". The recognition of the importance of the new technologies as supporting factors for sustainable development is also indicated by many other phenomena, such as the establishment of the G8 Digital Opportunity Task Force and of the United Nations Information and Communication Technology Task Force, as well as the choice of ICT as the main topic of the United Nations Human Development Report 2001. 
In order to perform this analysis the first matter to be considered will be the present situation of the public informatics system in Italy, verifying whether the conditions for the adoption and development of an e-government system are met and, if so, how. It will then be necessary to examine in what way e-government is able to benefit sustainable development. It will likewise be necessary to point out the risks connected with its introduction and development, specifying how they may be dealt with, in order to avoid having them make vain the advantages obtainable with application of ICT to the public administrations. Once this framework is in place, it will be possible to investigate how Italy, through ICT, can co-operate with developing countries for the purpose of fostering sustainable development within them ${ }^{5}$.

\section{The basic conditions for the development of public informatics and e-government}

A fairly common error in dealing with the theme of the introduction of ICT into the public administration is to suppose that the matter is resolved with the introduction of informatics technologies and of automatic procedures for data processing in support of the activity of the offices, which in and of itself is imagined as being sufficient improve the effectiveness and the efficiency of the public administrations. The experience gained with the development of public informatics in Italy has demonstrated that the matter is not so simple. The early efforts to introduce informatics systems into the public administrations in fact were concentrated almost exclusively on said material aspects, which proved to be insufficient in dealing successfully with the many problems encountered, thus greatly reducing the potential benefits to be had from computerised information systems ${ }^{6}$. Three problems in particular have characterised the introductory phase of informatics in the public administrations of Italy.

The first is the lack of correspondence between traditional "administrative culture" and "informatics culture". An informatics linkup in fact requires an organisation in the form of a network, relational and

${ }^{5}$ A key aspect is involved here, in view of the role assigned to Italy within the framework of the G8 DOT Force and regarding the projects for partnerships with certain developing countries which are currently in the phase of realisation, concerning which see the records of the International Conference "E-government per lo sviluppo", held in Palermo on April 10-11, 2002 and available at <www.palermoconference2002.org>.

${ }^{6}$ For an analysis of these problems, cf. E. Zaffaroni, "L'informatica nella pubblica amministrazione", op. cit., 2616 and following; P. Costanzo, "Aspetti e problemi”, op. cit., 291 and following. 
interactive operative models, and a marked propensity for the exchange of information. The traditional administrative organisation is instead characterised by pyramidal structure with high vertical integration in a hierarchical sense; by a sequential, inflexible type procedural model conceived as a "series of acts" to the production of which the offices contribute with a "sealed compartment" mentality, and according to a rule of secrecy shrouding information in its possession, which presupposes not only the absence of links between the single records on file, but also and more generally, their inaccessibility.

The second problem is the absence of a specific planning capability in the area of administrative informatics in the initial switchover phase, which was characterised by the sporadic nature of the undertaking and by uneven results. The cause of it all is to be found in the lack of an internal, autonomous planning capability and in the related necessity to seek outside help for the planning of automatic information systems. This need in turn has produced high costs and considerable difficulty in the linkup of the various computerised information systems.

The third and final problem is the reductive way in which the potentialities of informatics has been viewed. The introduction of informatics into the public administration generally has been limited to the reproduction of existing bureaucratic procedure, in the conviction that informatics proceedings would be the simple reproduction through informatics technology of traditional administrative proceedings, accompanied by the fear that any departure from routine would have exposed formal errors committed in the course of administrative activity $^{7}$.

The fact that these problems exist shows how the absence of certain preliminary conditions, necessary for creating a favourable context for the introduction of public informatics, risks seriously jeopardising the very possibility for the development thereof, and consequently

${ }^{7}$ In addition to the authors cited in the previous footnote, for problems connected with the use of informatics in administrative proceedings, cf. M. Cammelli, "Procedura, decisione amministrativa e automazione", ed. P. Rizzo, Burocrazia e computer, Roma, Ediesse, 1988, 51 and following; V. Buscema, "Discrezionalità amministrativa e reti neurali artificiali", Foro amm., 1993, 620 and following; G. Duni, "Il procedimento amministrativo tra L. 7 agosto 1990, n. 241 e introduzione dell'amministrazione telematica", Foro amm., 1995, 226 and following; A. Natalini, "Sistemi informativi e procedimenti amministrativi", Riv. trim. dir. pubb., 1999, 449 and following; A. Masucci, "Il documento amministrativo informatico", ed. G. Arena, M. Bombardelli, M.P. Guerra and A. Masucci, La documentazione amministrativa. Certezze, semplificazione e informatizzazione nel D.P.R. n. 28 dicembre 2000, n. 445, Maggioli, Rimini, 2001, 173 and following. 
the capacity of informatics to exercise a positive influence on sustainable development.

The first of such preconditions is the existence of a unitary coherent design defining overall strategy and specifying the goals it is hoped will be achieved once the switchover to the informatics system is complete, which is in turn part of a vaster scheme for the reform of the public administration, including its organisation and procedures. It is within the framework of this more general reform process that public informatics and e-government must be placed, which in order to make an effective contribution to bettering the quality of administration must be accompanied by significant action to bring about the adaptation of the organisation to the changes introduced by ITC, as well as by a fresh definition of the comprehensive plan of the activity to which they shall be applied ${ }^{8}$.

The second necessary precondition for the development of public informatics and e-government is the presence of a normative framework compatible with the use of ICT such as not to create obstacles to their functioning. In particular, it is necessary that the legal standards which govern the administrative organisation be consonant with the need for horizontal integration typical of ICT; just as that the norms regulating administrative activity be such as to permit the compatibility of the informatics technologies with the requisites pertaining to the formal validity and legitimacy of administrative acts. This is fundamental in order that the use of ICT by the public authorities not get slowed down by the fear of committing formal errors in their activity and by the consequent constant attempt to select from among the procedural steps made possible by the use of informatics only those that easily fall within the traditional scheme of bureaucratic activity.

The third basic condition regards the equipping of the public administrations with adequate technological structures. That is to say, it is necessary that at the time when the administrations are called upon to use e-government techniques, that have at their disposal suitable, constantly updated technological tools such as to allow them to keep

${ }^{8}$ It is fundamental, for example, that the application of the new technologies not be simply imposed from above on pre-existent procedures, but rather after the simplification of procedures has been accomplished, as stressed by laws setting up standards in recent years, beginning with Law n. 537 of December 24, 1993, going on to the principles contained in Section 20, Law n. 59 of March 15, 1997 and continuing with the law for simplification that has been approved on an annual basis starting in 1999. It is likewise important that the strategies for the development of public informatics and of e-government be co-ordinated with the strategy for the development of public communication, pursuant to provisions contained in Law n. 150 of June 7, 2000; and the examples could go on. 
abreast of the continuous advances that characterise digital technology . The realisation of this precondition is not to be understood in static terms, as a mere guarantee that the administrations will be supplied with the necessary technologies, but rather in dynamic terms, in the sense of the endogenous development by the administrations of a specific capacity to plan and to realise their own automatic information systems, so as to make them capable of fully adapting such systems to their own needs and of playing an active role in their concrete, continuous evolution. This requires that precise internal responsibilities be defined for the planning of automatic information systems; that the modalities for interaction with the suppliers of the administration be specified, so as to avoid the "capture" of the administration by given suppliers in a perspective not the most conductive to the general welfare; that special care be devoted to the training and specialisation of public administration operatives in informatics technology skills, so as to put them in a position to exploit to the utmost the possibilities offer by ICT.

The fourth and final basic condition is the presence of an overall attitude favourable to the introduction of informatics technologies, so that both they and, most importantly, actions for bringing about the necessary reforms and changes for their profitable use are perceived as opportunities rather than as restrictions imposed on public employees called upon to use them in their everyday professional activity. In order for this attitude to be instilled steadfast determination is first of all necessary on the part of the political organs that provide direction and set the objectives of the public administrations with respect to the realisation of the reform process and their use as indispensable tools in this perspective. Furthermore, it is necessary that there be great sensitivity on the part of the leadership regarding the advantages connected with the introduction of informatics in addition to a full awareness on the

${ }^{9}$ What is stated in the text obviously holds true for the introduction of hardware and software in the public administrations, but also and above all holds true for the creation of the necessary linkage for the informatics interconnection among the networks of the different administrations, the fundamental importance of which was first underscored by sections 1 and 2, Legislative Decree n. 39 of February 12, 1993 and further developed with the Directive by the Prime Minister of September 5, 1995 and with the plan for the realisation of the Unitary Network of the public administration (available at $<$ www.aipa.it $>$ ), and further repeated in subsequent initiatives that aim at substituting the design of the above network with a National Network of the Public Administrations (cf. <www.di.unipi.it/parete www.ct.rupa.it>). As regards the problem of the integration of public information systems, cf. M. Minerva, "Verso l'integrazione dei sistemi informativi pubblici: la rete unitaria della pubblica amministrazione," Dir. inf., 1998, 623 and following. 
part of all concerned public employees that the switch to informatics can benefit them in their work. In other words, within the public administrations themselves there must be a powerful thrust to overcome the obstacles that may prevent exploiting the full potential of informatics, in the sense of the need to overcome bureaucratic procedures, the culture of formal procedures, and in short, the numerous obstacles that traditional administration used to place in the way of internal and external communication. Moreover, it is also necessary for ordinary citizens, businesses, associations and all others who entertain relations with the public administration to effectively and insistently solicit the same to complete the switch to on-line procedures, and at the same time to demonstrate by making use of them the intense interest of society in the new ways of carrying out administrative activity with the aid of informatics. In short, then, it is necessary that the pressure for the introduction of ICT be intense and shared by both public employees and the public at large, so as to avoid having the whole process be perceived as being imposed from the top.

\section{Public informatics and e-government in the Italian public administrations}

Having made clear the basic conditions for the development of public informatics and e-government, the next step is to verify whether these conditions are present in the Italian public administration and, if so, to what degree. Such verification is necessary in order to understand what are the presuppositions, if any, for the effective use of ICT and the techniques of e-government as tools for the support of sustainable development and for the competitiveness of Italy as a country.

\subsection{The design of the administrative reforms}

It has been previously seen how the possibilities of a profitable use of public informatics and of e-government depend first and foremost on the presence of an overall design for the development of public informatics and the inclusion of the same within a broader context of administrative reform. At the present time, it can be said that this condition has been brought about in Italy, at least on the normative plane.

In fact, it must first of all be noted how the process of creating a comprehensive strategy for the development of automatic information systems in the public administrations has been underway at least since the approval of Legislative Decree n. 39 of February 12, 1993, the first act having legal force devoted exclusively to public informatics, and then strengthened and made more precise by subsequent normative 
acts - which will be treated in greater detail below ${ }^{10}-$ which are largely summarised in Presidential Decree n. 445 of December 28, 2000, a Consolidation Act on administrative documentation ${ }^{11}$, and by the adoption of a national plan for e-government ${ }^{12}$. The norms just indicated are important because they define the features of the automatic information systems in the public administrations, the rules to be observed in their development, the objectives to be pursued through them, and the conditions for the filing and transmission of data, as well as the conditions for the validity of documents generated by means of informatics, therefore offering a coherent, organic picture of what public informatics can and must consist of, at least on the level of what ought to be.

However, a fact of even greater importance is that the above-mentioned provisions are contained in organic form within a broader normative framework of administrative reform, where they are configured as indispensable tools for fulfilling the same.

The reform of the public administration is a process that has been underway in Italy for over a decade, and which was set in motion thanks to a coherent framework of legislative action beginning with the 1990 reform laws regarding local autonomy and administrative proceedings; these have affected both the organisation and the activity of the public administration, with the aim of producing a public administration of higher quality compared to the past, meaning more efficient, simpler, less costly, more transparent, less authoritarian, more open to the participation of individual citizens and more attuned to fulfilling their needs, less hidebound in terms of formal competencies and capable of greater horizontal integration, all according to a logic of transversal collaboration with respect to traditional competencies, in view of the more satisfactory results expected of the public administration in pursuit of the general welfare ${ }^{13}$.

With this design for reform, for all the various difficulties in carrying it out, the administration has begun to shed its traditional adminis-

${ }^{10}$ Cf. infra, par. 3.2.1.

${ }^{11}$ On Presidential Decree n. 445/2000, cf. G. Arena, M. Bombardelli, M.P. Guerra and A. Masucci, La documentazione amministrativa. Certezze, semplificazione e informatizzazione nel D.P.R. n. 28 dicembre 2000, n. 445, Maggioli, Rimini, 2001.

${ }^{12}$ The plan of action for e-government 2000-2002 was adopted on June 23, 2000 and is available at $<$ www.pianoegov.it $>$.

${ }^{13}$ Literature is plentiful on the reforms which have involved the Italian public administration beginning in 1990: for an overview limited to the measures of certain heads of the Civil Service Department who succeeded one another in the "period of reforms", cf. S. Cassese, "La riforma amministrativa all'inizio della quinta Costituzione dell'Italia unita”, Foro it., 1994, V, 249 and following; F. Bassanini, Tendenze delle riforme amministrative, Spisa, Clueb, Bologna, 1998; A. Piazza, Stato e prospettive delle riforme amministrative, Spisa, Clueb, Bologna, 1999. 
tration/authority image, which placed it on a level superordinate to the general public and separate from ordinary citizens, legitimised only as an executor of norms, and configured in an impersonal, bureaucratic way as an apparatus essentially occupied with the production of administrative acts ${ }^{14}$. The notion of a "citizen oriented" public administration is gradually supplanting the old image: the new public administration operates with the participation of the citizen in administrative activity; it is regulated according to the principles of publicity, economy, effectiveness, efficiency and simplicity; and legitimised not only by the observance of the norms, but first and foremost by the quality of the services rendered and by the results achieved ${ }^{15}$.

Therefore, all the prerequisites have been met in order for the Italian public administration to evolve in the direction of higher quality, which will permit it to operate in a significant way in favour of sustainable development. In this sense, then, the introduction of public informatics and e-government appear not as self-contained goals, but rather assume the value of instruments for the fulfilment of the reform of the public administration, as well as growing in tandem with the determination to assure that the transformations underway in the administrations produce concrete results. In view of the close correlation with the administrative reform underway for a number of years, it can be affirmed that at least an early risk can be avoided: the risk of considering the introduction of ICT as a self-contained phenomenon, and as mere technical fact which as such would not be able to play an effective role propelling the public administration to further sustainable development.

\subsection{The normative framework in the matter of public informatics}

As previously mentioned, today the normative framework regulating public informatics in Italy is quite complete and coherent. After an

\footnotetext{
${ }^{14}$ On the tradition features of the Italian public administration, a concise, effective picture is provided by M. Nigro, "Amministrazione pubblica (organizzazione giuridica dell')", Enc. Giur. Treccani, II, 1988, 1 and following.

${ }^{15}$ On the need for the public administration to find its legitimisation not only in formal observance of whatever relevant norm disciplining its action, but also in the quality of the results obtained and in the capacity to satisfy the needs it is accountable for, cf. G. Berti, "Stato di diritto informale", Riv. trim. dir. pubb., 1992, 3 and following; L. Iannotta, "La considerazione del risultato nel giudizio amministrativo: dall'interesse legittimo al buon diritto", Dir. proc. amm., 1998, 299 and following; L. Iannotta, "Previsione e realizzazione del risultato nella pubblica amministrazione: dagli interessi ai beni", Dir. amm., 1999, 69 and following.
} 
initial phase when the introduction of ICT into the public administration was left to chance and only scarcely regulated, corrective steps began to be taken, at first of a sporadic nature, and then increasingly more organic and coherent. Such measures were taken beginning in the late 1980s, and may be broken down into at least four phases.

\subsubsection{The evolution of the legal guidelines}

In the initial phase a whole series of norms were approved for laying the groundwork for the co-ordination of public informatics and designed to guarantee that its development would be regulated and no longer casual and spontaneous as in the past. Other provisions were then added which, albeit still in limited areas, provided for some modalities for the circulation of administrative documents by means of informatics and telematics instruments ${ }^{16}$.

However, the second phase was more important, to such an extent that it can be considered a turning point in the true sense of the word, beginning with Law n. 241 of August 7, 1990, which with a number of its provisions contributes to making the discipline of administrative proceedings less formalistic, while at the same time introducing new organisational figures, such as the figure responsible for administrative proceedings and the conference of the services, which are more in keeping with the horizontal integration model of administrative organisation and therefore also more aligned with the organisational logic typical of informatics. This phase then progressed with the approval of Legislative Decree n. 29 of February 3, 1993, which introduced as fundamental criteria for administrative organisation the duty of internal and external communication, and of an informatics linkage between

${ }^{16}$ Belonging to the first group are, in particular, the Decree by the Prime Minister of February 15, 1989, circ. FP n. 36928 of October 4, 1989, circ. FP n. 51223 of May 21, 1990, and circ. FP n. 87328 of March 31, 1992. Belonging to the second group are, in particular, Section 15-quinquies of Law n. 38 of February 28, 1990 (a conversion of Legislative Decree n. 15 of December 28, 1989), which provides for automatic systems for the issue of civil status and other registry office certificates (with the use of such devices as water-marked sheets and/or embossed stamps), as well as the possibility to substitute a personal signature with a graphic signature; and Section 6-quater of Law $\mathrm{n}$. 80 of March 15, 1991 (a conversion of Legislative Decree n. 63 of March 15, 1991). This latter norm, in particular, limited to just local public institutions, has provided for the possibility of substituting the personal signature with a printed indication in the document of the name of the responsible party, along with a proviso that the inflow and reproduction of data, information and documents, as well as the outflow of administrative records by means of informatics systems, shall always be accompanied by an indication of the source and of the individual responsible for the inflow/outflow. 
and among administrations (Section 2), and which further provides for the establishment of internal and external "communications centres", such as public relations offices (Section 12), and culminated with the approval of Legislative Decree n. 39 of February 12, 1993, which completes the normative design in relation to the full transition to informatics in the public administration, indicating in complete and organic fashion the standards and purposes that must guide the overall development of public informatics ${ }^{17}$.

The subsequent and likewise very important third phase got underway in 1997 with certain important norms for the simplification of administrative activity, whereby the development of public informatics was assigned a fundamental role. The first such was Law n. 59 of March 15,1997 , which perfects the design of the unitary network of the public administration (par. 1) and - a point of fundamental importance introduces the effective conditions for asserting a more evolved conception of informatics proceedings than the traditional one, by providing that "the acts, data and documents produced by the public administration ... with informatics and telematics devices ... as well as their filing and transmission with informatics devices, are valid and relevant for all legal intents and purposes". To this must then be added Law n.

${ }^{17}$ Based on Legislative Decree n. 39/93, in particular, the development of public information systems must be inspired by the following criteria: rationalisation and interconnection (Section 1, par. 3); development of an internal planning capability (Section 2, par. 1); the establishment of a co-ordination centre inclusive of public informatics (Section 4 and following); extension to all designated public administrations of the provisions regarding the electronic signature and on the responsibility for the inflow of data as already provided for the local institutions pursuant to the norms examined in the "first phase" (Section 3, par. 2); discipline of the modalities for use of acts in electronic form (Section 3). The purpose is to assure the improvement of services; the transparency of administrative action; the strengthening of the cognitive support for public decisions; the containment of the costs of administrative action (Section 1, par. 2). The objectives indicated by Legislative Decree n. 39/93 have subsequently been pursued through a priority interdepartmental project as outlined in Directive by the Prime Minister of September 5, 1995, which sketches an overall model for the informatics linkup of the public administrations. In particular, this model has its underpinnings in the following points: access to data and to the procedures located in the information systems of the other administrations, the bringing about of suitable conditions for allowing "dialogue" between administrations and for so creating unitary centres for the furnishing of data and administrative services, decentralising the administration and bringing it closer to the citizen; the bringing about of the conditions for dialogue involving the information systems of the various public administrations; the configuration of the unitary network as the "network of networks", in which every administration links up with the informatics networks of the other administrations, while maintaining responsibility for it own network as regards its planning, realisation and functioning. 
127 of May 15, 1997, which further specifies the design of the national network (Section 17, par. 19), as well as specifying certain potentialities proper to informatics as a tool for administrative simplification (Section 2, par. 5). Section 4 of Law n. 191 of May 15, 1997 instead introduces important provisions in the matter of working remotely (from home), sometimes known as "telecommute work".

To the norms just mentioned must then be added the numerous regulations for their application, particularly Presidential Decree n. 513 of November 10, 1997, and Decree by the Prime Minister of February 8, 1999, pertaining to informatics documents and digital signatures; Presidential Decree n. 428 of October 20, 1998, pertaining to informatics protocol; Presidential Decree n. 70 of March 8, 1999, pertaining to telecommute work; Decree by the Prime Minister n. 437 of October 22, 1999, pertaining to electronic identification documents; and the Directive by the Prime Minister of October 28, 1999, pertaining to informatics management of the flow of documents.

At the termination of the third phase there was thus an ample body of norms on the matter of public informatics, with the only problem being that of the excessively fragmentary nature overall. For this reason, a fourth and current phase was needed, as a result of which for the most part the norms for fulfilment just mentioned have been gathered together and co-ordinated in a single text, Presidential Decree n. 445/ 2000. Also in the this same period work was begun in earnest on the introduction and development of e-government, through the formal approval of a Plan of Action ${ }^{18}$.

\subsubsection{The possibilities of using public informatics permitted under current legislation}

The evolutionary framework outlined above serves to point out how a favourable climate currently also exists on the normative plane for the introduction of public informatics and e-government in the Italian public administrations.

In particular, an increasingly greater interconnection among the public administrations is provided for through the use of informatics systems. The intended purpose is not only to facilitate more intense internal and external communication, but also to achieve a more satisfactory level of integration between and among the different organisational articulations, with the prospect that this might lead to considering the territorial administrations physically closest to a given popula-

\footnotetext{
${ }^{18}$ Concerning which see preceding footnote (12).
} 
tion as front-office terminals, including for other administrations more distant from where the consumers of whatever public service habitually lead their lives ${ }^{19}$. Along the same line, it is provided that in addition to being able to communicate among themselves and exchange documents by means of the informatics system, the public administrations may stipulate opportune agreements giving other administrations the right to access to their informatics records, thus laying the groundwork for the passage from a vertically integrated territorial administration to a horizontally integrated delocalised administration.

To this end a drastic reduction is in progress of the importance attributed to the traditional profiles of the formal legitimacy of administrative activity, which hitherto have always constituted an obstacle to a more rapid exchange of data and other information among the different public administrations. The salient fact in this respect is the recognition of the full validity for legal purposes of informatics documents, which paves the way for the so-called "paperless administration", where automatic information systems may be used in all the different stages of administrative proceedings, including the decision-making phase, so that the advantages such systems offer in terms of swiftness and the quantity of data transmitted is not reduced by the obligation for the end product to be on paper ${ }^{20}$.

This paves the way for the possibility of highly significant actions in the interest of the speed and efficiency of the procedures, which can be speeded up and made more transparent thanks to the fact that access is no longer necessarily conditioned by one's having physical access to government offices, which can be directly gained on-line.

In the same way, interaction between the administration and the citizen is facilitated, while increasingly more opportunities for "electronic

${ }^{19}$ In this sense the Plan of Action for e-government expressly provides that "the front office administrations shall bring about an integration of the services of back office administrations in order to provide integrated services according to the needs of the citizen and not according to the organisation of the administrations providing the services" in such a way that "the citizen shall be able to obtain every public service, to which he or she is entitled, by applying to any front office administration qualified to render the service, regardless of any restriction in terms of territorial competence or residence".

${ }^{20}$ Worth mentioning in this regard is the profound difference that exists between the formulation of Section 3, par. 1, Legislative Decree n. 39/93, which makes reference to paper documents that must as a rule be produced by means of automatic information systems, and the formulation of Section 15, par. 2 of Law n. 59/97, which recognises the legal validity per se of the informatics document. Concerning the prospects of paperless administration and of tele-administration, cf. G. Duni, "Teleamministrazione", op. cit., 1 and following. 
contact" are envisioned at the various levels where such interaction may take place. For example, punctual forms of electronic contact between the citizen and administration are possible in those instances where only one contact is needed for the citizen to obtain the service or information required to resolve the matter ${ }^{21}$. However, also provided for are more significant modalities for the use of informatics in relations with the general public, such as providing that individuals do not have to go to public administration offices to pick up the forms and formularies necessary in order to take part in a proceeding, but instead can just "download" whatever electronic formularies have previously been made available through the administration's Web site, with the final step being to electronically submit the compiled forms to the same Web site ${ }^{22}$.

The opportunities provided by the rules and regulations do not end here because it is possible that, on the basis of the provisions that have been reviewed, certain services may be rendered entirely through electronics ${ }^{23}$, and even that through public informatics the real possibility for a citizen to participate in an administrative proceeding and, therefore, in shaping administrative decision-making may be increased and become more effective ${ }^{24}$.

${ }^{21}$ Concerning this form of realisation of e-government, in particular cf. G. Trauner, Le gouvernement electronique, op. cit., 29 and following.

${ }^{22}$ Involved are e-government modalities of the type identified by G. Trauner, Le gouvernement electronique, op. cit., 29 and following, as "E-form" and, at least in part, "Electronic Service Delivery". It should be noted in this respect that Section 9, par. 3 of Presidential Decree n. 445/2000, provides that "The public administrations shall attend to defining and making available via telematics electronic forms and formularies valid for all intents and purposes", while Section 38, par. 2, provides that "The requests and declarations submitted via telematics shall be valid when undersigned by means of a digital signature or when the undersigned is identified by the informatics system with the use of an electronic identification card" and Section 43, par. 6 provides that "The documents transmitted by anyone to a public administration via fax, or using another telematics or informatics device suitable for verifying its source, shall meet the requirement of submission in written form and the transmission of the same need not be followed by the original document". The overall effect of these normative provisions leads to the obvious conclusion is that there are no legal obstacles to the management of administrative proceedings through the use of informatics devices.

${ }^{23}$ Some significant examples of how services can be provided in electronic form by the public administration are contained in L. Marasso, Metodi e strumenti di egovernment, Maggioli, Rimini, 2001, 261 and following; these range from demographic services to the issue of licences and permits, from the payment of charges for social services to the organisation of home delivery of meals for the elderly, from the distribution of special tickets for public transportation to the restitution of private means subjected to administrative seizure, etc.

${ }^{24}$ It is to be observed, for example, how the provision contained in Section 43, par. 6 of Presidential Decree n. 445/2000, which forms the basis for the recognition of 


\subsection{The level of development of public informatics in the Italian} administrations

However, one must not be misled by the fact that a normative framework exists which is favourable to the development of public informatics and e-government into thinking that they are already a reality in the various Italian public administrations. The truth of the matter is that the question of the effective application of the norms is still open, with it being very often slow and incomplete due both to the inadequacy of the necessary technological infrastructure and to the delays in the taking root of an administrative culture favourable to their use and in the consequent identification within the administrations of the necessary skills for the use, planning and constant updating of the automatic information systems.

It thus must be observed that today, despite steps being taking in the right direction, many public administrations still exist with an inadequate level of technological development, where the hardware and software equipment is present, but not always up-to-date and, most importantly, not always exploited to the hilt. Furthermore, the effective level of development of the integration of the network among the administrations is even lower, not so much merely in terms of access to the Internet, which by now is rather common, as much as in terms of the creation of networks able to bring about the horizontal integration of the different public administrations ${ }^{25}$.

This situation depends a great deal on the persistence of an administrative culture dominated by the logic of a clear separation of the different organisational articulations, from which derives a low level of integration and a habit of managing information in a way far removed from mutual communication. This has produced an absence within the Italian public administrations of a specific sensitivity vis-à-vis the opportunities for organisational integration offered by informatics and, therefore, slight attention to its development in that sense.

In order to overcome the problem certain specific provisions have been introduced which were taken from the rules and regulations pre-

the complete validity of the transmission via informatics by anyone of documents to the public administration, can contribute to making quicker and more efficient the "submission of communications and documents", which provides the main way for participation in administrative proceedings pursuant to Section 10 of Law n. 241/90.

${ }^{25}$ On this point the indication contained in the Plan of Action for E-government 2000-2002 is fundamental, which states that "... the information systems of all the administrations shall be connected by means of a network among equals and without hierarchies that reflect institutional or organisational superstructures. The limitations and restrictions on interaction between the systems shall derive only from the nature of the services to be provided". 
viously reviewed, and aim at focusing attention on the strategic and operational aspects of informatics through a more exacting definition of the existing responsibilities within the administrative organisation for the use and development of automatic information systems.

In the first place, Section 2 of Legislative Decree n. 39/93 and Directive by the Prime Minister of September 5, 1995 expressly provided that the responsibility for the planning, management and verification of the proper functioning of the information systems of the individual administrations shall be identified within the administrations themselves. Every administration ought therefore to have a person responsible for the planning and development of the informatics system, who ought to play an active role, among other things to verify the adequacy of the technological infrastructures and the level of informatics integration in that particular administration, including actively intervening to report any malfunctioning and take whatever corrective measures necessary.

But the responsibility for the development of informatics is not limited to just this organisational figure. In fact, pursuant to the original contents of Section 20 of Legislative Decree n. 29/93, and now, after the abrogation of the same section only to be repeated in Legislative Decree n. 286 of July 30, 1999, the manager is called upon not only to answer for the official acts, but above all for the results achieved in terms of the allocated budget. This ties the manager's responsibility to his or her capacity to manage the allocated resources, among them being resources for informatics. For this reason, one of the specific duties of managers can be held to be that of always verifying and updating the level of the computerisation of the structures they are intended for, furthermore bearing in mind in making decisions affecting organisation the need for informatics linkage among administrations, which pursuant to Section 2 of Legislative Decree 165/2001 is considered as being among the criteria that must inform administrative organisation.

Finally, the responsibility for verifying the practical effectiveness of the informatics structures with which the offices are equipped and for calling attention to the eventual shortcomings, as well as for assuring the efficiency of the modalities for effecting the communications necessary for the performance of whatever administrative proceedings, and therefore for the acquisition or transfer of the pertinent information, is assigned by the rules and regulations to specific organisational figures, such as the person responsible for whatever administrative proceeding and the offices for relations with the public (URP).

It can thus be said that the requisites are present for proceeding in discerning and coherent fashion in the direction of an increased development of informatics in the Italian public administrations. Once again, 
however, the problem lies in the application of the relevant rules contained in the norms, which at present can certainly not be said to be complete.

\subsection{The overall attitude toward public informatics}

As previously stated, the transition of traditional administration to e-government is not automatic, nor does it come about by virtue of the mere presence of a favourable normative climate, or even just because the administrative structures are equipped with adequate technology. It is in fact also necessary that the norms be applied and that the technology be used correctly, but in order for that to happen there must be a full awareness both within and without the administration of the full potential of ICT, as well as strong pressure for making use of them to the end of overall improvement in the quality of the public administrations $^{26}$. An examination of the situation in Italy reveals that here, too, there are bright and dark spots.

At the political level the impulse for the introduction of ICT into the public administrations is present beyond a doubt, mainly because this allows its promoters to cast themselves in the role of modernisers of the administration bent on bringing about the simplification of its activity and the elimination of the red tape characteristic of traditional administration. The problem, though, is that this interest in having a computerised administration is often limited to a statement of principle, only to decline drastically when it comes time to move on to practical steps for fulfilment, which are surely very important but offer less opportunities for media coverage, and thus are less attractive to the politicians who ought to support them. In any event, computerisation is viewed as an unavoidable factor for the simplification and improved efficiency of the public administration, and thus tends to receive greater attention at all times when public demand rises for a more suitable administration in terms of the country's economic competitiveness, or else when the need to reduce or contain government spending becomes

${ }^{26}$ The need for constant pressure and attention on the part of the political and administrative leadership, as well as on the part of the various other interested social components is considered to be a strategic factor for the development of e-government; to cite but a few examples, cf. R. Heeks, "Understanding e-Governance for Development", Working Paper n. 11, University of Manchester, Institute For Development Policy and Management, 2001, par. D1 (<http://idpm.man.ac.uk/publications/ wp/igov/igov_wp11.shtml>); and the respective contributions by E. Likkanen and G. Bertucci at the "E-government for Development" International Conference held in Palermo on April 10-11, 2002, the records of which are available at $<$ www.palermoconference2002.org $>$. 
more pressing, which are matters that the inefficiencies of the public administrations clearly have a bearing on.

From within the administration support for the development of public informatics and e-government instead generally comes from those who would benefit from greater horizontal integration in performing their professional duties, and are placed in a difficult situation due to a shortage of "dialogue" among the different administrative departments. An example of this is found in the URP, whose specific duties include "promoting the adoption of telematics linkage systems and co-ordinating the civic networks" 27 and "guaranteeing the free flow of information to and from offices dealing with the public and other offices operating in an administration, as well as to and from offices dealing with the public in the various other administrations" 28 . Also to be included here are those responsible for administrative proceedings, who might greatly benefit from informatics linkage among the administrations in fulfilling their duty to "adopt any and all measures for assuring appropriate and timely preliminary investigations" and to "attend to the communications, the publications and the modifications pursuant to the provisions of the laws and regulations" ${ }^{29}$. But in recent times the need is beginning to be increasingly felt generally throughout structures involved in initiating proceedings or administrations certifying an official assessment, which Presidential Decree n. 445/2000 has provided as a general rule for the acquisition of data on the part of administrations, as a substitute for the request for certificates from citizens. It can thus be stated that there is a significant number of persons within the public administrations who are interested in sustaining the development of ICT; however, this pressure does not always make its presence felt forcefully in one united form, and in any case cannot be said to be general.

It must in fact be pointed out that outside the milieus indicated a certain scepticism and reluctance persist, and that in such places the development of public informatics tends to be perceived as a chimera or else as something imposed from above as the fruit borne of an imposition more than of a real need of the offices themselves. In many offices the tendency is to view mere basic automation as being sufficient, which complements but does not replace the traditional ways of administration, while the development of e-government is viewed with disfavour, among other things because better communication among offices and administrations threatens the loss of some of the informal

\footnotetext{
${ }^{27}$ Section 8, par. 2.c), Law n. 150 of June 7, 2000.

${ }^{28}$ Section 8, par. 2.c), Law n. 150 of June 7, 2000.

${ }^{29}$ Section 6, Law n. 241 of August 7, 1990.
} 
organisational power that the back office units often hold through control over the information and data necessary for conducting administrative activity.

Furthermore, it must be pointed out that for the most part the offices most interested in the introduction of ICT are at the operational level rather than at the top of the single administrations, and therefore less able to exercise direct influence over their strategies for development. The interest of the managers for having computerised information systems instead is not general despite the existence of the explicit responsibilities discussed in the preceding paragraph, and if there is decided pressure from some in favour, there is also much resistance from others due to the fear of, or refusal to abandon the traditional schemes of administrative activity, which many directors have remained attached to for their entire career. Probably this situation is destined to be resolved in positive fashion once the provisions in the matter of responsibility for results begin to acquire force, in view of the fact that informatics surely represents a strategic resource for reaching the objectives assigned to each organisational unit in the most rapid, efficient and effective way.

Rather significant pressure in favour of the development of public informatics and e-government in the public administrations also is exercised by society. This pressure goes hand in hand with two increasingly pressing requests by the general public, social groups, and enterprise, one being for transparency and participation in administrative activity, and the other for increasingly greater simplification. Regarding the first request, informatics is viewed as a possible means for gaining easier access to an ever vaster amount of information possessed by the public administrations, as well as for exercising one's personal right to participation - for example, to submit written records and documents pursuant to Section 10 of Law n. 241/90 - in a less onerous, more effective way. Regarding the second request, increasing importance is assumed by the demand of the general public for better service from the administrations ${ }^{30}$, as well as the demands of economic operators for faster service and greater transparency on the part of the administration in the management of the activities in which they are involved,

${ }^{30}$ Examples worth recalling include the demand for greater simplicity in the management of the demographic and vital statistics services, which can be met through the computerised management of the public records, and the request for greater efficiency in the management of systems for making appointments for medical services and/or assistance, which can likewise be assured through an adequate conversion to informatics. These are but a few of many examples that could be cited, including those in L. Marasso, Metodi e strumenti, op. cit., 261 and following. 
foremost among them being activities concerning public tenders ${ }^{31}$. However, these pressures, too, are frequently offset by other factors that limit their effective impact, such as the fact that not everyone has access to the Internet and the less than complete correspondence between the importance of the service provided and its accessibility via informatics, to mention but two examples.

This section dedicated to the verification of the presence in the Italian public administrations of the conditions for the full development of public informatics and e-government can thus be concluded by stating that in theory these conditions can be considered to be present, but in practice this is not always really so, including in operational terms. The passage to e-government, therefore, still requires a great deal of effort at the practical level, but the premises for using it to good advantage do exist, on condition that the importance of the factors forming the context are correctly perceived and always receive careful consideration.

\section{The potentialities of e-government for sustainable development}

The picture formed by the preceding considerations indicates that, albeit with certain limitations, in Italy the conditions are present for adopting the practice of e-government in concrete, non-sporadic fashion. This is further demonstrated by certain practical examples of e-government, that prove that resort to it is possible, especially if the matter will receive all due support not only from the technological standpoint, but also from the standpoint of all the above-mentioned critical areas, which must be dealt with positively to assure e-government's successful development.

For purposes of the present analysis, however, it suffices to be able to state that at this time in Italy public informatics is a reality, that the transition to e-government is feasible and that therefore an analysis of the effect that, in a compatible social environment, the two can produce has more than just theoretical value. The next step is to examine the modalities through which, by assuring a better brand of public administration, ICT and e-government can act as a flywheel for sustainable development.

In order to perform the analysis it must be remembered that the use of ICT by the public administration is capable of bringing about

${ }^{31}$ In this respect, consider the simplification which can be introduced in the matter of public tenders by the application of the provisions of Presidential Decree n. 101 of April 4, 2002, a regulation containing criteria and modalities for the use by the public administrations of telematics procedures for the procurement of goods and services (e-procurement). 
improvements in its very way of being under various profiles; namely, it makes it possible to increase the amount of information available, its completeness and its circulation; it makes the decision-making process more effective and faster, while at the same time making it easier to handle the attendant complexity; it increases the efficiency and effectiveness of the administration; it increases administrative transparency; it reduces the burdens placed on citizens; it greatly reduces the total cost of administrative action; and it betters the quality of services rendered, thus increasing the opportunities for the consumers of the same.

It is by taking advantage of these potentialities that public informatics and e-government can exercise a positive influence on sustainable development. However, in order to understand how this positive effect manifests itself it is necessary to specify the terms in which sustainable development can be measured, and thus the indicators for measuring the positive effect of public informatics and e-government in fostering $\mathrm{it}^{32}$. In this regard, it must be kept in mind that sustainable development is not only measurable with indicators of economic development (increase in the GNP, improvement of productive processes, renewal of energy sources, the perfection of mechanisms for appropriation and redistribution of income, etc.), but also with indicators of an institutional nature (co-operation, development of information for decision-making, improvement of technical and legal instruments for enforcing the norms pertaining to sustainable development); social nature (elimination of poverty, equal living conditions for all members of society, better education, safeguarding of health, improved residential conditions, etc.); and environmental nature (regulation of the use of water, seas and rivers; promotion of organic farming; conservation of biodiversity, pollution reduction, protection of the atmosphere, waste disposal). The analysis of the impact of the new technologies on sustainable growth will therefore be performed by distinguishing between these four key areas.

\subsection{The impact on institutional profiles of development}

First, informatics makes it possible to facilitate the access of the general public to the public administrations, thereby reducing the restrictions imposed by geography and the economic and social disparities that can make relations with the administrations more difficult,

\footnotetext{
${ }^{32}$ In the text reference is made to the indicators identified by the United Nations Commission for Sustainable Development at its third session of April 1995, the list of which is available at <www.un.org/esa/sustdev/indisd $>$.
} 
including access to the services provided by them. One way ease of access is accomplished is by strengthening the role of the local administrations, which can play a front-office role also on behalf of the central administrations, but from a location closer to the citizen; another way is by favouring a direct connection via informatics linking the citizen and the administrations, thus delocalising administration ${ }^{33}$.

Next, with e-government it is possible to increase the transparency of administration, facilitating access to documents and information in its possession, as well as making it easier for the interested parties to monitor the progress of proceedings ${ }^{34}$. This means less chance for inertia and for seeking refuge in legal formalities for the purpose of delaying and indirectly conditioning decisions, in addition to reducing the procedural "interstices" where maladministration, favouritism and corruption often find room to roost ${ }^{35}$.

In the same way, e-government makes clearer the prescribed role of all concerned in carrying out an activity, and thus renders visible how responsibility is effectively distributed, given that any actions taken through informatics channels are by their very nature directly traceable to their author. In this sense, e-government also acts as a factor for making public functionaries more accountable by providing incontrovertible evidence as to their effective involvement in the administrative procedures that form the basis of the substantive configuration of public accountability ${ }^{36}$.

${ }^{33}$ In this respect, see the items contained in the Plan of Action for E-government 2000-2002 cited above in footnote (19).

${ }^{34}$ Much emphasis is placed on the role that e-government may play in increasing the transparency of administrative action in the debate over the potentialities of egovernment as a factor for development. For example, cf. R. Schware, "Information Technology and Public Sector Management in Developing Countries", The Indian Journal of Public Administration, 2000; R.B. Heeks, "Understanding e-Governance", op. cit., par. C2. Regarding the situation in Italy, an idea of the impact that informatics technologies can have in the sense indicated in the text is to be had if one considers how their use in creating a link between the offices of a single administration or between more than one administration can enormously facilitate structures such as front offices which deal with the public in performing tasks such as providing "information to consumers in relation to records and to the status of proceedings" (Section 11, par. 2.b), Legislative Decree n. 165 of March 30, 2001).

${ }^{35}$ On the impact than an excess of formalism in administrative proceedings can have on "maladministration", cf. S. Cassese, "Maladministration' e rimedi", Foro it., 1992, V, 243 and following.

${ }^{36}$ On the various aspects regarding how the development of public informatics can act as a factor for making public functionaries more responsible, cf. R.B. Heeks, Information Systems and Public Sector Accountability, Working Paper n. 1, University of Manchester, Institute for Development Policy and Management, 2001, par. D1 
In this way e-government also creates the conditions for an increase in mutual trust between the citizen and the public administration, thereby encouraging the creation of the guarantees of certainty and transparency which have been rightly listed among the basic prerequisites for it to undergo development ${ }^{37}$. In this sense, it will suffice to consider the use of ICT for the management of administrative paperwork, and how through ICT it is possible to drastically reduce the burden placed on citizens and public offices alike in relation to the circulation of certificates, at the same time assuring the maximum guarantee of the reliability of the data put into circulation ${ }^{38}$.

More generally, e-government improves decision-making, making administrative proceedings more flexible and complete, and allowing a greater number of interests to be evaluated within their framework, thus making it possible to more adequately deal with the co-presence of economic, social and environmental needs which are at the root of the idea of sustainable development. In the same way ICT and e-government improve co-ordination among the public figures involved in administrative proceedings, thereby making their actions more effective, swift and coherent, and thus playing a role that becomes increasingly indispensable as the public powers scenario becomes increasingly complicated ${ }^{39}$.

In this perspective, e-government becomes a factor for the simplification of procedures and makes it possible to resolve the apparent contrast between participation and simplification without sacrifice to either, and without the increase in participation becoming an imposi-

(<http://idpm.man.ac.uk/publications/wp/igov/igov_wp01.shtml $>$ ), wherein it is observed in particular that "When a decision is taken, information about that decision and its outcomes must flow to all those to whom the decision maker is accountable. Without such an information flow and without the information system that carries that flow, there can be no accountability because there can be no knowledge of the decision". In relation to the Italian situation, cf. G. Duni, "Il progetto nazionale di teleamministrazione pubblica", L'informatica giuridica e il Ced della Corte di Cassazione, records of the Meeting at the Università di Roma "La Sapienza", Nov. 27-29, 1991, Milano, 1992, p. 87 and following (now also available at <www.teleamministrazione.it $>$ ).

${ }^{37} \mathrm{It}$ is significant in this respect that in A. Sen, Development As Freedom, University Press, Oxford, 2000, among those instrumental freedoms held to be necessary for development is included the guarantee of transparency and of trust in human relations, which provides "the freedom to deal with one another having guarantees of openness and clarity".

${ }^{38}$ On this point, cf. M. Bombardelli, "La semplificazione della documentazione amministrativa: strumenti e tecniche”, G. Arena, M. Bombardelli, M.P. Guerra and A. Masucci, La documentazione amministrativa, op. cit., 87 and following.

${ }^{39}$ The positive impact that e-government produces on the decision-making of the public administrations is stressed by R.B. Heeks, "Understanding e-Governance", op. cit., par. C1. For a recent treatment of the growing complexity of the relations among the public authorities, cf. S. Cassese, "L'arena pubblica: nuovi paradigmi per lo Stato", Riv. trim. dir. pubb, 2001, 643 and following. 
tion in procedural terms. E-government in fact allows the simplifying of the formal steps, leaving more time for participation while simultaneously making it quicker and easier to manage the same.

Moreover, e-government makes it possible to improve the efficiency, economy and effectiveness of administrative activity by reducing the complexity and length of proceedings, cutting costs for every single action and bettering the performance of each individual performer. In this way ICT also contribute directly to development by causing the costs of administrative activity to diminish, and thereby preventing the cost of administration from putting a brake on the country's economic development ${ }^{40}$.

\subsection{The impact on social profiles of development}

The recourse to e-government can further lead to improved efficiency and effectiveness of the public administrations in the rendering of services. The use of ICT therefore improves the quality of the administration as an organisation delegated to create the conditions so that individuals can develop their personal capacities and thereby lead a better life - which constitutes one of the core aspects of sustainable development. The use of ICT turns out to be fundamental for improving the rendering of a great many services. Considering only the most important, just think of the role that they can play in health care (appointments, information about the services provided, co-ordination among the various health care system structures, tele-assistance) and in education (longdistance education, recovery of dropouts, new teaching methods). More generally, the use of informatics technologies and e-government techniques can benefit all the services provided by the public administration, if not in terms of the end product, at least in the intermediate stages ${ }^{41}$.

In this way e-government makes it possible to better personalise the actions of the administration in terms of real needs. It therefore is an agent for the empowerment the weaker social categories (women

${ }^{40}$ The ultimate objective of the reduction of public expenditure has characterised all of the various stages in the development of automatic information systems in the public administrations, at least from the time of the inclusion of such objective among the goals pursuant to Section 1, par. 3.d) of Legislative Decree n. 39/93. The positive impact of e-government as a factor for the transformation of administrative procedures in the interest of greater efficiency and economy is underscored by R.B. Heeks, "Understanding e-Governance", op. cit., par. B.

${ }^{41}$ For example, think what it means to be able to manage the data pertaining to a preliminary investigation into proceedings via informatics - in particular data in relation to the public records - or to be able to identify at a distance the consumers of a service rendered by the administrations through the use of an electronic personal identification card, or of the possibility of sharing records among different administrations, etc. 
and youth) less "well-introduced" when it comes to the evolving dynamics of the economy and society, allowing a more equitable distribution of opportunities among the different social groups and geographical areas ${ }^{42}$.

The recourse to e-government thus facilitates contacts between the general public and the administrations and puts both in a better position to communicate with each other, and therefore makes it possible for the administrations to better calibrate their actions in terms of the real needs of society ${ }^{43}$. This is most useful, among other things because intervention by the administration can help create the habit of interacting by means of informatics instruments, which in turn can act as a flywheel for endogenous, autonomous development within society of a capacity to establish interactions functional to the progress and welfare of its members ${ }^{44}$.

The recourse to e-government also makes it possible to increase the quantity and quality of the information available to citizens in all walks of life, thus increasing their ability to participate in the political and administrative affairs of the country, to gain broader knowledge of the opportunities available, and to better define their personal strategies, professional and otherwise. A fundamental point is involved here because implicit in the very definition of sustainable development is the need for persons to be given the opportunity to actively contribute to their personal development, owing to which the democratic participation of all in political life and in the determination of the goals pursued in concrete terms by the administration is fundamental. Similarly, an increase in individual freedoms is favoured by enormously improved opportunities for communication among individuals ${ }^{45}$.

42 Significant in this sense is the affirmation contained in Point 6 of Declaration E/2000/L9 of the Economic and Social Council of the United Nations, concerning the fact that the ICT have a huge potential "... to help foster sustainable development, empower people, including women and youth, build capacities and skills, assist smalland medium-sized enterprises, reduce poverty, and reinforce popular participation and informed decision-making at all levels...".

${ }^{43}$ In this regard, see the examples cited in R.B. Heeks, "Understanding e-Governance”, op. cit., par. C2.

${ }^{44}$ R.B. Heeks, "Understanding e-Governance", op. cit., par. C3, speaks in this respect of e-Society. As for Italy, it should be pointed out how the prospect for development recently indicated in the text is particularly important in reference to the application of the principle of horizontal subsidiarity sanctioned by Section 118, par. 4 of the Constitution.

${ }^{45}$ Suffice it to consider the example of the impact that the development of interpersonal relations made possible by informatics technologies can cause in the sense of the more complete realisation of the freedom of assembly and of association pursuant to sections 17 and 18 of the Constitution. 


\subsection{The impact on environmental profiles of development}

The development of public informatics can also be beneficial in making development more compatible with environmental safeguards. This may take various forms.

First of all, by making it easier to process information the use of ICT makes it possible to perfect the monitoring of the dynamics produced by economic activities on the environment. This greatly augments the capacity of the administration to control the dynamics and the effects of productive processes, including sources of pollution, which in turn allows it to better attend to its duties related to safeguarding the environment.

Furthermore, informatics information management is able to increase the transparency of the same, which is a well-known mainstay of the system for the public safeguarding of the environment ${ }^{46}$, therefore making it possible to strengthen and better co-ordinate the actions of the various public and private players operating in the area of environmental protection.

In like fashion, improved decision-making allows more deliberate consideration of environmental concerns within the framework of the public administration's decision-making process.

In addition to these direct advantages, there are others of an indirect nature deriving from a reduction in the environmental impact produced by administrative activity itself. For example, think of how the "delocalisation" of the public administration made possible by e-government gives citizens the possibility of gaining access to services provided by the administrations and to submit requests to participate in administrative proceedings without having to be physically present in the office, thereby not placing a significant added burden on motor vehicle traffic. Involved here is a fundamental advantage, which is even more pronounced if coupled with the spread of telecommute workers in the public administrations, which produces the same positive effects on traffic since the public employees involved obviously no longer have to go to the office every day.

${ }^{46}$ It must be recalled in this regard that access to environmental information is a right that was recognised to all citizens by Section 14, par. 3, Law n. 349 of June 8, 1986 - several years before Law n. 241/90 recognised a general right to access to administrative documents - inasmuch as such access is a necessary and indispensable tool for the safeguarding of the environment. Since through ICT it becomes possible to make environmental information more ample, more up-to-date and more easily obtainable, ICT can without a doubt be considered a factor for strengthening environmental safeguarding and, through them, for compatible development. 


\subsection{The impact on economic profiles of development}

The introduction of ICT and e-government in the public administration can exercise great influence on the economic profiles of development as well.

First, it makes it possible to simplify administrative activity and to increase its efficiency and economy, thus reducing the expenditure necessary for it to function, and therefore reducing overall public spending. This evidently represents an important contribution to the economic development of the nation, inasmuch as it helps reduce the brake put on the economy by public debt.

If this first profile is conspicuous for being absolutely obvious, it must be noted that cutting costs is not the only way that the computerisation of the public administration can contribute to the economic development of the country.

Once again in view of the positive impact that informatics can have in terms of greater efficiency and simplicity in administrative activity, it should be noted that this effect has some important economic repercussions owing to the fact that it allows the administration to fully carry out its tasks, while at the same time placing a much lighter burden on economic operators and on the general public, with a consequent immediate savings in resources that they would otherwise be forced to waste under a complicated and inefficient administration ${ }^{47}$.

Along this same line, then, it must be observed that the presence of a computerised, more efficient and transparent public administration is important because it creates trust among economic operators and is able to attract investments by its very presence ${ }^{48}$.

Moreover, the greater efficiency and greater effectiveness made possible by public informatics and e-government have a further repercussion on economic development when referred specifically to the administrations for the governance of the economy. Computerisation does in fact allow these latter to better attend to their tasks of sustaining and controlling the economy, and in so doing causing an appreci-

${ }^{47}$ In this regard, think of the great saving of economic resources allowed by the substitution of certificates with direct verification pursuant to Section 43 of Presidential Decree n. 445/2000, or else the saving permitted by the introduction of the single counter for productive activities pursuant to Section 27 of Legislative Decree n. 112 of March 31, 1998, and pursuant to Presidential Decree n. 447 of October 20, 1998. It is significant in this respect that the realisation of both of these agents for simplification requires the resort to informatics technologies in order to be effective.

${ }^{48}$ This aspect of development received consideration, for example, in the keynote address and in the closing address at the International Conference "E-government for Development", held April 10-11,2002 in Palermo and available at <www.palermoconference2002.org>. 
able improvement in certain variables extremely important for the national economy ${ }^{49}$.

But the positive effects mentioned thus far by no means complete the list in an economy ever increasingly conditioned by and dependent on the quantity of information available to the operators. Another that must be added is connected with the increase in available information and the greater transparency thereof made possible by the introduction of ICT and e-government. Through these, in fact, it becomes much easier for the general public and economic operators alike to learn about and gain access to much important economic information originating with the public administration. To take the most obvious instance, consider the matter of the announcement of tenders by the public administrations, which can reach a much larger number of economic operators thanks to public informatics channels, thereby favouring the transparency of the public procedures and a higher number of companies taking part, which leads to more competition and, through it, to increased economic development.

Finally, within this same area of the availability of information relevant for the development of economic activities, it must be observed how informatics allows the public administrations to set up information services that can prove most useful for the development of certain economic sectors ${ }^{50}$, as well as for creating a more favourable climate for starting new economic activities based on the use of informatics ${ }^{51}$.

\section{The limits of public informatics and of e-government as factors for sustainable development}

The fact that public informatics and e-government have great potentialities for the sustainable development and increased competitive-

${ }^{49}$ To cite a significant example, consider the great advantages offered by the computerisation of the tax authority both in terms of the simplification of procedures provided for the levy and of the fight against tax evasion. Important indications on the characteristics of the "telematics tax authority" in Italy are to be had by consulting $<$ www.agenziaentrate.it>. On this same point, cf. P. Costanzo, "Internet (diritto pubblico)", Digesto discipline pubblicistiche, Aggiornamento, 2000, 362 and following.

${ }^{50}$ Consider, for example, the importance of traffic information on for economic sectors tied to commercial transport, or the importance of weather reports for economic sectors tied to the tourist industry or agriculture.

${ }^{51}$ In fact, in the absence of a favourable environment the circumstance indicated in Point 4 of Declaration E/2000/L9 of the Economic and Social Council of the United Nations - stating that "Unless access to and use of ICT is broadened, the majority of people particularly in the developing countries will not enjoy the benefits of the new knowledge-based economy" - is destined to continue. 
ness of Italy cannot automatically be interpreted to mean that they produce just positive effects on development.

In the first place, in fact, it must be remembered that their full potential is only partially expressed on the operational level, so their practical effects are correspondingly limited.

In particular, it should be remembered that the heritage left by traditional bureaucratic procedures is still exercises a powerful influence; so deeply is it rooted in administrative practice that it acts as a brake on e-government and therefore makes an increasingly greater simplification of the procedures particularly urgent, with an equally urgent effort need to reduce as much as possible the time required for the fulfilment of the norms relating to informatics documents ${ }^{52}$. Besides, the public administrations' technological equipment is still neither complete nor adequate, so that a great deal of attention will be required to rectify the situation, above all as regards the development of interconnecting networks, for which it is of fundamental importance to establish a common co-ordination centre ${ }^{53}$. Moreover, the problem of the training of the personnel who will be called upon to put e-government techniques into everyday practice certainly must be dealt with more incisively. Beyond a doubt, the matter is delicate, because in order bolster these skills it does not suffice to teach the use of informatics programmes, but is necessary to make staff appreciate the profound cultural change required by the switch to ICT as ordinary tools of administration ${ }^{54}$. Finally, an adequate channel still must be found for assuring thoroughgoing use of ICT throughout society so as to make the most of their potentiality in promoting development, and so that they

${ }^{52}$ It must in fact be remembered that, in the everyday life of public administration the normative provisions in the matter of the simplification of procedures are realised in a disparate way, and not by all administrations, while the use of informatics documents is often still on an experimental basis only.

${ }^{53}$ The operation proved to be rather difficult, as demonstrated in Italy by events surrounding the Authority for Informatics in the Public Administration; established by Section 4 of Legislative Decree n. 39/93 as an independent administrative authority, at present it is the object of changes affecting its very nature which are transforming it into a mere bureau of the Ministry for Innovation and Technology.

54 The problem represented by the existing gap between traditional administrative culture and informatics culture has already be spoken of above (par. 2); it is evident in the rank and file operators and in management culture alike. Regarding the latter in particular, it should be borne in mind just how many problems may be created, in terms of having a winning strategy in the introduction of e-government, by what is defined in R.B. Heeks, "Understanding e-Governance", op. cit., par. D1, as the absence of a "captain on the bridge", capable of steering the administrative structure involved around the operational obstacles that may be encountered in the transition from traditional methods. 
become tools for the social advancement of the users. An approach limited to a superficial level of pure entertainment is to be avoided, since that might even create new forms of economic dependency ${ }^{55}$.

But the limits of public informatics and e-government as factors for sustainable growth do not end with the difficulties in fully realising of their positive aspects. In fact, it must be considered that the introduction of ICT and of e-government can also produce certain effects having a negative impact on development, which must be kept firmly in mind in order to counteract them and prevent them from attenuating the positive effects.

Specifically, one of the problems that public informatics can create is the widening of the "digital divide" as a result of an uneven distribution of the possibility of gaining access to informatics systems, which, if not rectified, can lead to increased inequality and disparity of access to the services furnished by the public administration ${ }^{56}$. That would obviously have the effect of working against sustainable development by creating an overall reduction in opportunities available for people to develop their personal skills. In order to resolve the problem it is therefore of fundamental importance that in the strategies for the development of public informatics attention be focused not only on access to informatics, but especially on guaranteeing access to the relations made possible by informatics ${ }^{57}$.

${ }^{55}$ In this respect, it bears keeping in mind the contents of points 6 and 9 of Declaration E/2000/L9 by the Economic and Social Council of the United Nations, in reference to the fact that in order for the introduction of ITC to have a favourable impact on development they must never be considered as a substitute for efforts to develop the skills of persons and the basic sectors of the economy, with respect to which ITC must instead serve as a means. Otherwise, there is a risk that the use of ICT may remain an end unto itself and become enmeshed in the creation/satisfaction of needs wholly within the world of the technologies themselves.

${ }^{56}$ On the "digital divide" and the risk that development of public informatics and of e-government may widen the gap and exacerbate the consequences, see point 5 of Declaration E/2000/L9 by the Economics and Social Council of the United Nations. For that matter, the problem is very much present in the debate over the relation between ICT and sustainable development. For example, cf. R.B. Heeks, Government Data: Understanding the Barriers to Citizen Access and Use, Working Paper n. 10, University of Manchester, Institute for Development Policy and Management, 2000 (<http:/ /idpm.man.ac.uk/publications/wp/igov/igov_wp10.shtml>); A. Kozumin, "Information Technology and Development: Is the 'Digital Divide' an Inevitability?", Public Administration and Development, 2000, 20, 167 and following; N. Korac-Kakabadse, A. Kozumin and A. Korac-Kakabadse, "Information Technology and Development: Creating 'IT Harems', Fostering New Colonialism or Solving 'Wicked' Policy Problems?", Public Administration and Development, 2000, 20, 171 and following.

${ }^{57}$ From this standpoint, it becomes fundamental to accompany the development of public informatics and e-government with initiatives aimed, on the one hand, at 
A second problem engendered by the introduction of e-government lies in the fact that, although ICT are useful because they succeed in better satisfying traditional needs, at the same time they create new needs, which in turn require satisfaction and must be considered within the dynamics of sustainable development. It has be taken into consideration, then, that with the advent of ICT the satisfaction of needs no longer regards just the possession of goods and other assets or the availability of "material" services, but also the possibility of access to services of a virtual nature, whose significance will become increasingly felt in the overall dynamics of the development of society. This must be kept in mind in the sense that through the use of ICT the public administrations must extend to the utmost the possibility for all segments of the population to have access to these services. It is also true because in their providing of services the public administrations must not be enticed by a completely virtual logic, and must therefore always keep a firm grip on the real issues that computerised services are able to cope with ${ }^{58}$.

A third problem caused by the new technologies is the creation of new forms of power, which may induce a new form of diffidence in ordinary citizens just at a time when e-government is opening the way to an egalitarian approach and a more participatory role for the general public vis-à-vis traditional public administration. The forms of power referred to are two in number. One form is held by those who decide matters of access to ICT and what gets put on ICT: the problem becomes not just of protection in the regards of a measure adopted, but also that of reacting against the arbitrary exclusion from the possibility of gaining access to the procedures and services managed via informatics channels. The other form is the power that can be exercised by those who control the ICT support structure, in particular the informatics

educating people to use the ICT; and on the other, at facilitating access to the same in the interest of fostering the ability of individuals to use ICT as a tool for strengthening their interpersonal skills, including vis-à-vis administrations. In view of this, it is important to create "public access points" (telecentres) as mentioned, among other places, in point 14.e) of Declaration E/2000/L9 by the Economic and Social Council of the United Nations. By the same token, it is important to create support structures at a worldwide, national and local level, a task which the United Nations has taken upon itself with initiatives such as those described at $<$ www.undp.org/info21 $>$ and $<$ www.netaid.org $>$.

${ }^{58}$ In the development of ICT applied to the public administration it is therefore necessary to first concentrate on the services that are most important for satisfying the needs of the citizenry and not on the more "spectacular" forms of informatics applications, some of which may even get purposely created for the sake of allowing the introduction or development of new informatics applications. 
network, which can obviously condition what services are provided through ICT and how ${ }^{59}$.

A fourth problem involves the safeguarding of individual privacy, made increasingly vulnerable by the massive resort to informatics technologies able to process personal data at an extremely sophisticated level, which allows cross-checks to be performed and the data to be combined in many forms, thus laying the groundwork for an increased invasion of privacy and a more complete control over the lives of individuals. To cope with the problem regulations have been adopted in Italy - as in many other countries - for the safeguarding of personal data, which introduce beefed-up measures for protecting data processed by informatics systems ${ }^{60}$. However, it is necessary that such normative provisions be effectively enforced and that attention to the safeguarding of personal data be kept at a high pitch, because otherwise the development of public informatics and the spread of e-government can act as an agent for limiting personal freedom rather than as an aid to development.

A fifth problem relates to the security of relations entertained via informatics systems, which are automatically exposed to all the security risks associated with the new technologies. Two dangers merit special attention. The first lies in the possibility that the adoption of informatics may make it more difficult to positively identify the individual, nationality, legal residence and the like of those who use it to establish legal and economic relations, with the risk of increasing the uncertainty surrounding the relations themselves and thereby causing the advantages made possible by the informatics network in terms of simplicity and speed to be lost sight of, including as regards public administration activity. The second danger is the more specific risk that with the massive resort by the public authorities to the new technologies for performing their activity, such activity will be more exposed to possible attacks by informatics criminals, who might so succeed in interfering heavily not only in legal relations involving private citizens, but also in

${ }^{59}$ For an identification and the various possible types of impact of these forms of power, cf. J. Rifkin, The Age of Access, J.P. Tarcher/Putnam, New York, 2000. The author deals with the issue in general terms, but the problems identified offer many points of interest for further examination from a juridical standpoint.

${ }^{60}$ The Italian legal standards in the matter of the safeguarding of personal data were set by Law n. 675 of December 31, 1996, which later underwent a series of additions and changes. In Italian legislation the safeguards also are extended to include data gathered without the aid of informatics, but there are different, more restrictive provisions regarding this latter eventuality. For an complete survey of the national and Community provisions that discipline the safeguarding of personal data in Italy, cf. $<$ www.garanteprivacy.it $>$. 
legal relations affecting the general welfare. Therefore, yet once again in the development of public informatics and e-government what cannot be renounced is the need to guarantee to the utmost degree the security of individuals, the data regarding them and the transactions performed by them ${ }^{61}$.

Involved here is a whole set of extremely important issues, which should receive all due consideration from the very moment that a proposal is made to switch over to an e-government system, because if they are neglected the consequences can appreciably diminish the advantages to be derived from the transition to electronic administration.

\section{Co-operation with the developing countries for the expansion of public informatics and e-government}

The analysis conducted thus far has demonstrated how the use of ICT and the practice of e-government can have a positive impact on sustainable growth only if situated in a context where certain basic conditions have been met and proper measures are taken to prevent certain negative effects that computerisation itself can cause.

This is why whenever a proposal for co-operation is made involving countries with widely differing rates of development, and with the intent of promoting sustainable development through e-government, the interested parties need to be alerted to the fact that the project cannot be considered complete once the informatics technology has been exported and a plan for e-government has been prepared ${ }^{62}$. While obviously necessary, such measures risk leading to failure if taken alone. Before or during the time when such measures are carried out it is in fact necessary to so act as to bring about the conditions that have been seen to be indispensable for the profitable use of ICT as a function of a type of development that places human beings in a central position in a way compatible with the natural environment.

${ }^{61}$ For a broader view of some of the possible juridical implications involving the problems just mentioned, cf. P. Costanzo, Internet, op. cit., 362 and following.

${ }^{62}$ For current trends in Italy's strategies for co-operation with developing nations for the introduction of ICT, a version from a perspective that appears unbalanced in the sense last indicated in the text is found in the contribution by L. Stanca, Minister for Innovation and Technology, available in the records of the International Conference "E-government for Development", held in Palermo on April 10-11, 2002. The

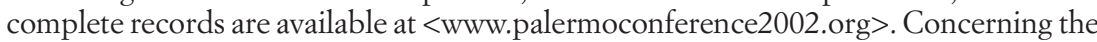
fact that policies for development through the introduction of ICT cannot be limited to the export of technologies, Declaration E/2000/L9 of the Council for Economic and Social Development of the United Nations is quite insistent, especially in points 13 and 14. 
Therefore, it is necessary for developed countries to co-ordinate matters with the developing countries in order that their administrative functions are reformed so as to make them suitable for e-government ${ }^{63}$; so that the maximum participation of the citizenry in public affairs is assured; so that normative provisions get adopted that are consonant with the use of e-government; so that the "endogenous" responsibilities for the development of public informatics and e-government get precisely identified and specified; and so that constant pressure is exercised by the political class, by the administration and by the society at large in the interested countries for the use of the technologies indispensable for guaranteeing that the adoption of e-government will be a success.

Accompanying this, there must material aid in the supply of the necessary technology, on terms such as not to aggravate what is very often already a precarious situation of foreign indebtedness in the interested nations.

However, not even this will suffice, since the transfer of technology must absolutely be accompanied by an effort to augment the endogenous capacity for the planning and development of technology in dynamic fashion and according to autonomous models of development, rather than being limited to reproducing the models of the industrialised countries ${ }^{64}$. Otherwise, there is a risk that those who furnish the technology necessary for the introduction of public informatics and e-government will powerfully condition the modalities for development of the countries with a lower rate of development. Therefore, it is not enough to furnish the technicians of the interested countries with manuals for the installation of the hardware and the use of the software: what is needed is a co-operative effort to develop an autonomous capacity to manage and plan technological change.

To this end, it is necessary to plan the "export" of models of e-government with objectives that are appropriate and realistic, avoiding great leaps forward and overly ambitious projects that would only risk creating

${ }^{63}$ This is an action which might turn out to be simpler in developing countries than in developed countries, where the administrative structures to be reformed are much more inflexible.

${ }^{64}$ Many of the representatives of the developing nations insisted on this point at the International Conference "E-government for Development" held in Palermo on April 10-11, 2002, the records of which are available at <www.palermoconference2002.org>. For a thorough examination of the issue being discussed in the text, cf. N. Korac-Kakabadse, A. Kozumin and A. Korac-Kakabadse, Information Technology and Development, op. cit., 171 and following. 
"cathedrals in the desert" ${ }^{65}$. Once the basic conditions have been met, it then becomes necessary to operate in such a way that the interested countries succeed in elaborating their own "way to computerisation" as part of a broader, coherent plan for economic development.

In this sense, plans for the development of e-government cannot be limited to just the single objective of improving the reliability of the administrations of the interested countries in order to create greater trust on the part of economic operators and thus attract more foreign capital. This objective is certainly extremely important, but there are other equally important ones that must go hand in hand with it, and which in addition to "development" must give due weight to "sustainability", which entails taking into account social, environmental and institutional factors as well as economic. This being the case, it follows that the countries interested in development are required to play a highly active role in tailoring public informatics and e-government to fit their own specific needs.

${ }^{65}$ Concerning this point as well, cf. N. Korac-Kakabadse, A. Kozumin and A. Korac-Kakabadse, Information Technology and Development, op. cit., 171 and following, as well as the contribution by C. Barbarella at the International Conference "E-government for Development", held in Palermo on April 10-11, 2002, the records of which are available at <www.palermoconference2002.org $>$. 


\title{
Control of administrative corruption and the rules of public ethics
}

\author{
Bernardo Giorgio Mattarella*
}

\begin{abstract}
1. Introduction -2 . The control of administrative corruption in Italy -2.1 . Repression and prevention -2.2 . The normative parameters -2.3 . The relation between politics and the administrative agents - 2.4. Public personnel - 2.5. Administrative action and controls -2.6 . Controls in the private sector -3 . Rules of conduct for public employees and the codification thereof -3.1 . The Code of Conduct for public employees - 3.2. The specificity of the rules of conduct in the public sector -3.3 . The scope of the rules of public ethics -3.4 . Further open questions -4 . The difficult translation of the principles of public ethics into individual practice -5 . Public ethics and sustainable development.
\end{abstract}

\section{Introduction}

First of all, I believe that I should make clear the reason for my choice of this topic and its relation to the theme of the meeting. Having to concern myself with the sub-theme in relation to "responsible, transparent, efficient and honest public administration", I thought of focusing attention on the matter of the control of administrative corruption and of the definition of rules of conduct for public employees, because it seems to me that there are at least two points of contact with the general theme of sustainable development.

In the first place, maladministration works in somewhat the same way as pollution, because it implies the improper exploitation of resources belonging to everyone by just a few: as has been recently observed, it is a "form of agreement by the minority for the purpose of appropriating for itself the assets of the majority of the population" 1 Furthermore, the control of corruption, like that of environmental pollution, cannot be conducted only through limited short-term measures,

* Università degli Studi di Siena.

${ }^{1}$ Camera dei deputati - Comitato di studio sulla prevenzione della corruzione, $\mathrm{La}$ lotta alla corruzione, Laterza, Roma and Bari, 1998, p. 4. The Report, spoken of in the text, is also published in parliamentary records (AC, XII legislatura, Doc. CXI, n. 1).

Public administration, competitiveness and sustainable development, edited

by Gregorio Arena \& Mario P. Chiti, ISBN 88-8453-100-4

(C) 2003, Firenze University Press 
but must be lasting, because the fight is against an enemy that can never be eliminated once and for all, but that can be contained. In this sense, it can be said that one of the elements of the "sustainability" of policies for development is their suitability for avoiding corruption. This explains why the "good and clean governance", that institutions such as the World Bank and International Monetary Fund impose on nations receiving loans, often includes measures for fighting corruption ${ }^{2}$.

In the second place, the public administration obviously plays a pivotal role in policies for development and in defence of the environment, both of which continuously give rise to opportunities for administrative corruption and require that standards of proper behaviour be defined. The principle of sustainable development, implying the integration of policies in both the above areas, restates the terms of the role of the public administration and requires the adapting of strategies in the fight against corruption and the principles of public ethics.

The purpose of this paper is to examine the control of corruption in Italy, in order to obtain some general indications (which will be put in italics). I shall begin by giving an account of the initiatives and of certain measures put into effect in recent years, and then focus on the definition of rules of conduct for public employees. I shall next examine the principles indicated in the title of my assigned topic (responsibility, transparency, efficiency, honesty): involved are principles that easily lend themselves to being translated into rules of individual conduct, but the actual translation encounters considerable difficulty. I shall conclude with some considerations on the relation between public ethics and sustainable development.

\section{The control of administrative corruption in Italy}

\subsection{Repression and prevention}

As one of the greatest Italian philosophers wrote: "Profiteers, politicians of few scruples and little dignity, fraudulent administrators, unfaithful or venal employees, and thefts large and small are things common to every age and nation" ${ }^{3}$. This explains why the control of corruption is a recurrent theme in various legal systems, and also in international and supranational organisations ${ }^{4}$ : as regards the European

${ }^{2}$ Ample documentation in this regard is available at the following web sites: $<$ www.worldbank.org/> and <www.imf.org/>.

${ }^{3}$ B. Croce, Storia d'Italia dal 1871 al 1915, 5th ed., Laterza, Bari, 1934, p. 193.

${ }^{4}$ For example, the Council of Europe has elaborated a civil convention and a penal convention against corruption, a recommendation that defines twenty principles 
Union, consider the provisions contained in the Treaty of Rome concerning "maladministration" (which provide for the establishment of parliamentary investigation commissions and intervention by the $\mathrm{Om}$ budsman) $)^{5}$ and the measures taken consequent to the Santer Commission crisis, which among other things culminated with the adoption of a code of conduct for the commissioners and another one for Commission staff 6

In this respect, the European experience is analogous to Italian experience: measures to be used in the fight against maladministration were adopted after cases of misconduct came to light. For that matter, Croce added that similar episodes "increase and explode with serious consequences in certain times and in certain countries, due to certain circumstances". From this standpoint, the coming to light of corruption which certain investigating magistrates have defined as "systemic" and the subjection of two percent of public personnel to criminal action $^{7}$ constitute an acute phase of a matter which - although difficult to relate, just because it dwells in the shadows ${ }^{8}$ - often appears repetitive, including in Italy (the most natural comparison, including in terms of political impact, is with the Rome banking scandal in 1893)9.

From this derives a first general indication for the control of corruption: as previously mentioned, what is required is not bursts of speed and sporadic frenzied activity, but perseverance.

The responses given by the Italian legal system to the phenomenon of corruption in the 1990s can be judged by this light. Initially, the system essentially responded with the tool of penal repression ${ }^{10}$, which has led to numerous trials and various convictions, but has also shown itself to be insufficient, as is made evident by the fact that the number of crimes in connection with corruption has not diminished, a circum-

in the fight against corruption, a model Code of Conduct for public officeholders and a European Code of Conduct for local and regional elected officials. Most of the documents of the Council of Europe may also be consulted on line at <www.coe.int/ $>$.

${ }^{5}$ Sections 193 and 195.

${ }^{6}$ Both are available on line at <www. europa.eu.int/>.

${ }^{7}$ La lotta alla corruzione, op. cit., p. 11.

${ }^{8}$ S. Cassese, "Ipotesi sulla storia della corruzione in Italia", Etica pubblica e amministrazione. Per una storia della corruzione nell'Italia contemporanea, ed. G. Melis, Cuen, Napoli, 1999, p. 183.

${ }^{9}$ For an overview, cf. E. Gustapane, "Per una storia della corruzione nell'Italia contemporanea”, Etica pubblica e amministrazione, op. cit., p. 13.

${ }^{10}$ Although there were those who emphasised the need to combat corruption through "a legislative overhaul": G. D'Auria, "La corruzione e le leggi", Corruzione e sistema istituzionale, ed. M. D’Alberti and R. Finocchi, Bologna, il Mulino, 1994, p. 38. 
stance admitted by the investigators themselves and confirmed by judicial statistical data. A "sustainable" policy in the fight against corruption obviously cannot hinge on investigations and penalties, which do not eliminate the causes of corruption, and which in turn have significant costs in economic and human terms.

From this derives a second indication: the control of corruption at the administrative level must aim first of all at its prevention.

It is above all for this reason that the recurrent proposals for the creation of new bodies with functions of investigation, inquiry and control have met with well-founded criticism: in particular, the proposal made by the Special Commission for the Fight against Corruption of the Chamber of Deputies ${ }^{11}$, to create a Commission for Guaranty with the task of gathering information on a great number of public employees and of co-ordinating the activities of various administrative and jurisdictional organs: the bill for following through on the proposal met with the apparent favour of a large part of the forces in Parliament, but soon enough got bogged down. The primary observation made was that the functions of this authority (renamed "Gendarmone", roughly 'the Big Policeman') were heterogeneous, overlapped the functions of existing administrative and jurisdictional organs and were too burdensome to be performed effectively.

From this derive two further indications: if the controls on administrators do not function, it is necessary to improve them, and not to multiply the functions and the organs for control; it is useless to gather great quantities of information destined to remain unverified.

Toward the middle 1990s attention began to shift to preventive remedies: the related debate has produced, among other things, two reports prepared by study commissions ${ }^{12}$, the establishment of an ad hoc parliamentary committee (in the Chamber of Deputies), a wideranging parliamentary investigation (in the Senate) and numerous bills, but relatively little in the way of concrete and suitable results.

A useful basis for the purpose of evaluating certain measures adopted and certain suggestions not taken is the Report by the Study Committee on the Prevention of Corruption, appointed by the Speaker of the Chamber of Deputies in 1996. It proposed twenty-two types of

${ }^{11}$ A select committee for the examination of bills containing measures for the prevention and repression of corrupt acts, established by the Chamber of Deputies with a resolution approved in September 1996.

${ }^{12}$ In addition to the previously-mentioned report (La lotta alla corruzione) by the study commission chaired by Sabino Cassese, cf. the report by the study commission established at the Dipartimento della funzione pubblica (Civil Service Department) and chaired by Gustavo Minervini. 
remedies against corruption, grouped under five headings: legal parameters; relations between politics and the public administration; public administration personnel; administrative activity and controls; controls in the private sector. The prevention of corruption requires operating on a number of fronts.

\subsection{The normative parameters}

As regards the normative arrangement, the remedy indicated by the Report is a reordering of the norms: too many rules create inflexibility in the system, inducing the citizens to violate them and offering the controllers opportunities for extortion; the unwieldy standards allow a choice of which discipline to apply, thereby favouring corruption. In this respect, it must be observed that all recent governments have made mention in their programmes of the need for 'delegislating' (meaning the turning over of given matters of law from the statutory level to a lower, and consequently more flexible level) and for codification; beginning in 1997 a law for annual simplification has been in effect, providing for the reordering of given sectors on a yearly basis ${ }^{13}$. The policy of reordering norms has brought certain results (among the latest being the single texts for administrative documentation, expropriation and the buildingindustry), but overall this activity is making slow progress.

\subsection{The relation between politics and the administrative agents}

The Report provides various indications in the matter of the relations between politics and the public administration, which have had little follow-up. The discipline governing the way politics are funded has not changed, which is cause for concern, among other things because in addition to official funding there is secret funding through newspapers and radio stations belonging to political parties and groups. Nor has the discipline of appointments to top offices of government institutions and agencies changed, so that such appointments are still frequently made on the basis of party affiliation. As for public leadership, on the one hand the respective duties of political personnel and of administrative managers has been defined more precisely, by specifying the principle of the distinction between political direction and the management of administrative affairs. On the other hand, a trend has developed which is still underway to subject anew a large part of the managers in public administration to the politicians, introducing the spoils system for many

${ }^{13}$ Art. 20, paragraphs 1 and 11, L. 15 March 1997, n. 59. Recent Italian laws are available on line at <www.normeinrete.it/> 
high administrative offices. The introduction gets justified in the name of the need of the "democratically elected" political majority to be able to count on executives who are faithful executioners of its policies: it is therefore the democratic principle itself which enters into conflict with the principles of impartiality and neutrality in public administration, which also are important in constitutional terms and to which considerable importance is attributed for the control of corruption.

The issue which currently is of the greatest moment in Italy in the field of public ethics - conflict of interest of government officeholders may be judged from the same perspective. The Parliament has been engaged in the matter for several years, but the personal position of the present Prime Minister (and head of the opposition in the previous legislature) weighs on the solution of the problem, being the owner of assets and economic activities such as to cause a potential conflict of interest in the greater part of government activities. One consequence is that the debate over conflict of interest often gets mixed up not only with ordinary political confrontation but also with other no less important matters such as competition in the television industry, the plurality of the news media, the ineligibility for elective office of holders of concessions granted by the public administration, and the questionable compatibility of government office with outside activities that require time and energy. A second consequence is that the two bills which to date have been approved by one branch of Parliament ${ }^{14}$ reflect the preoccupation - at times disguised with observations on constitutional law - with avoiding forcing a person who has received a broad popular consensus to chose between elective office and entrepreneurial activities, essentially by having to give up one or the other.

In particular, this explains why the proposal currently being exam-ined by the Parliament essentially eludes the conflict of interest issue, by providing for obligations to abstain from certain acts and for transparency but whose transgression is not in fact subject to penalty, and concerns itself with other questions (in particular, with separating public management from private management, which serves not to avoid conflict of interest, but to assure that holders of public office sufficiently devote themselves to carrying out their public duties). The proposal rejects, then, what is indicated in the above-mentioned Report as the only decisive solution to the problem: the effective divestment of interests through a blind trust with the trustee having the power to sell properties and modify the consistency of the assets.

Naturally, rather than eliminate the problem, it may be decided to attenuate it with obligations of abstention and transparency and adequate punishment in the event of failure to meet them. However, we

${ }^{14}$ For the current legislature, AC 1707 and AS 1206. In the previous legislature, AC 1236 and AS 3236. 
must not deceive ourselves into thinking that in this way the problem of the current Prime Minister can be solved, since because of its magnitude it cannot be solved by a law: the solution indicated by the Report - in addition to encountering the political difficulties previously mentioned - would imply the sale of huge assets, with the need to reinvest the money, which makes unrealistic the idea of a blind trust; the obligation of abstention would have to apply to most government decisions, something unthinkable for someone in a position of general political leadership; transparency is not always effective in the presence of a business group with diversified interests concerning which it is not easy to assess the effects of decisions by public authorities.

In this case as well, certain general indications can be gleaned from the Italian experience: the regulation of the conflict of interests, like that of the ineligibility to bold elective public office and of incompatibility, is a tool for the correction of democracy, which serves to avoid the negative effects of the functioning of the democratic principle; such discipline must be general and independent of events in the lives of the individuals involved; it must be prearranged in a timely manner to allow the interested parties sufficient time for compliance. There is a further indication as well: it is unreasonable to expect the norms to solve problems that cannot be resolved by this means, and instead must be dealt with using more suitable tools (such as the vigilant exercise of political rights and the proper exercise of the powers of control and punishment).

\subsection{Public personnel}

The measures for the prevention of corruption in administrative personnel proposed in said Report contemplated, among other things, improved working conditions and the recovery of the prestige of public service, as well as the strengthening of the technical staff (engineers, architects, land-surveyors and informatics experts at the service of public administrations). Particularly important aspects are involved here, which unfortunately continue to be neglected, including due to obvious budgetary considerations. As the founder of the Italian school of political science wrote, "the public employee has duties unknown to the private sector employee, must also have special rights and guarantees, and nothing is more demoralising to him than to see his career abandoned to the caprices and favouritism of petty politicians" 15 . On the other hand, the link between corruption in the public administration and the pay differential

${ }^{15} \mathrm{G}$. Mosca, Ilpericolo dello stato moderno, 1909, also in Scritti sui sindacati, ed. F. Perfetti and M. Ortolani, Bulzoni, Roma, 1974, p. 94. 
in the upper and lower echelons of the bureaucracy is more than just a theory (a decrease in the differential produces an increase in corruption in the upper levels, as a means for recouping high income ${ }^{16}$. As regards the technical staff, it will suffice to refer to an observation made by the President of the Council of State at a parliamentary hearing in 1998: "It worries me a great deal that technical expertise has been entirely cancelled ... On a daily basis we are faced with the very serious circumstance of the unsuitability of current structures and professional skills to stand comparison with the private sector, to plan, to direct and to test and try out" ${ }^{17}$.

It can be inferred from this that the adequate remuneration of public personnel and the presence of an adequate technical staff are important conditions for preventing corruption.

Other measures concerning administrative personnel regard the elaboration of codes of conduct and the definition for public employees of what constitutes incompatibility, of obligations regarding the declaration of personal assets, and of activities subsequent to the termination of public employment. The duties of public employees and the matter of disciplinary responsibility will be taken up in a paragraph below. Here it may be recalled that, on the one hand, in 1998 regulations clearer than previously were set concerning incompatibility and the holding of more than one job or office at once ${ }^{18}$. On the other hand, along this same line it must also be remembered that there is frequently a tendency to overdo things, as demonstrated by another, much criticised proposal made by the Chamber of Deputies Select Commission for the Fight against Corruption, aimed at the creation of a personal assets registry office containing information on a great number of politicians and public employees. In this respect, it must be observed that, on the one hand, measures for transparency also have their costs (above all for the interested parties, who are required to make a periodic declaration); while on the other hand, buge quantities of information normally correspond to a lack of effective controls.

\subsection{Administrative action and controls}

The proposals contained in the Report relating to administrative action and controls regard, among other things, administrative con-

${ }^{16}$ On this point, cf. S. Cassese, "Ipotesi sulla storia", op. cit., p. 182 and following.

${ }^{17}$ Senato della Repubblica - I Commissione permanente, XIII legislatura, Indagine conoscitiva sugli strumenti istituzionali atti a prevenire i fenomeni di corruzione, session of Tuesday, March 31, 1998, Hearing of the President of the Council of State, Renato Laschena. Particularly useful on the subject is E. Gustapane, "La crisi dei corpi tecnici dello Stato", Corruzione e sistema istituzionale, op. cit., p. 213.

${ }^{18}$ Art. 53, d. lgs. 30 March 2001, n. 165. 
trols, contractual activity of public administrations, and the relation between criminal procedure and disciplinary procedure.

As regards administrative controls, the matter underwent reform in the 1990s in the sense indicated by the Report, with the passage from controls over the process to controls over the end product, even though the new forms of control, modelled on private sector practices, have encountered difficulty in fulfilment. On this subject, it needs to be mentioned that the 2001 reform of Title V of Section II of the Constitution of the Republic of Italy involved among other things the abrogation of the norms that provided for controls on the administrative acts of regions and local bodies. Aside from the limited effectiveness of the controls on individual acts in the prevention of corruption, the circumstance offers an occasion for a more general consideration in connection with decentralisation: as is sometimes observed ${ }^{19}$, decentralisation operations often entail the risk of greater corruption, due not only to a lessening of controls, but also to the lower quality of the personnel staffing the local institutions compared to national institutions, as well as to the failure to recreate at the local level the structures and professional skills previously found in performing the same functions at the national level (even the crisis enveloping the technical staffs mentioned earlier is bound up with decentralising operations, in addition to other factors).

Corruption in activities covered by third-party contracts is better combated not by modifying the norms (which the national legislature cannot do anyway, since the subject matter is essentially disciplined by Community law), but by effectively using the public tender process. In any case, it is worth pointing out a recent initiative that has allowed the public administrations to make considerable savings, with a corresponding reduction in opportunities for corruption: a 1998 law $^{20}$ provides that in the procurement of goods and services by the public administrations conventions shall be stipulated with the suppliers which even public administrations other than national may take part in, in order to make purchases under the terms established generally. The related administrative functions have been assigned to a State-controlled company ${ }^{21}$, which offers assistance to public administrations in stipulating contracts and allows them to accept via the Internet ${ }^{22}$. This solution lowing.

${ }^{19}$ S. Cassese, "Maladministration' e rimedi", Foro it., 1992, V, col. 245 and fol-

${ }^{20}$ Art. 26, L. December 23, 1999, n. 488.

${ }^{21}$ Consip S.p.A.: decree by the Minister of the Treasury, of the Budget and of Economic Programming dated February 24, 2000.

${ }_{22}$ Available at <www.consip.it/ and www.acquisti.tesoro.it/>. 
allows the advantages of centralised management to be applied to the single administrations while respecting their need for autonomy.

As for the relation between criminal proceedings and disciplinary proceedings, a 2001 law $^{23}$ worth mentioning aims at placing a greater value on the disciplinary responsibility of public employees, thus representing an internal remedy that might prevent the commission of serious crimes though the punishment of less serious forms of misconduct, except that the public administrations make little use of it: "to the point that the relevant proceeding tends to take the form of an eventual effect of the criminal trial rather than of an autonomous tool for preventive defence in the hands of the administration" ${ }^{24}$. Contrary to what ought to be, disciplinary proceedings are normally far fewer than criminal proceedings against public employees. The relation between the two proceedings is rather problematic, including because of the "full independence of disciplinary action that the administration exercises over its own functionaries from the outcome of the criminal proceeding" 25 , something consistently upheld by judicial rulings as a safeguard for the employees. The Constitutional Court has intervened more than once to censure the excessively automatic transposing of the outcome of a criminal trial to a disciplinary procedure. Besides, as demonstrated by a ruling handed down just recently by the Court ${ }^{26}$, with this law the legislators seem to have correctly identified the limits within which this type of transposition may be effected: on the one hand, the verdict of a criminal trial has a binding effect in disciplinary proceedings not only in the event of acquittal, but of a guilty verdict as well "insofar as the verification of the circumstance, of its constituting a penal offence and of the allegation that the defendant committed it"; on the other hand, automatic features are admissible between the outcome of the various phases of a criminal proceeding and administrative disciplinary measures, provided that they are congruous with the type of crime involved, as well as with the stage of the criminal proceeding.

\subsection{Controls in the private sector}

Finally, as regards controls in the private sector, the most recent legislation provides contradictory indications pertaining to policies for

${ }^{23}$ L. 27 March 2001, n. 97.

${ }^{24}$ C. Franchini, Il controllo del giudice penale sulla pubblica amministrazione. Introduzione al tema, Cedam, Padova, 1998, p. 19.

${ }^{25}$ Cons. St., sez. IV, 18 September 1905, n. 363, also in Le grandi decisioni del Consiglio di Stato, ed. G. Pasquini and A. Sandulli, Giuffrè, Milano, 2001, p. 85.

${ }^{26}$ Constitutional Court, May 3, 2002, n. 145, in relation to the suspension following a non-definitive verdict of guilty as charged. 
privatisation, liberalisation and simplification, as well as to the regulation of stock companies.

In the past decade all successive governments have made the above policies their own, but their fulfilment has often encountered difficulty: substantial privatisation has not always followed formal privatisation, even though it is necessary for resolving the problem pointed out by the other study commission on corruption, of which it has been said: "the excessive presence of the public hand in the economy, in terms of management as well as regulation, has often resulted in giving priority to the ties between politicians and entrepreneurs rather than the pursuit of the economic purposes proper to the enterprises"27. From this standpoint, the substantial return to the public sector of banking foundations (institutions that hold substantial equity interests in privatised banks) just few years after their privatisation, brought about through the imposition of expenses and the increased participation of politically-appointed personnel in their management ${ }^{28}$ can only be viewed negatively. The operations promoting liberalisation and simplification, successfully conducted in sectors such as commerce and telecommunications, are likewise often balanced with measures leading in an opposite direction ${ }^{29}$.

There are also contradictory signals in the matter of company law. If the 1998 norms in the matter of financial intermediation ${ }^{30}$ have specified the duties of the boards of auditors and of outside certified auditors and assigned new powers to the partners, the recent depenalisation of false financial statements ${ }^{31}$, an offence that is frequently linked to the corruption of public functionaries, again moves in the opposite direction.

It can be concluded that the fight against corruption needs to be waged in terms of the administration and employees alike. The remaining portion of this writing is devoted to the rules of conduct for public employees.

\section{Rules of conduct for public employees and the codification thereof}

\subsection{The Code of Conduct for public employees}

As a great economist, who also served as the President of the Republic of Italy, put it, "Men are too selfish or evil or unaware so that

${ }^{27}$ Commissione Minervini, Relazione finale, op. cit., p. 51.

${ }^{28}$ Art. 11, L. December 28, 2001, n. 448.

${ }^{29}$ As shown in the essays collected in the volume I governi del maggioritario. Obiettivi e risultati, ed. G. Vesperini, Donzelli, Roma, 1998. For the more recent period, see the column "Attività normativa del governo", ed. G. Napolitano, Riv. trim. dir. pub.

${ }^{30}$ D. lgs. February 24, 1998, n. 58.

${ }^{31}$ D. lgs. April 11, 2002, n. 61. 
when they find themselves at the head of a powerful organisation they do not succumb to the temptation to reap personal gain, to the loss of those they represent" 32 . It can be said that the definition of the rules of conduct for public employees, effective beginning in 1994 with the definition of a Code of conduct ${ }^{33}$, rests on this healthy scepticism, but it also rests - in more positive terms - on the faith in the usefulness of fixed standards of behaviour for those with a desire to behave properly, even in situations of uncertainty as to how to behave. Written standards furnishing detailed indications for what line of conduct to adopt in like situations did not exist prior to 1994, except for special corps, such as military units (for instance, the national police, whose service regulations are highly detailed, to the extent of regulating the women's makeup and the trim of the men's moustaches ${ }^{34}$ ). The absence of norms, as sometimes pointed out by scholars ${ }^{35}$, is linked to the crisis of disciplinary responsibility previously mentioned, which has not performed its proper role of filter and prevention. In this respect the law that provided for the Code marked the beginning of a turnabout in Italian legislation, with other, more detailed rules regulating personal behaviour being introduced in following years for various categories of public employees and private subjects, and other codes of conduct expected ${ }^{36}$.

Ever since its enactment the Code of Conduct for employees in the public administrations has fuelled debate - a debate which in some ways is similar to the debate underway in Anglo-American culture for roughly the past two decades, and in other ways is a bit provincial just because it deals with issues of a general nature without taking into account the experience of other countries in dealing with the same prob-

${ }^{32}$ L. Einaudi, La bellezza della lotta, (1923), also in Le lotte del lavoro, Einaudi, Torino, 1972, p. 13.

${ }^{33}$ Enacted by a decree of the Ministro per la funzione pubblica dated March 31, 1994, later re-enacted by the same Minister on November 28, 2000.

${ }^{34}$ D.P.R. October 28, 1985, n. 782.

${ }^{35}$ S. Cassese, "Idee per limitare la corruzione politica", Corriere giuridico, 1992, p. 702, and "'Maladministration' e rimedi”, op. cit., col. 246. In the traditional public law conception of public employment, the absence of detailed rules was attributed to the fact that the disciplinary power of the public administration was founded on a relation of "special supremacy" rather than on a contractual requirement, which justified the discretion of the administration in the evaluation of the disciplinary offence, even in the absence of specific provisions. In this regard, cf. S. Battini, "Il personale", Trattato di diritto amministrativo, ed. S. Cassese, pt. gen., t. I, p. 455 and following.

${ }^{36}$ Such as those provided by the set of rules in the matter of safeguarding privacy and regarding personnel involved in performing tax audits. On the increasing use of codes of conduct, on the causes of their spread and on the features of the codes, cf. S. Cassese, "I codici di condotta", Doc. Giustizia, n. 7-8/1994, col. 1371. 
lems. Often conducted more with a journalistic than scholarly approach, the debate, overall, has not been terribly stimulating. Rather than give an account of this debate, it appears useful to expound the theory that has gained the most consensus in Italy as well as abroad: the codes of conduct are useful as components in a complex strategy for fighting corruption, for instilling shared values in public sector personnel, for providing rules of conduct for doubtful cases, for furnishing criteria to the organs for control ${ }^{37}$ as a yardstick for judging conduct, for creating certain expectations in the administered, and, in short, for shifting the borderline between tolerable and intolerable conduct in the direction of better administration.

Nor is this the time to dwell at length on the contents of the Code of Conduct, which are not very different from codes of conduct for public employees by now commonplace in various systems and found in the models proposed by international institutions, such as the United Nations and the Council of Europe. The core values are: honesty, impartiality, independence, efficiency, transparency, care in dealing with the public and the safeguarding of the administration's image.

It is necessary only to mention the presence - alongside "traditional" values, such as the constitutional values of discipline and honour (Section 54 of the Constitution), and of impartiality and efficiency (Section 97) - of "new" values, which reflect the administrative reforms of recent years: for example, references to the right to access to administrative documents, to administrative liberalisation and simplification, to the new guidelines for running the public services (respect for the quality of services rendered, continuity of the service, competition and consumer choice), to the evaluation of management results, to decentralisation and to the principle of subsidiarity. In this way the administrative reform principles get translated into canons for individual behaviour. Therefore, the Code does not merely serve to translate general principles into precise rules, but also updates the principles themselves, which previously were to be identified with provisions going back to 1948 (found in the Constitution) and to 1957 (in the few relevant legislative provisions $)^{38}$.

${ }^{37}$ Including the criminal judges themselves, who - albeit rarely - make reference to the Code as an exemplification of conduct that is acceptable and that which is not, and thus as a tool for the interpretation of the norms referred to for incrimination. Examples are found in the rulings Cass. pen., VI, 26 March 1996, n. 2996; and Cass. pen., VI, April 20, 2001, n. 16245.

${ }^{38}$ Single Text containing the provisions concerning the by-laws for civil employees of the State, adopted with d.P.R., January 3, 1957. On the various possible models for the relation between the law and codes of conduct, cf. G. Alpa, "Autodisciplina e codice di condotta", Sociologia del diritto, n. 2/1995, p. 133. 


\subsection{The specificity of the rules of conduct in the public sector}

What must be stressed is that those principles continue to be specific principles for work in the public sector, only in part corresponding to the principles that regulate the behaviour of private sector employees: even if certain of the more recent reforms have consisted of the introducing into the public administration organisation of institutions typical of the private sector (for example, in the area of controls), many of the "new" values (such as transparency, decentralisation and the principle of subsidiarity) also reflect the peculiarity of the rules of conduct for public employees.

Underlying the codification of the rules of behaviour for public employees is, then, the concept of the specificity of these rules, often asserted by judicial rulings: for example, recently the Council of State has decreed that "the public employee, in carrying out his functions, must behave in compliance with professional ethics, which is correlated to a sense of morals and of honour" ${ }^{\prime 3}$. That the duties of public employees are distinct from those of private sector employees is also shown by the fact that the first duties mentioned, unlike the second, do not always derive from the economic interest of the employer. Think of the obligation of courtesy toward the consumers, or the obligation to respond quickly to complaints in the same order they were lodged: in the private sector, such obligations derive from the need to acquire customers or consumers (to such an extent that, in the absence of effective competition, laws are used to impose the related obligations on the companies). This is a need that the public administrations do not have, operating as they do in a monopoly situation: for them and their employees, similar rules depend on the principles contained in the Constitution and in the other norms cited, which also translate into rules for individual behaviour.

This specificity derives partly from the fact that the duties of the public employee do not only consist of carrying out job duties for an employer, but also of performing a function vis-à-vis two distinct "masters": the administration and the citizenry; and partly as a consequence of the existence of constitutional principles, which the administration/ employer has no control over, and therefore are non-negotiable. This explains why the definition of the duties of public employees is made not subject to collective bargaining: the existence of said constitutional principles constitutes a limit on the subjection of labour relations involving the public administrations to collective contracts, as has been the case in Italy in the last decade (previously the relation was generally regulated by unilateral acts of the administration). 
The matter of disciplinary responsibility has instead been assigned to collective bargaining, by that meaning the definition of forbidden acts and penalties. An aspect of particular interest in the Italian experience can be identified precisely in the way the relation between the definition (unilateral) of the duties and of the forbidden acts and penalties (contracted) has been resolved. The law provides that the Code of Conduct shall be defined by the Civil Service Department, once the more representative trade union organisations have been heard; that a copy of Code shall be given to each new employee at the time of hiring; that the Code shall be included in annexed form in collective bargaining contracts; that the directives that the administrations formulate to ARAN (acronym for the organ that concludes collective contracts on behalf of the public administrations), for purposes of collective bargaining, shall provide for the co-ordination of its contents with the provisions contained in the contracts regulating disciplinary matters. This original solution allows reconciling the non-negotiability of the duties of public employees, which derive from the very nature of the relation and from constitutional principles, with the objective of making public employment homogeneous to private employment in the matter of disciplinary responsibility. At the act of hiring, the public administration indicates his (or her) duties to the new employee, which remain the same independently of what agreement may be reached as to the consequences of the violation thereof.

An indication can be drawn as to the juridical value of the codes of conduct: whereas the rules of conduct for public employees are based on non-negotiable principles, the consequences of the violation thereof may be established contractually.

\subsection{The scope of the rules of public ethics}

Having identified this strong point in the Italian experience concerning codes of conduct, it is now necessary to stop and consider certain weak points and open questions. Some of these regard the province of the Code's application.

In the first place, at this point the system briefly described must come to terms with the previously-mentioned federalist reform of the State. On the basis of the new distribution of legislative power, the central government will be responsible for the discipline of the personnel employed just by the national government itself and the national public institutions. As regards the personnel staffing the regional and local bodies, therefore, the system as described is destined to be substituted by norms enacted by the pertinent governments. It is obviously to be hoped that these new norms will in any case maintain a provision for adequate rules of professional behaviour. 
As for that, the normative powers of the regions and local institutions could contribute to adapting the general provisions contained in the Code to the individual circumstances of the different administrations and careers. In fact, however detailed the provisions of the Code may be, they inevitably remain general, being applicable to all public personnel: despite the fact that the law allows the single administrations to supplement and further specify the provisions of the Code ${ }^{40}$, this possibility has not been exploited. There is, instead, a need for differentiation, which underlies the provision for specific codes for given personnel categories (magistrates, national government lawyers) ${ }^{41}$ and for the adoption of codes of ethics on the part of the single administrations (such as the competition Authority, "Autorità garante della concorrenza e del mercato" 42 ). The general principles of conduct can be specified for the individual categories of personnel.

Another open question in Italy is the matter of rules of conduct for political personnel. The process of codification described had its origin in 1993 with the programming announced by the government then headed by the current president of the Republic (C.A. Ciampi), which called for the elaboration of codes of conduct not only for career personnel, but for elective personnel as well. There was no follow-up on this particular point notwithstanding the fact that political corruption normally is considered no less serious and widespread a problem than administrative corruption. In certain respects, the rules established for public employees could be usefully applied to elective officers as well: for example, a recent ruling handed down by the Court of Cassation upheld the conviction for embezzlement of public funds of a member of a municipal council for having used the municipal phone line for "lengthy and repeated personal conversations of an erotic/sentimental nature" 43 ; involved here is a problem that the cited Code of Conduct for public employees deals with, by permitting the use of the telephone for private purposes only in exceptional cases ${ }^{44}$. However, in other re-

${ }^{40}$ Art. 54, paragraph 5, d. lgs. n. 165 of 2001.

${ }^{41}$ Art. 54, paragraph 4, d. lgs. n. 165 of 2001. The various codes are published in Le regole deontologiche di avvocati e notai e $i$ codici etici della magistratura, monthly dossier n. 6/1995 of Guida al diritto.

42 The code of the Antitrust Authority appears in Giorn. dir. amm., 1995, p. 1190.

${ }^{43}$ Cass. pen., VI, February 1, 2002, n. 3883, Guida al dir., n. 18/2002, p. 61.

${ }^{44}$ In the case of public employees, judges often make reference to the Code of Conduct in connection with the embezzlement of public funds involving charges deriving from the "definitive appropriation of the electronic impulses by means of which the voice is transmitted", as in the following rulings: Cass. pen., VI, n. 16245/2001, previously cited; Cass. pen., VI, December 15, 2000, n. 3879. 
spects, the problems of public ethics regarding political staff are different, thus requiring specific rules: here we are thinking of the relation with the electorate, of behaviour in election campaigns and of the financing of politics.

However, in the present political phase the elaboration of standards of conduct for political personnel would encounter the same difficulty already spoken of in reference to the problem of conflict of interest. It would meet with an additional obstacle in an almost Jacobin attitude fairly widespread in the world of politics whereby anyone who has been elected, being the repository of popular faith, ought not to be made the subject of judgement other than by the electorate. The rules of public ethics instead serve the very purpose of limiting and correcting the functioning of the democratic principle. The warning of an outstanding priest, scholar, politician and founder of the Italian Catholic Party ought to be kept in mind: "When power takes form as solutus a lege hominum [free of the laws of men] it is easy to come to believe oneself solutus a lege Dei [free of the laws of God], meaning above morals" 45 .

There is also a problematic aspect in the area of application of the rules of public ethics: that of private subjects who perform public functions, to whom at present the rules enacted for public sector employment do not apply. And yet, the problem of guaranteeing the proper pursuit of the public interest and the rightful expectations of the administered is posed for them as well; they, too, not only are accountable to an employer, but to another "master" as well - the collectivity. The most obvious example in the wake of the notorious scandals in recent months involves audit firms, and in general the numerous private professionals to whom the laws assign functions of control and certification (companies that attest to the fitness of private companies to carry out public works, shops authorised to control exhaust fumes). But there are also various other hypotheses concerning formally private subjects that perform administrative functions (such as institutions for specialised assistance: agencies for assistance to workers whom the law qualifies as private juridical persons, to then impose various administrative functions on them and allocate financial resources to them for their fulfilment). The phenomenon is destined to increase, now that the reform cited on a number of occasions has included the principle of horizontal subsidiarity in the Constitution, which imposes advancing "the autonomous initiative of citizens, both individual and associated, for the performance of activities of general interest" (Sec-

${ }^{45}$ L. Sturzo, Politica e morale, (1938), also in Opera omnia, I serie, vol. IV, Zanichelli, Bologna, 1972, p. 11. 
tion. 118, par. 4 of the Constitution). This principle produces advantages in terms of the participation of the citizenry in administrative activity, but even greater risks of corruption: the observation is frequently made that the outsourcing of public functions often lies at the origin of new corruption ${ }^{46}$.

In effect, the regime of public administrative functions performed by private subjects is one of the major themes facing administrative law scholars - a theme which up until now has been mainly dealt with in reference to the organisations that perform them and to the juridical regime of related activities (for example, in the matter of the controls of the State Audit Court). It may also be dealt with from the standpoint of individual duties. In outsourcing administrative functions, it would be necessary for the public administrations to adopt conditional decisions similar to those mentioned earlier made by the World Bank or the International Monetary Fund, imposing programmes for proper administration including rules and controls on interested private parties.

There is thus a problem of the relation between the rules of public ethics and the rules of private professional ethics. Only in certain cases - and often in an inadequate way - do the norms concern themselves with the deontology of private subjects: for example, for the learned professions. From this standpoint, the provision contained in the previously-mentioned Code of Ethics of the Antitrust Authority stating that outside consultants shall pledge themselves to observe the Code is praiseworthy. On more than one occasion the same Authority has shown itself capable of using private codes of conduct to further public goals, imposing on a business syndicate the adoption of a code of conduct inspired among other things by the principles of competition ${ }^{47}$, in lieu of a stiff fine, and in addition to various other obligations.

\subsection{Further open questions}

Two further problematic aspects remain. The first regards the publicity of the rules of behaviour, which is essential. If their codification serves to instil shared values in employees and to create rightful expectations in the minds of the citizenry, it is evident that employees and the general public must be put in a condition to know and apply the rules of bebaviour. The law provides that the Code of Conduct for

${ }^{46}$ Relevant observations are found in K. Kernaghan, "The Post-Bureaucratic Organization and Public Service Values", International Review of Administrative Sciences, vol. 66, n. 1/2000, p. 98.

${ }^{47}$ Measure dated December 7, 1999, n. 7807 (I342), Farmindustria/Codice di autoregolamentazione. 
public employees shall be distributed to all employees, but few administrations do so (among them, the University of Siena), while the Code is practically unknown to the general public (and to professionals in the field of law as well, seeing that it is often left out of the collections of administrative laws), to such an extent that from time to time there are those who propose the enactment of a code of conduct for public employees!

The other problem is one of content, and regards the restrictions subsequent to the termination of employment, which are practically nil. In other systems, such as in the United States, the rules of public ethics establish a broad discipline in the area of post-employment restrictions; while in other systems, such as in France, judges are very severe with respect to the practice of pantouflage ${ }^{48}$. In Italy perhaps the problem is less serious, given the lesser professional qualification of the leadership, which for that matter has recovered a certain attractiveness in recent years. In any event, the problem is not new: Luigi Einaudi's polemics against the transfer of State managers to companies controlled by the State or having contractual relations with the State goes back to the early twentieth century. In more recent years, at times the suspicion has been that the hiring of certain people by private firms served to "reward" functionaries who, in carrying out their public duties, had acted in the interest of their future employer. The Code of Conduct effectively contains provisions addressing the point, but its effectiveness is limited to the period when the public employee is still such: it would be necessary to add limits and binding rules covering the subsequent phase as well.

\section{The difficult translation of the principles of public etbics into individual practice}

It is evident from what has been said thus far that many principles regard the rules for operations in the public administrations as well as rules for those employed there. The Constitution itself establishes norms for both in the same Section 97, and, in the matter of liability for damages to third parties, extends responsibility to both. Certain principles, which have inspired recent reform legislation, are also susceptible to translation into rules of individual behaviour. And yet, as effectively demonstrated by the example of civil liability (which is full for the administration, but limited by law to just fraud and serious negligence in

${ }^{48}$ For example, cf. Conseil d'Etat, December 6, 1996, n. 167502, Beaufret, Giornale di diritto amministrativo, 1997, p. 927. 
the case of employees), such translation is often difficult, or at least it is difficult to make those principles effective for individuals. In order to illustrate this phenomenon, reference can be made to the four principles mentioned in the sub-topic of this report: responsibility, transparency, efficiency, honesty.

In recent times the matter of responsibility has undergone more rapid evolution (even if tardy compared to other systems) ${ }^{49}$, characterised by a progressive broadening of the financial responsibility of the public administration and of the managers of public services: the prejudice has been overcome against the payment of compensation for damages to legitimate interests, which at one time guaranteed a protective shield of immunity to the public administrations for damages caused to third parties $^{50}$; the right to indemnity, charged to the State, for the excessive duration of trials has been introduced ${ }^{51}$; in the matter of public services provisions have become widespread assigning rights to indemnity to consumers, even in the absence of proof of the damage suffered ${ }^{52}$; a legal norm, unfulfilled, also has provided for the right to indemnity for the failure to enact administrative measures, or delay in doing $\mathrm{so}^{53}$. To this accentuation of the forms of responsibility of the public administration there is no corresponding accentuation of the responsibility of employees: as has already been observed, disciplinary responsibility does not perform the important role of prevention that it might; even the importance of management responsibility, a new form of responsibility of administrative directors for the management results, seems to be downgraded by the tendency to again subject many directors to a broad power of appointment and removal by the politicians. Certain personnel categories, such as the magistrates and - in recent events - members of the police force, seem to claim immunity from every form of responsibility.

As the examples just given demonstrate, the difficulty in making the responsibility of employees become truly effective often is caused by the defensive attitude assumed by labour organisations and by organs for selfgovernment. The same can be said for another of the principles mentioned: efficiency. It is at the basis of many recent reforms (in the matter of administrative proceedings, administrative controls, public finance, among

${ }^{49}$ Cf. L. Torchia, "La responsabilità", Trattato di diritto amministrativo, pt. gen., ed. S. Cassese, Giuffrè, Milano, 2000, p. 1451 and following.

${ }^{50}$ Cass. civ., sez. un., July 22, 1999, n. 500, Giom. dir. amm., 1999, p. 832.

${ }^{51}$ Law n. 89 of March 24, 2001.

${ }^{52}$ Cf. G. Napolitano, Servizi pubblici e rapporti di utenza, Cedam, Padova, 2001, p. 321 and following.

53 Art. 17, par. 1. f), L. March 15, 1997, n. 59. 
others), which have attributed greater importance to the value of efficiency on the part of the public administrations. But yet once again the transposition of this value to the individual level encounters much difficulty.

As one of the best-known Italian scholars in the field of administrative law wrote in 1920 about public employee labour unions, "They fight ... for career advancement, which they want based exclusively or at least prevalently on the criterion of length of service and delegated to commissions which include their representatives" ${ }^{4}$. These words, reactionary at the time they were written in the aversion expressed to the presence of the union movement in the public administration, are still fresh today as regards the aversion of the unions to the merit principle - an aversion so great as to have recently caused the abandonment of a project for the introduction of mechanisms rewarding efficiency in teaching careers in the public school system.

Beginning in 1990 the principle of transparency as pertains to administrative activity has been resolutely asserted by the law and just as resolutely upheld by judges. For employees, the principle is posed essentially as concerns declarations about their personal economic interests and the amount of their personal assets. However, this must be reconciled on the one hand with the right to privacy, and on the other with the previously indicated uselessness of gathering huge quantities of information. It can thus be said that transparency, insofar as employees are concerned, ought to be restricted to limited, truly relevant information.

Finally, as for the value of honesty, the practical implementation is often easier for the administrations than for the employees. Regarding the former, for example, judicial rulings firmly uphold the principle of good faith (among other things, in the matter of the withdrawal of previous measures, and of precontractual responsibility). Regarding the latter, as we have seen, it has not proved possible to even define elementary rules for preventing and resolving conflicts of interest. A further significant example involves the Council of State: nobody doubts the rightness and justice of its decisions and opinions, but - as regards individuals - in recent years a heated debate has developed over the question of outside paid assignments entrusted to councillors of State by both public and private subjects.

\section{Public ethics and sustainable development}

It has been seen how the principles of public ethics are historically variable and require updating to keep apace with the evolving of the

54 O. Ranelletti, Il sindacalismo nella pubblica amministrazione, also in Scritti giuridici scelti, vol. V - L'organizzazione pubblica, Novene, Napoli, 1992, p. 138. 
principles of administrative legislation and the adding of new values to old. It can therefore be stated that also public ethics is a function of the administrative functions ${ }^{55}$ : the history of public administration in Italy, moreover, demonstrates that the increase of administrative functions bas always caused an increased risk of corruption ${ }^{56}$. It is reasonable, therefore, to question ourselves about the impact of the principle of sustainable development on the prevention of corruption and on the rules of public ethics. In order to evaluate this impact, it appears opportune to distinguish between the two components of the concept of sustainable development, and therefore between the functions connected with development and those in relation to the conservation of resources.

As regards development, by now theories have been abandoned that once viewed corruption as a tool for efficiency, capable of improving the functioning of the workings of the bureaucracy ${ }^{57}$. Italian history demonstrates that economic development is fostered by honest public administration ${ }^{58}$. What is more, the strategies to be employed in the fight against administrative corruption and the definition of the rules of public ethics likewise must take into account the models for development and the role that the policies for development assign to public authorities: in recent years the tendency is to curtail this role, to encourage competition and to ease the restrictions on business. As stated, the strategies for combating corruption and the principles of public ethics reflect this evolution: on the one hand, the attenuation of the strictures and controls on the operators is proposed as a tool of prevention, in that such restrictions frequently present occasions for extortion; while on the other hand, such principles as liberalisation, simplification and the right of customers to choose, find room in the oft-cited Code of Conduct for public employees.

By this time policies for growth ought to be integrated, within a perspective of sustainable development, with "the needs connected with environmental safeguards": the growth of economic activities must be "pro-

55 Cf. S. Cassese, Le basi del diritto amministrativo, 6th ed., Garzanti, Milano, 2000, p. 18.

${ }^{56}$ Cf. G. Melis, "Introduzione”, Etica pubblica e amministrazione, op. cit., p. 10 and following.

${ }^{57}$ The principal contributions to the related debate appear in vol. I (Explaining Corruption, ed. R. Williams) of the work The Politics of Corruption, ed. R. Williams, Cheltenam, UK and Northampton, MA, USA, Edward Ellar, 2000. Also useful are the records of two meetings held in Italy: Ethics and Efficiency in the Modern State. Are They in Conflict?, ed. E. Borgonovi and C. Savazzi, Egea, Milano, 1994; Responding to Corruption, ed. P. Bernasconi, La città del sole, Napoli, 2000.

${ }^{58}$ Once again, see the previously cited essays in Etica pubblica e amministrazione. 
portionate, balanced, sustainable" 59 . This need can induce limiting the scope of what has just been stated above. The easing of controls on private activities, for example, can reduce the risk of corruption, but it can also increase risks to the environment, as in the case of the "declaration of the beginning of activity" made by the interested party, which above all in the matter of the building industry substitutes for authorisation and thus implies the substitution of a preventive control with an after-the-fact control: the broadening of the area of application of this institution, effected by a recent law ${ }^{60}$, evidently reflects a balancing of interests that may entail a greater sacrifice of environmental concerns. The rules of public ethics, too, as we have seen, defy the logic of the marketplace, because they reflect the interest (including the future interest) of the collectivity, which is often at odds with that of a normal employer.

All this demonstrates that the nature of the notion of sustainable development is a compromise requiring the reconciliation of differing needs, while at the same time proving the usefulness - for such balance - of the rules of public ethics, which in turn reflect the differing needs and can counterbalance the choices in favour of one or another public interest.

As has recently been observed, the objective of sustainable development is assigned "to a plurality of tools, inspired for the most part by different logic" ${ }^{1}$ : which is to say, both traditional and innovative, at times conforming to the market and at times correcting the market. The strategies for the control of corruption and the rules of public ethics will also have to adapt themselves to this plurality of approaches.

The complex of problems bound up with sustainable development indicates that ecology is the science of limits and uncertainties, which induces the abandoning or modifying of many traditional concepts ${ }^{62}$. As for reaching the goal of a public administration that is responsible, efficient and honest, the first step is to realise that in order to do so it is necessary to operate on several fronts, with composite strategies and adopting a variety of tools.

${ }^{59}$ Articles 6 (ex $3 \mathrm{c}$ ) and 2 of the Treaty for the founding of the European Community.

${ }^{60}$ Art. 1, paragraph 6, L. December 23, 2001, n. 443.

${ }^{61}$ F. Salvia, “Ambiente e sviluppo sostenibile”, Riv. giur. ambiente, 1998, p. 243.

${ }^{62}$ Cf. E. Tizzi and N. Marchettini, Che cos'è lo sviluppo sostenibile? Le basi scientifiche della sostenibilità e i guasti del pensiero unico, Donzelli, Roma, 1999, p. 179 and following. 



\title{
The person as a strategic resource in the administration of sustainable development
}

\author{
Alessandra Pioggia*
}

\begin{abstract}
1. Introductory remarks on the theme of sustainable development, on the role of the administration, and on human resources -2 . The crisis of the ordering capacity of legislative abstraction and the possible new role of the individual resource -3 . The indicidual in the administrative organisation: autonomy, valuation, and responsability of management -4 . The individual and work in the employment of the new administration -5 . The individual citizen as a resource of the new administration.
\end{abstract}

\section{Introductory remarks on the theme of sustainable development, on the role of the administration, and on buman resources}

The concept of sustainable development, as it is known, has many facets, all of them related in various ways to the current and future quality of human life. The core of the notion is the idea of an overall improvement of the living conditions of the society compatible with the needs of future generations. Therefore it involves economic, environmental, socio-cultural, and institutional factors. This objective is fundamental, but also complex; in order to achieve it a series of integrated actions is required necessarily providing a key role for the governance of the processes that cannot but directly involve all levels of public administrations: to them are mainly entrusted activities involving operations, guidance, control, promotion and penalties, which are all necessary in order to pursuit the objective of sustainable development.

By this time, there is a widespread awareness of the function of the national and supranational administrations in these processes, as it is clear from the references made to them in many fundamental documents: first, Agenda $21^{1}$, beyond including the "institutional" factor among the indicators of sustainable development, devotes an entire

\footnotetext{
* Università degli Studi di Perugia.

${ }^{1}<$ http//www.un.org/esa/sustdev/agenda21text.html>.
} 
section to the role of efficient, participatory administrations in reaching this objective; second, among the common European indicators of "local sustainability" many indices, such as the level of satisfaction of the citizens, the quality of services, public participation, and the rational management of land use $\mathrm{e}^{2}$ refer to the performance of the administrations; finally, point 3 of the Lisbon Action Plan provides for the involvement of the entire structure of local administrations in the path towards development ${ }^{3}$.

A common conviction emerging from all these references is the necessity for the administrations willing to play a leading role in sustainable development to attain increasingly to higher quality and greater efficiency levels.

In Italy, as in the rest of Europe, the past decade witnessed a steady succession of attempts to reform public administrations for the very purpose of improving operational standards.

The aim of the present contribution is to provide an illustration of certain juridical instruments introduced by the recent reforms, in order to explore the different possibilities of making the best use of the factors that administrations employ in operating, including a basic resource - "people".

The hypothesis that will be examined here is that one of the key features of the transformations currently underway in the Italian administration involves an attempt to employ human resources in a different and innovative way as compared to past attempts ${ }^{4}$.

${ }^{2}<\mathrm{http} / / \mathrm{www}$.minambiente.it.SVS $>$.

${ }^{3}<$ http://www.sustainable-cities.org/lis_it.html $>$.

${ }^{4}$ In the course of the last decade, Italian legislators acted to regulate anew the functioning and organisation of public administration with many normative measures, which deeply transformed the arrangement thereof. Of key relevance in this respect is Legislative Decree N. 29 of 1993, modified by a series of subsequent measures, among which Legislative Decree N. 80 of 1998, currently incorporated in the single text on public employment adopted with Legislative Decree N. 165 of 2001. Important innovations were then introduced by Legislative Decree N. 286 of 1999 on the reform of the system of internal controls. Legislative decrees N. 300 and N. 303 of 1999 revised the organisation of the Government and of the Office of the President of the Council of Ministries, whereas Law N. 59 of 1997 redefined the allocation of the administrative functions among various levels of government. Most of the delegations contained in this law were carried out with Legislative Decree N. 112 of 1998. Moreover, Law N. 127 of 1997 introduced important measures for the simplification of decision-making and control processes of the public administration. Finally, Law N. 94 of 1997 and Legislative Decree N. 279 of 1997 provided for the reform of the national budget. These normative texts are available on the Web site of the Italian Senate: <http// www.senato.it> Additional information is available on the Web site of the Office of the President of the Council of Ministries: <http://www.palazzochigi.it>; and that of the Civil Service Department: <http//www.funzionepubblica.it $>$. 
This is not dictated by the ambition to suggest sound general solutions at all levels where administration is called upon to better answer to the need for sustainability in the development of growing societies. More modestly, the hope is to succeed in indicating some modalities, through which individuals are employed and exploited in the dynamics of the administration, without overlooking the existing limits of this kind of operations.

In choosing the title of this speech the word "person" was preferred to the expression "human resources" that is frequently used in tandem with "material resources". This choice is meant to indicate that even in lexical terms individuals do not constitute an interchangeable asset that is neutral with respect to how it is used, but are instead endowed with specific characteristics and energies that the administration can employ as means for change.

The preference for "person" is also explicatory of the intent to broaden the viewpoint of the analysis to include, along with public administration personnel, those with whom the administration entertains relations, meaning individual citizens who, as will be seen, can also constitute a resource for administering.

The novelty of such a perspective can be fully appreciated only in consideration of the break it represents as compared to the idea of administration based on an opposite logic informed by criteria that have attempted to eliminate the individual, personal, and subjective aspect of the administrative action and organisation.

What has been preferred under the first profile is the unilateral public decision as a guarantee of the prevalence of an interest predefined at the legislative level, impervious to individual considerations and intended as a representation of the entire collectivity as opposed to the specificity of the individual.

Under the second profile, organisation has been configured as an inflexible fact delegated to the law and other normative sources, which, in defining the way the offices and their competencies are articulated, expresses - also in the static administration's way of being - the predetermination of a path where those who act in the offices represent a merely instrumental element.

At the origin of these basic choices there is the need for guarantee that is met by reworking the organisation of the public offices and related activity, as a gradation corresponding to the stages of the implementation of whatever legislative decision, with each succeeding step being legitimated by the connection with the previous one and predetermined in relation to it. From this derives a natural prevalence of the objective element, intended as a preconstitution of the sequence, by means of which the abstract will expressed by the law takes concrete 
form. Within this framework a complete break within the rigid scheme that would be necessary to give more room to the individual would prove useless and perhaps harmful. The role of the individual is thus exhausted in the function of the political legitimation of the legislative power. He consequently remains extraneous to the process of the production, fulfilment and execution of the law.

In this regard, it has been effectively emphasised how at the bottom of the public law culture, which has created the categories of modern administration, there is a sort of "anthropological pessimism", which, in opposition to individualities in perennial conflict, has posited the positive value of the collectivity organised institutionally, and, therefore, in a State.

The picture remained unchanged at the time when the plurality of social classes enfranchised by the advent of universal suffrage caused the number of interests included in the public arena to multiply, forever putting an end to the notion of a unitary public interest.

The response to this greater complexity was to institutionalise conflicts, for which reason pluralism has become a variable of public organisation, while the law has been recognised as the place for the resolution of conflicting interests and for the selection of those prevailing from time to time.

It was asked to legislators to dampen and neutralise conflicts by providing solutions, which the administration could apply while remaining, at least formally, extraneous to the dynamics of strife.

Faith in the capacity of the law to definitively resolve conflicting interests has confirmed the idea of an administration that represents in both operational and organisational terms the sequence of events necessary to move from an abstract solution to a practical decision. Such administration is legitimated, then, by the fact of being a "machine" for obedience to the law, and organised by law according to rigid schemes for the distribution of tasks among the offices.

There is no room along this way for individualities to emerge in terms of organisation, even less in terms of action. With respect to the order which the synthesis produced by legislation instils throughout the administration, the individual, as a specific element untranslatable into the general qualifications necessary to abstract rules, represents disorder.

In the individual's relationship with the administrative activity, he (or she) is "the administered"; that is, the object of a unilateral decision, which translates the abstract public interest into a practical decision. Within the administrative organisation the individual is instead a component part of the office, a necessary resource - though neutral as regards the modalities for the functioning of the apparatus. 


\section{The crisis of the ordering capacity of legislative abstraction and the possible new role of the individual resource}

What seems to have become increasingly inadequate in most recent years is the very underpinning of the situation just described, meaning the possibility to recognise to the law and, more generally, to the abstraction and resolution of differing interests that the law presupposes, the capacity to reduce and regulate the complexity of social realities.

In the background there is the profound transformation of the structure of society, upon which the model of modern administration was built.

The current scenario is reflected increasingly less accurately in a vision of reality where the powerful interests are stabilised in a perpetual controlled conflict requiring a stabile administration able to translate legislative decisions into action.

Nowadays, technology and information transform the perception of time and space, and redesign society's interests and needs on the basis of schemes that are difficult to reconcile with the concept of duration (time) and territoriality (space), which the traditional model for rules-making and administration rests upon.

Phenomena such as globalisation, the transnationality of economic processes and the world-wide dimension of certain environmental concerns annul the territorial reference for many of the fundamental issues affecting society.

Contemporaneously, we witness a fragmentation and multiplication of ties that form and dissolve themselves in relation to various interests and increasingly more rapidly, so that the time required for making rules is overly long to such an extent that by the time they come into being they are frequently already outdated.

Analyses of the social dynamics of law describe a profound crisis of the ordering capacity of the juridical approach, as it has been understood up to now in continental European culture. What has lost ground is the idea that through law it is possible to furnish solutions and provide answers.

The monopoly of law as written by legislators and put into practice by the administration is increasingly more threatened by dynamics, which tend to drastically reduce the importance of the typical juridical categories to make room for new, atypical forces.

What derives therefrom is a considerable transformation of the role of law, which loses its function as the only seat for the resolution of disputes and conflicting interests, and as the sole appointed place where solutions are found, instead acquiring that of the delimitation of areas where the same disputes and conflicting interests are reproposed in a 
dynamic fashion, and solutions to them are formulated from case to case on the basis of differing factors.

In relation to the time of execution/fulfilment, all this is expressed in a shift in expectations from guarantee, which results from the conformation to a unitary, predetermined model, to efficiency, which instead derives from the capacity for differentiated responses. If in the first case what is asked to the law is the capacity to describe the expected behaviour, what is asked in the second is to circumscribe spaces, within which it is possible to include differing forms of behaviour.

A different type of involvement of the administration also derives therefrom in the process of the creation and life of the law, with repercussions in terms of both organisation/management and decision/action.

Under the first profile the administration is asked to conform to increasingly higher standards of efficiency, but most of all to provide a swift response to different needs and demands. This means that the greatest expectations are concentrated on organisation for cost cutting, quicker service and the providing of more and different products.

Many of the possible responses to demands of this kind are not found in the law, nor could they be, since they presuppose punctual organisational solutions tailored to fit the actual circumstances.

In a word, it could be said that the key to the new organisation is summed up in "flexibility," in contrast to the inflexibility and predetermination typical of the traditional model.

Under the different heading of activity, today the administration is faced with a twofold challenge: one, meeting the demand for better quality services and end products; two, the multiplicity of the factors, which must be taken into account in making programming and planning decisions.

Meeting these two challenges entails changing the administration's traditional modus operandi.

The former translates into the introduction of "results" among the parameters of public action, side by side with legality.

The latter recognises the necessity of coming to grips with a composite reality where the data to be considered in formulating programmes of public action are manifold.

This last aspect is particularly evident in interventions that bear contemporaneously on different, potentially contrasting elements, all of fundamental importance for the collectivity.

Sustainable development is among the objectives that best exemplify the new type of demand made on the public institutions. The issues that arise in attempting to reach this objective continue to regard the various interests involved and the use of resources, but many new ones have been added in reference to the environmental, economic, 
productive, and/or social impact produced by every decision in the short, medium and long-term.

If one wanted to summarise the features that best characterise the new administration in its activity, it might be said that today public decision-making is conspicuous for a new interest in results and for greater complexity as compared to the past.

This is the general picture wherein new prospects arise for the "person" factor in the course of administering.

The "subjective" factor may in fact bring a dynamic element to the system, making it more flexible and potentially better able to respond to the changing needs of a reality that is increasingly more complex. In the activation of individual resources lies a possibility of using organisational resources in a way at once more economic and more efficient, of changing the way such resources are employed in the sense of serving whatever needs the action calls for, of introducing into public decision-making elements left out of the synthesis performed by norms, of instilling a result-oriented outlook and safeguarding interests active outside institutional circuits.

The thesis sustained is that the reforms over the last few years have gone in this direction, albeit with vicissitudes and uneven results.

In this perspective it seems useful to analyse certain of the solutions and legal instruments, through which an attempt has been made to introduce the subjective/individual factor into administrative organisation and action in order to assess, whenever possible, their results and limits.

\section{The individual in the new administrative organisation: autonomy, valuation, and responsibility of management}

An area where the administrative system's decision to invest in the subjective factor appears most convincing regards the role recognised to management in the new model of administration.

In the background there is an affirmation of the principle of distinction between political direction and management. Involved is a modality for the articulation of competencies through a functional definition of the two different phases of the administrative decision-making process arranged in sequence. The first phase concerns the identification of the objectives of the activity and the allocation of resources, and is a matter proper to the organs for political legitimation. The second, operative phase is for the realisation of the same objectives, and is the province of the bureaucratic management organs, to which the law recognises an area of reserved competencies in the matter of administrative management. 
However, the heading, under which the individual aspect is found is not that of activity in a strict sense, understood as the adoption of acts and measures coherent with the guidelines. In fact, in this field the manager not only executes programmed acts that frequently exhaust the discretionary element inherent in the decision, but also is in any case an organ of the administration and as such acts in the name and interest of it. Different is the case of certain choices that are organisational, preliminary or in any event instrumental to activity pertaining to administration and provisions, which the manager answers for directly and personally.

From a legal standpoint this is essentially realised by the inclusion of three elements in the organisation of the public offices: autonomy, evaluation and responsibility.

The first element takes concrete form in the introduction of an individual, subjective decision-making phase as an addition to organisational tools. This is made possible by a legislative decision to limit the province of public law sources, as well as by the consequent functional definition of an area, within which decisions are made by the managers in the exercise of private powers.

Let us examine the details.

The principles in the matter of the organisation of the public offices are presently contained in the single text on public employment ${ }^{5}$, which in Section 2 identifies a first sequence of organisational sources, to which is delegated the discipline of the tasks and way of functioning of the offices. In this provision it is established that public administrations shall define, in accordance with the general principles established by law and by means of organisational acts, the fundamental lines for the organisation of the offices, the offices of greatest importance, and the methods for assigning the headship thereof, as well as the overall number of staff.

Therefore, the relevant public law sources are twofold: legislative, whose only remaining task seems to be to establish "the general principles" in the matter of organisation; and administrative (regulations and general administrative acts), which intervene to regulate the subject matter on the basis of the principles laid down by law.

If one considers the material ambit delegated to administrative sources, however, it is evident that it is insufficient to exhaust the entire matter of organisation, since it only contemplates the "fundamental lines for the organisation of the offices" and not the detailed discipline, and the identification of "the offices of greatest importance" and not all the offices, etc.

${ }^{5}$ Legislative Decree N. 165 of 2001, available at <http://www.senato.it/parlam/ leggi/deleghe/01165dl.htm>. 
What is witnessed is a sort of withdrawal by the public sources of organisation, which no longer exhaust all possible choices, but instead limit themselves to a general discipline of the subject, leaving room for a further decision-making level. This latter is now the competence of the management organs, to which legislators have left the adoption of further "decisions for the organisation of the offices".

As anticipated, the other key element in the situation lies in the nature of the acts adopted by the managers in the matter of organisation, which are defined by the law as acts undertaken with "the capacity and the powers of a private employer".

What this means first of all is that at this level the organisational choices are not effected in the exercise of a discretionary public power, but are the expression of a private autonomy. All this is functional to a more flexible organisation, and forms a corollary to the privatisation of employment by public administrations. Such privatisation would have been only formal in nature except for the fact that the transformation of the legal regime pertaining to labour relations came in tandem with the parallel privatisation of the organisational choices that most directly bear on the modalities of job performance.

However, along with these assuredly pivotal aspects, the introduction of a level of private decision-making in the organisation of the public offices is one of the most tangible indications of the reform's investment in what we have called the subjective factor.

An organisational choice made by a manager with the capacity and powers of a private employer is not in fact configured as measure taken by the administration as such, but as the personal decision of the subject who adopts it, imputable only to the same.

The novelty is not merely formal, but rather marks the entrance into administrative organisation of a dynamic force unknown to the discipline of the offices entire based on public law, as was true up until the reform of the1990s.

The making of organisational decisions in the exercise of a private power, albeit within the limits previously established with reference to public law sources, does not mean translating an abstract precept contained in a higher-ranking source into practical terms. The differing nature of the power (private) that the manager exercises in organising the offices represents a break in the different stages of the process that begins with the general principles established by law, continues along the basic lines set by regulation, and finally identifies the offices of greatest importance and makes it possible to frame the pertinent organisational decisions as "free" choices within a circumscribed sphere.

Within this sphere any lawful decision is possible in the abstract, just because a "legitimate" decision in the public law sense does not exist. 
This means that in order to modify the organisation of the offices at this level it is not necessary to modify the public law sources of reference, which would instead be necessary if the organisational decisions to be changed were in the form of the execution/fulfilment of previous decisions. All of this represents a decisive gain in terms of flexibility and the potential for adapting the organisational set-up to fit the changing requirements of the activity.

However, what this means above all is that each manager can "make the difference" compared to another based on his or her personal qualities.

Linked to this point is the second instrument identified as a sure sign of the emergence of the individual factor to the organisational level: evaluation. Involved here is a verification process that allows such personal qualities to emerge and to be assigned a value.

Above and beyond the different facets and problems in application bound up with these processes, it is interesting to note how in the early stage of the reform, evaluation was essentially conceived as a verification of the results produced by the activity of each manager. What was to be taken into consideration was supposed to be mainly the costs of management and the achievement of objectives. A certain importance was also to be attributed to the modalities for action though a finding in relation to the proper and economical management of public resources, as well as the observance of impartiality and the proper course of administrative affairs.

Therefore, while there was an evaluation of the subject/manager, it was essentially through the "objective" data in relation to the activity.

The current situation partially differs. The same evaluation, which per se was already an appropriate tool for allowing specific individual qualities to come to the light, has become even more subjective, not in an arbitrary sense, but in the sense that attention is shifted from objectively measurable factors (activity/products) to aspects typical of and exclusive to the individual, such as personal skills and attitudes in the field of management.

The reform of the internal controls ${ }^{6}$ in fact distinguishes between the control of management, which aims at ascertaining the costs, output and products of the activity, and the evaluation of staff with management responsibilities. This latter is specifically for the purpose of ascertaining the job performance of the managers, as well as their behaviour with respect to the development of the professional, human and organisational resources assigned to them (organisational competencies).

${ }^{6}$ Legislative Decree N. 286 of 1999, available at <http://www.senato.it/parlam/ leggi/deleghe/99286dl.htm>. 
The reference to "performance" and above all to "behaviour" makes evident the new attention to aspects able to reveal the specific qualities of the individual manager and to assign a value to them.

All this is also reflected in the third legal instrument indicating the importance of the individual in the organisation: responsibility. The assignment of powers, including organisational, to a manager in fact corresponds to a particular type of responsibility normally defined "for results", which serves to indicate the connection between results, understood in a broad sense, and a series of consequences affecting the manager in terms of pay and labour relations.

The subjection to such responsibility represents the link necessary for giving substance to the two aspects considered above and for relating certain juridical consequences to them, which take into account that the autonomy and organisational capacity of managers must in any case be directed to reaching the objectives set by the leadership organs.

Significantly, this type of responsibility has been considered as at once answering the need to assure effective compliance with the political direction given and the autonomy of the managerial function. In fact, it takes the place of every other form of control over the "free" activity of the manager, which is to say over the choices made within a sphere of autonomy, and cannot be evaluated in terms of the legitimacy/correspondence to a predetermined model.

Responsibility for results is construed by the regulations as the subjection of the manager to a series of consequences connected to the emergence, through the evaluation process, of how the said manager has used his autonomy in the employment of the resources allocated for the achievement of expected results. Obviously, responsibility has a positive side that takes concrete form in the pay variable awarded in relation to results obtained or the assignment to a higher position of leadership responsibility. Just as obviously, there is a negative side ranging all the way from failure to receive the monetary reward for results attained, to involuntary retirement from public service.

Above and beyond the characteristics of such a responsibility, which here can only be described in summary fashion, the point to stress in terms of the interpretation proposed is how - unlike with other forms of legal responsibility - responsibility for results does not concern the violation of the rules or the causing of damage, but managerial performance evaluated in terms of both results and conduct.

This makes it possible to state that the heart of the legal mechanism of managerial responsibility is not a hypothetical "culpable act", but a whole set of factors where the fitness of the individual, the adequacy of the activity, and results obtained all intertwine. 
All this has the effect of producing a further consequence readable in terms of the introduction of the individual element into the organisation, albeit considered in a partially different sense than heretofore.

Based on a process specular to the process of the administrative organisation's investing in personal resources, one consequence is that attaining a result that is efficient, in addition to being legitimate, becomes in the "interest" of those who work in the administration, in the sense that attached to results are consequences that regard them directly and personally.

This, too, is symptomatic of the role of the individual resource in an administration called upon not just to apply rules, but increasingly more to deal with complex goals that require taking into account manifold interests and calling for a variety of job performance able to adapt swiftly to changing needs in an increasingly more articulated society.

In a situation of this sort it is evident that the requisites demanded of those who operate at managerial levels in the administration can not revolve around just a knowledge of the technical and legal rules in relation to the activity to be performed, but must also give due weight to managerial skills and attitudes.

Not to be overly technical, it might be said that the passage is from the expert manager to the motivated manager.

Here certain traces are to be found in connection with the discipline regulating admission to positions of leadership in the national health service ${ }^{7}$, which includes among its requirements a certificate of attendance in management training courses stressing administrative, organisational, and leadership skills.

The foregoing taken as a whole obviously represents a clean break with the model where the administrative employee formed a neutral resource vis-à-vis the functioning of the offices.

That notwithstanding, there is no lack of difficulty in implementing this kind of process.

The state of advancement in the application of many of the novelties introduced by the reform of the sector is not such as to allow an overall assessment to be made of the results and the limits of all aspects considered.

Nevertheless, one thing already clear is that the various instruments identified are closely interconnected, so much so that if all are not employed together the likelihood is that at best no effective change will be produced, and at worst there will be negative effects on the system.

${ }^{7}$ Cf. Presidential Decree N. 484 of December 10, 1997, available at <http:// www.mclink.it/com/filsel/leggi/lex98/1484_97.htm>. 
At present, there are many situations where the obstacles deriving from uneven fulfilment of the three aspects - autonomy, evaluation and responsibility - are creating problems.

One rather widespread difficulty, especially at the local level of public administration, is that of bringing the organisational autonomy of management up to an adequate level, owing to the resistance of the political organs to effectively limit the public law discipline of the offices to the "fundamental lines" and to the identification of the units "of greatest importance".

On the other hand, the managers are not always really interested in having areas of autonomy for themselves in the employment of organisational resources to the detriment of the organs for providing direction, among other things because the dynamics of their relations with the latter are often far removed from the idea of a complete realisation of the principle of distinction between political direction and administrative management.

Finally, the lack of real room for decision-making in organisational matters makes it difficult to even evaluate "the difference" between managers, consequently weakening the evaluation system, with repercussions in terms of accountability processes as well.

\section{The individual and work in the employment of the new administration}

Signs of the tendency of the administrative system to take a fresh approach to investing in persons in its employ are also evident in certain aspects of public administration labour relations.

In the first place, the decision to privatise the pertinent discipline per se represents an overture to increased flexibility in relations in the workplace and, therefore, goes in the direction of being able to employ persons in a way more in keeping with the real contribution of each.

For purpose of comparison, in the public law regime the idea of the pivotal role of the office prevailed, so that by specific appointment the worker used to become part of an organisational entity, of which he or she constituted the so-called "personal element", whereas in private sector employment the pivotal role is played by the contractual commitment to perform work, which is susceptible to taking different forms within the organisation, albeit within the limits of agreed professional activities.

The employee no longer represents an element in the organisational system where the mere fact of belonging to a certain office used to determine the job duties. In the current system the employee constitutes a resource usable as such, and not just within the limits of his or her initial placement in the system. 
From a technical legal standpoint all this cannot be realised by simply changing the sources for the discipline of the relationship from public to private, but instead requires a rethinking of the relation between organisation and work.

The passage from the idea of an organic staff understood as the framework for the assignment of each staff member to a single office, to the concept of a pool of human resources with a plan for distribution among the various managerial units, can be read in this sense. This entails that within the organisational division, each with its appointed head, the employment of staff and assignment to the single offices must be decided by the head. In fact, only decisions regarding the total number of staff are up to the political organs.

All this is in turn closely tied to our earlier consideration on managerial autonomy in the organisation of the offices.

If, as previously maintained, a sphere exists for organisational decisions not predeterminable in the light of public law discipline in the matter, then it evidently is not possible to inflexibly link the single job performance to a given office. Here, then, we see that corresponding to the private power to define the articulation of the offices at a certain level is an identical private power to fit job performance to needs, in terms of the way the organisation has been set up.

It is in this perspective that the provision contained in the single text on public employment stating that "the decisions regarding the organisation of the offices and the measures inherent to the management of labour relations shall be made by the organs responsible for management with the capacity and the powers of a private employer" can be fully comprehended.

The national contracts by sector or branch ${ }^{8}$ have moved in the same direction with their revision of the system for grouping personnel so as to make the profile of the duties ascribable to each category broader and thus, more flexible. Only when different ways of using staff are effectively available it is in fact possible for the manager to be recognised a real (private) power for shaping job performance.

The different approach to making use of the contribution of the persons who work in the public administration is therefore delineated in the changeover from a model where human resources were one component of a rigid organisational system, where the articulation of the offices was linked to the organic staff, to qualifications and to a list of duties, to a model with a higher degree of flexibility where the organisational decisions made with private powers are linked not only to the possibility of employing people in a manner functional to the decisions

${ }^{8}$ The texts of the contracts are available at the Web site of ARAN, the agency for collective bargaining for the public administrations: $<$ http://www.aranagenzia.it $>$. 
in the matter of the articulation of the offices, but also to the possibility of shaping the articulation around the different professional skills and aptitudes expressed by the workers.

A powerful potential for making the best use of individual human resources lies in this arrangement.

The management of work relations with private law instruments within a framework of greater flexibility introduces the subjective relations factor into the dynamics of work in the employ of the administration. This allows individual differences and specific characteristics to emerge and be used to best advantage, whereas in the previous model they were widely neutralised by the placing of each in a rigid scheme: organisation, office, qualification, job duties.

All this naturally also presents some risks in relation to the eventual misuse of the pertinent instruments, but the greatest risk is that of a substantial draining of their meaning due to the inability of the system to equip itself in a way that is coherent with the new perspectives for investment in personal resources.

A necessary complement for the success of the new arrangement is in fact an effective mechanism for recognising, putting to good use, and rewarding personal performance, so as to allow those responsible for the way staff is used to put sound personnel policies into effect.

Practical experience in this field in recent years has yielded results that are less than satisfactory, above all as concerns the mechanisms for economic incentives for individual and collective productivity.

In the public administration productivity incentives have been prevalently conceived as the redistribution of economic resources to employees as a type of pay raise. As a result, the tendency is to distribute incentive funds uniformly among all staff members or, at best, to connect the amount of the incentive awarded and "outside" factors, such as attendance records or the type of duties assigned.

The attempts made in national contracts involving specific departments to link productivity incentive funds to a requirement to formulate projects and objectives, and to subject the results to some sort of evaluation have been of little avail, as is likewise the case with the ban on the distribution of at least a portion of available incentive awards to the entire staff. To the contrary, the reaction has been an effort at the decentralised bargaining tables to get around the rules and neutralise their potential effects.

If to this is added the merely economic nature of the incentive and the small sums involved, it is easy to understand why this experience has basically been a failure.

At present, with the most recent national contracts an attempt has been made to overcome some of the system's most obvious shortcom- 
ings by making the arrangements for productivity incentives more flexible, in order to encourage experimentation useful for adapting them to different needs and to allow putting them to different uses even within the same administration.

A very significant act was the attempt to break the rigid link between the quality of individual job performance and merely economic incentives. In fact, it is provided in certain department contracts that the same evaluation system prearranged for the awarding of incentives shall be used to reward certain professional experiences that tend to enhance the professional skills possessed or acquired by individual employees. Involved here are horizontal advancements and certain subleadership positions where the quality of individual job performance is taken into account in making the assignment. This opens up new possibilities for the use of incentives from the standpoint of coherent personnel policy.

In this perspective, it is conceivable that such instruments, which so far have produced meagre results, might be used with greater success in tandem with other devices for recognising and rewarding professional contributions within the administration.

On a different plane, another modality for the valorisation/investment in personal resources present in the administration is to stimulate individual contributions to certain processes for the betterment of the organisation and its activity.

However, signs of this are still feeble.

A significant measure in this sense was contained in the decree for the reform of public employment (Section 12, par. 5 bis, 5 ter, and 5 quater of Legislative Decree N. 29 of 1993), with the provision stating that staff may promote initiatives aimed at the improvement of public services, at the simplification and acceleration of procedures, and at increasing ways of gaining access to information. A positive verification of the results of such initiatives was to be included in the personal records of the employee and was to count toward competitive examinations and in career advancement.

At present, traces of the recognition of the need for individual contributions from staff to the functioning of the administration, with particular reference to public relations, are to be found only in the Code of Conduct for employees of the public administrations ${ }^{9}$, where, for example, it is asked to the employee to carry out his professional duties in such a way as to limit the demands made on citizens, by simplifying administrative activity and making it as efficient as possible.

${ }^{9}$ Decree of the President of the Council of Ministries of November 28, 2000, available at <http://www.palazzochigi.it/servizi/provvedimenti/>. 


\section{The individual citizen as a resource of the new administration}

Discourse regarding the new role of the individual as a resource in the relationship between the citizen and the public administration is a much more delicate matter, and has its roots in an evolution of the administrative system that is not limited to the reforms of recent years. It is in the relationship between the administration and the administered where the basic features of an administration are in fact mostly evident.

However, certain recent innovations undoubtedly do represent significant events in the progress of the changing ratio between the regulatory function and the providing of services, with the balance progressively tipping in favour of the latter.

A first observation regards the greater attention of the administrative system to the needs of the citizen, which, as previously indicated, translates into a greater concern for the results produced by administrative activity, as well as into greater guarantees for individuals and better performance of services.

This has opened new prospects for control and verification of the administration "from below" on the part of citizens.

In the traditional model, where the functions of regulation and order prevailed, the foregoing role was limited to and mediated by the legitimation afforded by the electoral process to the top organs in the public administration, and thus exhausted in a phase preliminary to administrative action itself. In today's model, however, other new factors come into play: in addition to social groups, individuals now have a say.

The point has been tellingly made that if a function of an administration providing a service is to satisfy the consumer of that service, then it follows that only the consumer is authorised to judge the quality of the result obtained. This is certainly true for services, and is also partly so for administrative work in a narrow sense.

Evidently, the modalities making it possible for the citizen to control the administration differ for services and administrative activity.

Control over administrative services by citizens entails providing mechanisms for gathering consumer evaluations and making effective use of the opinions expressed in the activity and organisation of services.

The provisions contained in the so-called "services charters" - written information on products provided and consumer rights - move in the direction of paying more attention to the consumers' opinion. The need to sound the opinion of those who use a service is expressly stated in the pertinent discipline, with a view to bettering administrative performance and increasing consumer satisfaction based on the opinions expressed. 
The recent provisions on the matter of public information and communication ${ }^{10}$ can be read in the same light; the provisions state that the administrations shall set up channels for the verification of the quality of services and consumer satisfaction by listening to public opinion and through internal communications.

If the system is slowly starting to record consumer opinion, the time when a legally significant recognition will be granted to such opinion still seems a long way off.

Still, a trace of this is contained in the provision for the possibility of reimbursement for the sum paid for a service in the event that it fails to meet the specified standards of quality and timely service ${ }^{11}$.

The step is significant in and of itself, being useful in affording the citizen more protection, but it is not automatically able to set in motion processes for the transformation/improvement of the service. To this end a system of accountability would seem more appropriate, with direct involvement of both consumers and public administration employees by holding them responsible for their actions. In this way, for all intents and purposes the citizen would be able to become an active party in dealing with management, in a relation mirroring that of the leadership organs and operative managerial organs.

Under the different heading of administrative activity in the area of provisions and measures, the reforms of the recent years have produced a set of tools, which ought to favour forms of control over administrative action by those to whom such activity is directly addressed and other interested parties. Involved here are institutions set up for furthering transparency and participation, designed to enable the citizen to be informed about an action as soon as it takes place, and to intervene with the administrative agent.

This provides the key for reading such tools as the requirement to give notice of the beginning of proceedings, which informs the interested parties that the administration has begun the decision-making process, or the requirement to allow access to administrative records, which makes possible the acquiring or viewing of necessary documentation ${ }^{12}$.

Another of the possible fruits of participation is an agreement between the administration and the interested parties on the discretion-

${ }^{10}$ See Law N. 150 of 2000, available at <http://www.senato.it/parlam/leggi/ 00150l.htm>.

${ }^{11}$ Directive of the President of the Council of Ministries of 27 December 1994, available at <http://www.palazzochigi.it/servizi/provvedimenti/>.

${ }^{12}$ See Law N. 241 of 1990, Gazzetta Ufficiale, Aug.18. 1990, N. 192, made available by the Istituto Poligrafico dello Stato, along with all other issues from 1987 on, at: $<$ http://www.ipzs.it>. 
ary content of a decision with regard to a measure being taken. The contribution of a participant can extend to suggesting an alternative solution to the administration's original proposal, with such input necessarily being taken into account by the decision-making authority whenever pertinent.

Probably, behind the break with the obligatory unilateral nature of the administrative action and its typicalness there is also the awareness of the impossibility of resolving the dynamics set in motion by differing interests once and for all, meaning by law. Hovering in the background is the perception that the world is too multi-faceted and changeable to be contained in a abstract general provision such as found in legal standards.

However, the reality is that today these institutions still have not had an appreciable effect. One plausible theory is that what is involved here is not a mere normative novelty, but a transformation so profound as to require time for it to be absorbed by the administration and citizenry alike.

Above and beyond the possible outcome in terms of mutual accords, the participation of private individuals in public decisions can represent a resource of great importance, considering that the administration operates in a highly complex context where certain interests operate outside institutional circuits because they lack channels for access to them or because these interests have come into being so rapidly that there has been no chance for the administration to attend to the matter, while at the same time the data and information, which the administration must take into account are increasingly more and the time available for making decisions is increasingly less.

Just think of the myriad facets in connection with the idea of sustainable development, which is an idea based on the need to reconcile a great many aspects and factors that are not always compatible.

It is no mere happenstance that the following statement is contained in Agenda 21: every local administration ought to engage in dialogue with the citizens, local organisations and private enterprise, and adopt its own local Agenda 21. Through consultation and consensus building, the local administrations should obtain from the local and business communities whatever information necessary for formulating the best strategies.

According to this guideline, participation of citizens in administrative decisions is not conceived as a function of potential agreements, but construed as a true and proper contribution to the decision-making process regarding collective interests, which cannot be unilateral because of the complexity and magnitude of the consequences, so that an on-going process for creating awareness and consensus is required.

In this whole question, however, there is no use hiding the potential dangers that might be lurking if the institutions were to abdicate their role as the appointed place for resolving differing interests. 
The risk is in fact twofold.

On the one hand, it must not be forgotten that in participation there is always the danger that the interests of the weak will be excluded from the decision-making process, most of all since the process takes place increasingly less in the political seat as an expression of collective interests, and increasingly more in the administrative seat in relation to private interests.

On the other hand, the mechanisms designed to involve individual citizens and associations in public decisions might lead to a weakening of responsibility for decisions made, which is and must remain exclusively public, on pain of otherwise causing certain dynamics of power to be removed from the democratic process.

In contrast, making citizens responsible can be conceived within a different framework. The individual can in fact be called upon to make declarations, for which he or she assumes full responsibility, in place of public certification.

Here the involvement of citizens in administration is not so much in the form of a contribution to/participation in public decision-making as a sort of "self-administration".

Within the framework of the reforms, including for the purpose of simplifying relations between the citizenry and public institutions, ways have effectively been provided for the substitution of certain public certificates with declarations made by individuals ${ }^{13}$. Along the same line, there are instances where those seeking authorisation to perform certain activities can merely declare that they meet legal requirements without having to wait for the administration to examine the case. These are possible situations where the citizen himself plays an active administrative role.

In view of these last remarks, a final consideration can be made concerning the fact that based on a reconstruction of the characteristics of the reforms what emerges is not only a new administration, but also a new type of citizen. In view of the instruments now available for allowing individuals a greater role in administrative action, the new citizen that the reform seems to have in mind is certainly more aware and informed than before, more attentive to the system, and more of a participant in the life of the community. The new citizen is now in a dialectical position with proposals and pretences, rather than in a position of passive waiting. Here, we are evidently dealing with a citizen conscious of his or her rights and responsibilities, and able to interact with a public administration that must place increasingly greater trust in the individual citizen.

${ }^{13}<$ http://www.funzionepubblica.it/intranet/Autocertif/index.htm>. 


\title{
Policies for sustainable development: economic globalisation and administrative globalisation
}

\author{
SteFAnO BATTINI*
}

\begin{abstract}
1. Introduction -2 . The environment internationalises the economy: sustainable development in the discipline of "Agenda $21 " .-3$. The economy internationalises the environment: global trade and the safeguarding of health in the discipline of the so-called "SPS Agreement". - 4. Conclusions. Toward administrative globalisation?
\end{abstract}

\section{Introduction}

"As long as States exist, meaning sovereign political organisations occupying a given territory, universal organisation will never be able to be anything but administrative, meaning based on social interests and not on political interests .... If the organisation were to be politi$\mathrm{cal}$, as a result the States as such would necessarily, de facto, disappear as sovereign political bodies .... Perforce, a universal political organisation would more or less rapidly become sovereign, and once become sovereign, would deprive the States of their own sovereignty: the task of defending all possible interests of human life would be incumbent upon it".

This is how one of the first essays dedicated to the theme of international administration, published in 1902 by a Russian scholar ${ }^{1}$, concluded. In these words can already be found in embryonic form the basic features of the institutional structure of the international system of rules and regulations, and its underlying assumption.

The features are those of a system founded on distinction and on separation. This separation is first and foremost between the forms of organisation that preside over political - and therefore conflictual -

* Università degli Studi di Urbino.

${ }^{1}$ P. Kazansky, "Théorie de l'administration internationale", Revue générale de droit international public, vol. 9, 1902. 
relations among the States, and the forms of organisation that instead govern administrative relations, connoted by the co-operation of the States in the economic and social field. However, separation is also found among organisations of the second type, with each body being autonomous and competent for only a well-defined area or subject matter.

The presupposition regarding this structure, as Kazansky clearly perceived, is represented by the principle of the intangibility and indivisibility of the sovereignty of the State, which would not tolerate competition from other forms of public power for general purposes over its territory.

The observation has been repeated so frequently as to have become a commonplace, for which reason today it must be reconsidered in view of the oft-declared crisis of the nation-State, called upon to share with other authorities increasingly greater portions of sovereignty. As is wellknown, the sharing process contemporaneously involves lower levels, meaning with local authorities; horizontal levels, meaning with the private sector; and higher levels, meaning with international bodies.

Under this latter heading, for a county like Italy the most important phenomenon is without a doubt represented by its participation right from the very beginning in the European integration process. As is well-known, the process started out with a functional approach by creating distinct international organisations with limited duties of an economic nature, then underwent a progressive evolution toward a supranational type of institutional structure of a political nature, finally arriving at a peculiar form of union of legal systems, for the conceptualisation of which the notion of "European juridical space" ${ }^{2}$ has recently been proposed in Italian literature.

However, participation in "European juridical space" must not mislead us into underestimating the fact that Italy is also involved, with full rights, in the process of constructing a "global juridical space" ${ }^{3}$. In

${ }^{2}$ M.P. Chiti, "The EU Legal Order", Institutional Reforms in the European Union. Memorandum for the Convention, EuropEos, Roma, 2002. Italian literature on the institutional profiles of the European Union is highly developed. Among recent works of a general nature with particular attention to administrative profiles, cf. M.P. Chiti and G. Greco, ed., Trattato di diritto amministrativo comunitario, Giuffré, Milano, 1998; M.P. Chiti, Diritto amministrativo europeo, Giuffré, Milano, 1999; G. della Cananea, "L'amministrazione europea", ed. S. Cassese, Trattato di diritto amministrativo. Diritto amministrativo generale, vol. II, Giuffré, Milano, 2000; E. Chiti, Le Agenzie europee, forthcoming; C. Franchini, "I principi dell'organizzazione amministrativa comunitaria", Rivista trimestrale di diritto pubblico, 2002, n. 3; S. Cassese "La signoria comunitaria sul diritto amministrativo", Rivista italiana di diritto pubblico comunitario, forthcoming.

${ }^{3}$ S. Cassese, "Lo spazio giuridico globale," Rivista trimestrale di diritto pubblico, 2002, n. 2. 
fact, in the case of Italy more than just the national economy is involved in the processes of globalisation. While the country's economic involvement is obvious from statistical data - to cite but one of many examples, in 1996 1,324 Italian industrial groups were active beyond national borders, as were 240 Italian banks (115 of which outside of Europe) - for present purposes the salient fact is that Italy constitutes a significant component of the foundation upon which the "globalisation institutions"4 rest: Italy is a member of G7; it ranks sixth on the list of major contributors to both the UN and the International Monetary Fund; it holds an interest in the World Bank (8.5\%) equal to that of France, the United Kingdom, Germany and Japan; citizens of Italy occupy 18 high executive positions and 5 important political positions in the UN administration alone; while in the 1991-1997 period Italy was a signatory to 87 multilateral accords and 628 bilateral accords 5 .

Within this framework, then, it becomes particularly important for the Italian scholar in the area of public powers to devote attention to the structure of the international institutional system, and to ask himself in particular whether the changes that have affected the principal of the intangibility of State sovereignty are destined to be reflected in its characteristics - whether, in other words, the principle of separation, upon which the system is still based to a considerable degree, ought not to be progressively abandoned and eventually replaced by a different guiding principle: the principle of connection and co-ordination among the various components forming it.

From this standpoint there could be no more suitable testing ground than the policies for sustainable development, if it is true that the concept leads, in the words contained in a recent report by the Secretary General of the United Nations, to the "inextricable connection" between environment and development, and to the simultaneous pursuit of economic, social and environmental objectives.

Naturally, on this occasion it would not be possible - nor perhaps would it be useful on any occasion - to approach the theme of sustainable development through systematic analysis, in consideration of the fact that in a certain sense the expression belongs to the category of "indeterminate legal concepts", just as does globalisation, which nonetheless are terms that will both be used in this writing.

In order to flee the risks of indeterminacy at least in part, it becomes necessary to circumscribe the object. We shall limit our illustra-

${ }^{4}$ M.R. Ferrarese, Le istituzioni della globalizzazione, Il Mulino, Bologna, 2000.

5 The source of the data is the Ministry of Foreign Affairs, Il ministero degli affari esteri al servizio dell'Italia nel mondo - Rapporto di sintesi, Roma, 1998. 
tions below to two cases - two "fragments", one might say, involving the international system - where the confrontation, typical in national systems, between interests pertaining to environmental protection and/ or health on the one hand, and the promotion of economic development on the other, instead takes place on the international scene. This is because, as with our first illustration, the global dimension of environmental problems requires that the related themes in connection with economic development be dealt with at level transcending the State; or else because, contrariwise, it is the globalisation of economic relations that attributes international importance to environmental protection and health policies, as with our second illustration.

After an examination of both the above, in our concluding remarks some more general observations will be made in reference to the initial question raised concerning an eventual change in the structure of the institutional system proper to the international system.

\section{The environment internationalises the economy: sustainable development in the discipline of "Agenda 21"}

The progressive thinning of the ozone layer, the greenhouse effect and climatic changes, deforestation, the reduction of biodiversity, and other similar, extremely serious problems ${ }^{6}$, have at least two features in common.

First, they constitute per se global problems (so-called "global commons"). Only the citizens of all the States together can resolve them, just as the citizens of all the States suffer the effects of the failure to do so. Consequently, public policies intended to effectively deal with objectives of this nature cannot but be elaborated, or orchestrated, at the international level.

Second, the problems involved are multidimensional, so to speak. They are at once the product and the cause of a complex of economic and social phenomena, whose solution therefore requires measures and actions which contemporaneously take into account such factors in their entirety. Consequently, national and international public policies aimed at effectively dealing with similar threats to the environment cannot but entail interaction involving a mix of sectors by integrating and bal-

${ }^{6}$ For some summary indications on the most pressing environmental issues of a global nature facing the international community, see the chapter entitled "Sustaining Future" contained in the so-called "Millennium Summit Report" by the Secretary General of the United Nations, We the Peoples. The Role of the United Nations in the $21^{\text {st }}$ Century, United Nations Department of Public Information, New York, 2000, p. 54 and following. 
ancing environmental protection interests with numerous other collective interests, among which in particular those pertaining to economic development in a broad sense.

The global nature of environmental problems therefore requires a joint effort by all the States, while the multidimensional nature of the same problems makes it incumbent upon all the States to accept limitations and conditioning such as to make the respective socio-economic structures compatible with an adequate level of protection for natural resources and human health.

The fact is, however, that not all States perceive the complex relation between environment and development in the same way: concerns for safeguarding the environment are more felt in the wealthier States which have already reached a satisfactory level of development, among other things by making the related environmental costs also weigh on countries which today are still "developing". These latter instead - and not entirely without reason - appear decidedly less disposed to submit to conditioning and limits weighing heavily on their own course of economic development for the sake of global requirements to protect the environment.

This is the context where the concept of sustainable development was born and prospered, which, as is commonly known, received its normative consecration in the so-called Declaration of Rio, approved in 1992 by the United Nations International Conference on Environment and Development (UNCED).

This concept in fact represents a compromise solution between the interests - environment and economic development - as well as a result of mediation among the States which assign differing priorities to the $\mathrm{two}^{7}$ : the third principle contained in the Declaration of Rio explicitly

${ }^{7}$ On the complex activity of the mediation and resolution of differing interests expressed at the Rio Conference and its official acts, cf. G. Sjosted et al., Negotiating International Regimes: Lessons Learned from the United Nations Conference on Environment and Development, IIASA, Graham and Trotman, 1994. General treatments of sustainable development by now are legion, among the most noteworthy being P. Sands, "UNCED and the Development of International Environmental Law", Yearbook of International Environmental Law, 3, 1992, 3; P. Sands, "-International Law in the Field of Sustainable Development", British Yearbook of International Law, 65, 1994, 303; Lang, ed., Sustainable Development and International Law, London, 1995; A. Boyle and D. Freestone, International Law and Sustainable Development, Oxford University Press, Oxford, 1999; Le Nations Unies et la protection de l'environnement: la promotion d'un développement durable, Septièmes recontres internationales d'Aix-en-Provence, Editions A. Pedone, Paris, 1999; J.C. Dernbach, "Sustainable Development as a Framework for National Governance", Case Western Reserve Law Review, 49, 1998, 31-32; J.S. Applegate and A.C. Aman, "Syncopated Sustainable Development", A.D. Tarlock, 
recognises the "right to development" 8 to the poorer countries, while the fourth principle contained in the same declaration establishes that environmental protection must be considered an integral part of such development process, thus accepting the demands of the richer countries?.

In brief, due to a sort of spill-over effect the global dimension of environmental themes constitutes a factor for internationalisation, or globalisation, including of economic development policies.

The mutual integration of environmental protection policies and economic and social development policies is reflected in a particularly significant way in the discipline contained in one of the most important documents approved, along with the Declaration, by the Rio Conference of $1992^{10}$ : the "Global Programme of Action on Sustainable Development", better known as Agenda $21^{11}$.

Although on a formal plane Agenda 21 is a legally non-binding document, it might be defined as a sort of programme for international governance. It has several interesting features, which signify its originality compared to the more traditional instruments of international law.

One such feature pertains to the scope of the discipline contained in Agenda 21.

In contrast to most international treaties, it does not constitute, nor even concur in constituting, an international regime, by which is meant, according to the most accredited definition, a "set of principles, norms, rules and decision-making procedures, around which converge the aspirations of the actors in a given thematic area" ${ }^{12}$. The provisions contained in Agenda 21 do not in fact involve just a single sector, but regard a broad, diversified series of more than 40 "programme areas", ranging from the reduction of poverty (Chapter 3 ) to demo-

"Ideas Without Institutions: The Paradox of Sustainable Development", Indiana Journal of Global Legal Studies, vol. 9, 2001, p. 1 and following, p. 35 and following.

8 "The right to develop must be fulfilled so as to equitably meet developmental and environmental needs of present and future generations". The concept of sustainable development thus leads to a third compromise solution; namely, the balancing of the right to economic well-being of the present generation and the right of future generations to inherit a planet whose natural resources have not been destroyed.

9 "In order to achieve sustainable development, environmental protection shall constitute an integral part of the development process and cannot be considered in isolation from it".

${ }^{10}$ Also on the occasion of the Rio Conference several important multilateral accords were stipulated in environmental matters: the Framework Convention on climatic change, the Convention on Biodiversity and the Convention for combating desertification.

11 The document is available at: <http://www.un.org/esa/sustdev/ agenda21text.htm>, visited on 13 February 2002.

${ }^{12}$ S. Krasner, ed., International Regimes, Cornell University Press, Ithaca, NY, 1983. 
graphic development (Chapter 5); from the protection of the atmosphere (Chapter 9) to human health conditions (Chapter 6); from urban settlements (Chapter 7) to deforestation (Chapter 11); from biotechnology (Chapter 16) to product safety; from the condition of women and children (chapters 24-25) to the conservation of biodiversity (Chapter 15); etc.

A second original feature has to do with the structure of the norms contained in Agenda 21.

In general, international treaties take the form of a contract; they regulate relations among the States and define the mutual rights and obligations thereof. Consequently, international law places external restrictions on the sovereignty of the States, just as internal law is generally held to place strictures on the autonomy of private individuals: all forms of behaviour not expressly forbidden are allowed ${ }^{13}$. However, the structure of Agenda 21 differs from this, in that it does not regulate relations among States, but instead identifies and assigns functions which the States themselves are called upon to perform ${ }^{14}$. In this way it seems to transform the sovereign power of the States into discretionary power,

${ }^{13}$ As late as 1927 , in the celebrated Lotus case the International Court of Justice upheld the principle according to which the States are allowed to do everything not expressly forbidden by international law (S.S. "Lotus", 1927, P.C.I.J. (ser. A) N.. 9, at. 18). However, today this conception of international law no longer appears to correspond to reality, if for no other reason than, as has been observed, owing to the proliferation of the rules of international law, which cover "a broad and growing range of economic, political and social matters" (P. Sands, "Turtles and Torturers: The Transformation of International Law", International Law and Politics, vol. 33, 2001, p. 548).

${ }^{14}$ With reference to each of the numerous "programme areas" comprising it, the Agenda 21 discipline is articulated in terms of objectives, activities and means of implementation (above all, financial resource). As made explicit in the Preamble, such structure is inspired by the concept of global partnership, and consists of a "dynamic programme" which "will be carried out by the various actors according to the different situations, capacities and priorities of country and regions". It should further be noted that the carrying out of the functions pursuant to Agenda 21 is not assigned only to the States, but, as just mentioned, to "various actors". While it is certainly true that in this regard the States assume primary responsibility, nonetheless other categories of subjects also figure for the purposes of Agenda 21, among them being local public authorities (cf. Chapter 28 of Agenda 21, entitled "Local Authorities' Initiatives in Support of Agenda 21 ", on the basis of which, in particular, each local authority is called upon to elaborate, based on proceedings that assure the participation of the local communities, a "local Agenda 21"), non-governmental organisations (cf. Chapter 27 of Agenda 21, entitled "Strengthening the Role of Non-Governmental Organizations: Partners for Sustainable Development"), and, above all, international governmental organisations for specific sectors. Therefore, these latter co-operate with the States for the realisation of a programme which is elaborated outside their respective systems, and which is imposed on them just as it is on the States. 
meaning one to be exercised in view of purposes, goals and interests defined at the international level.

The third and final original feature - the one of greatest interest for present purposes - regards the organisational mechanisms created in order to implement the programme contained in Agenda 21. Because of its nature cutting across sectors, it does not constitute a new international regime. It does not fit into a single already existent regime, nor does it establish a new international organisation, nor simply increase the competencies of a previously-constituted organisational apparatus. In reality, the implementation of Agenda $21^{15}$ requires the participation of most if not all the international organisations; the institutional structure provided for the implementation of Agenda 21 is above all prearranged to assure the co-ordination of the various components of the international institutional system.

Highly significant in this regard is the choice of the intergovernmental component of that structure. The Commission on Sustainable Development ${ }^{16}$ is, in fact, not a new conference where all the States that undersigned Agenda 21 are represented, but a subsidiary organ (functional commission) of the Economic and Social Council of the United Nations, which is the body charged with the co-ordination of the various specialized agencies part of the UN family. The functions of the commission include the overall control and monitoring of the process of implementing Agenda 21; for example, through an analysis and evaluation of the reports submitted by the States and by the various international organisations belonging to the United Nations system ${ }^{17}$. Moreover, along the same line, although it is composed of representa-

${ }_{15}$ The process of implementing Agenda 21 is the object of periodic review, normally once every five years, within the framework of successive world summit conferences. The August 2002 World Summit on Sustainable Development in Johannesburg proposed to evaluate the progress made in the ten years since the adoption of Agenda 21 , and increase efforts to put the programme into practice. For a general assessment of the implementation of Agenda 21, cf. Report of the Secretary General of the United Nations, Implementing Agenda 21, E/CN.17/2002/PC.2/7, available at <http:// www.johannesburgsummit.org/html/documents/documents/html>.

${ }^{16}$ The Commission itself was established by the Council as a functional commission of the Economic and Social Committee of the United Nations with ruling n. 207/ 1993, whereas its functions were established by the General Assembly of the United Nations with Resolution n. 47/191 of December 22, 1992. The Commission is composed of 53 members elected for a three-year term by the Economic and Social Council from among the representatives of the Member States of the United Nations and of the special agencies.

${ }^{17}$ Cf., respectively, 3.b) and 3.f) of Resolution 47/191 of the United Nations General Assembly. 
tives of States, it is required to provide itself with procedures that "allow the relevant international organisations both within and without the United Nations system, and including the multilateral financial institutions, to appoint special representatives to the Commission"18.

However, in the implementation of the programme contained in Agenda 21 the task of co-ordinating and integrating the international public authorities is primarily assigned to the administrative system, set up within the framework of the Administrative Committee on Co-ordination (ACC), recently reformed and renamed the Chief Executive Board (CEB). Chaired by the Secretary General of the United Nations, this body brings together the top executives of the international organisations directly or indirectly linked to the UN, including the Bretton Woods group (the International Monetary Fund, the World Bank and the World Trade Organisation). The ACC in turn has established a special Inter-Agency Committee on Sustainable Development (IACSD), composed of high-level international civil servants of the international organisations that are members of the ACC and that are involved in carrying out Agenda $21^{19}$. In order to assure continuity and effectiveness in the performance of its functions, the IACSD, which meets only twice a year, has created a liaison network hinging upon the figure of the task managers, who are responsible for co-ordination, the identification of common strategies and the exchange of information, each in relation to one or more Agenda 21 "theme areas". As a rule, the task manager is a member of the staff of the international organisation which, in that specific theme area, can be considered the reference point for the "primary" interest, so to speak. For example, the director of the health department in relation to sustainable development of the Secretariat of the World Health Organisation (WHO) is the IACSD task manager for the implementation of Chapter 6 of Agenda 21, in the area of the protection and promotion of human health. Another example is the general director of the natural sciences section of the Secretariat of UNESCO, who is the IACSD task manager for the implementation of Chapter 35 of Agenda 21, entitled "Science for Sustainable Development", and so on ${ }^{20}$.

${ }^{18}$ Cf. 8.b) of Resolution n. 47/191 of the United Nations General Assembly.

${ }^{19}$ IACSD members comprise fifteen United Nations bodies, including such funds and programmes as UNICEF, UNCTAD, UNEP; 15 international organisations associated with the United Nations, including the ILO, FAO, UNESCO, WHO and IBRD; and three secretariats of international conventions, specifically, the conventions on climatic change, biodiversity and deforestation.

${ }^{20}$ The complete list of task managers and certain other information on the organisation of the IACSD are available at: <http://www.un.org./esa/sustdev/tmafp.htm>. 
Therefore, what we are dealing with is an original institutional phenomenon, which to a certain extent is reminiscent of the concept of composite administration. Unlike the general rule, in this case there is no administrative apparatus pertaining to an international organisation; to the contrary, here there are different international organisations which, through their own representatives, are part of a sole administrative system. It will be necessary to return to the question of the significance of this phenomenon in our concluding remarks.

\section{The economy internationalises the environment: global trade and the safeguarding of health in the discipline of the so-called "SPS Agreement"}

As mentioned, the theme of sustainable development can also be approached from a different standpoint. Instead of starting with the global dimension of certain environmental themes, in order to illustrate the effect of internationalisation that derives from it in terms of economic development policies, it is possible to take an opposite tack. As a matter of fact, in certain cases it is the global dimension of the economic dynamics that explains the international importance progressively assumed by environmental regulations or the safeguarding of human health, which do not per se aim at dealing with problems of an intrinsically global nature.

As is generally known, beginning no later than the 1970s with the success in most of the more developed countries of liberal and free trade policies, the goal of economic growth has been pursued not through the positive intervention of the national States, but through the progressive opening up and integration of the national markets, something which has frequently entailed abstention and withdrawal on the part of the States. As is equally well known, the consequent increased mobility of capital and of goods, together with technological progress, ended up displacing its creators - the States - and provoking a crisis in them whose nature and entity is subject to no little debate in scholarly circles ${ }^{21}$.

What does appear certain, however, is that the complex of economic phenomena commonly summed up in the abused formula of

${ }^{21}$ The subject matter is obviously too complex and the existing literature is too extensive to be examined here. For a review of the principal scholarly interpretations, a useful reading is provided by M. de Vries, "L'attaque de l'État: comparaison des arguments", RISA, n. 3/2001, p. 443 and following. In recent Italian legal literature, cf. S. Cassese, La crisi dello Stato, op. cit.; U. Allegretti, Diritti e Stato nella mondializzazione, Città aperta edizioni, Troina, 2002. For a sociological profile, cf. M.R. Ferrarese, Le istituzioni della globalizzazione, op. cit. 
globalisation has produced an asymmetry between the dimension - glo$\mathrm{bal}$ - of the markets and the dimension of the regulation of economic activities, which has difficulty in freeing itself of national borders.

In terms of international relations, this asymmetry is a source of growing complexity since the relevance of national rules beyond the confines of the national system that produced them, while once an exception $^{22}$, today tends to become the rule ${ }^{23}$. In fact, the national disciplines travel with the goods that are produced within the framework of them, and for that reason acquire, so to speak, a "global impact" that the national regulators are forced to reckon with ${ }^{24}$.

For example, in a global market where customs barriers are forbidden, the setting of particularly high national environmental standards can have an equivalent effect on another State, which is to say one capable of protecting domestic business from the competition of other countries which enjoy a "comparative advantage" in a particular sector. Overregulation, therefore, can negatively affect the economic development of another State, in addition to more generally affecting overall economic growth connected with the liberalisation of international trade.

On the other hand, in a market where goods and capital move freely, the setting of less stringent standards can contribute to reducing the costs of businesses that locate within that State, which therefore might gain advantage in international competition (so-called ecological

${ }^{22}$ Cf. O. Mayer, Le droit administratif allemand, Giard-Brière Editeurs, Paris, 1906, $\mathbb{S} 62$ (Le droit administratif international): «C'est à titre exceptionnel - et pour lequel il faut un fondement spécial - que l'action d'une puissance étrangère est considérée comme juridiquement valable sur notre territoire; à l'inverse, notre État ne prétend que par exception à exercer son autorité dans la sphère du territoire étranger».

${ }^{23}$ As P. Sands observes ("Turtles and Torturers. The Transformation of International Law", op. cit.), starting with an examination of the now-famous "turtles and shrimp" case decided by the Appellate Body of WTO (United States - Import Prohibition of Certain Shrimp and Shrimp Products, Report of the Appellate Body, WTO Doc WT/DS58/AB/R - Oct. 12, 1998), "what one state does or permits to be done within its territory can be of legitimate interest in another state, however distant. Local acts are internationalized, and national boundaries seem more permeable".

${ }^{24}$ In considering the effects of the globalisation processes on national administrative law, reference is made to a "Global Impact Statement" in A.C. Aman, "Proposals for Reforming the Administrative Procedure Act: Globalization, Democracy and the Furtherance of a Global Public Interest”, Indiana Journal of Global Legal Studies, vol. 6, 1999, p. 417. According to Aman, "the administrative rulemaking process should include an explicit direction to consider seriously the global implications of proposed rules .... If, for example, stringent environmental regulations will shut down certain industries and move them offshore, what impact is this likely to have on global pollution? ... Such questions can help create a global discourse and a debate on the global public interests related to domestic regulatory proposals". 
dumping ${ }^{25}$. Therefore, environmental under-regulation can negatively affect the economic development of other countries, with the further risk, feared above all by environmental organisations ${ }^{26}$, that the latter countries may in turn be induced to lower their own environmental protection standards, creating a "race to the bottom", where the least severe regulator would end up prevailing ${ }^{27}$.

The risks of over-regulation and under-regulation both point out the need for the harmonisation of international standards and national regulations capable of producing a significant impact of international trade.

Involved are dynamics familiar to the countries forming the European Union, where, as is known, the process of creating the common market required assigning policies not envisioned in the establishing treaties to a supranational level, just because of the distortion produced in the marketplace by a lack of uniformity in the national regulations. Perhaps the most significant example of this is to be found in Community environmental policy, which before being given its own specific normative basis by the European Single Act (1986), had developed within the framework of the Treaty norm pertaining to the approximation of laws of the Member States, marked by a "strong ancillary connotation regarding the measures aimed at pursuing the objective of establishing a market and having it function properly"28.

Now the process of the formation of global markets appears to be giving rise to analogous tendencies ${ }^{29}$. Proof of this is offered by the fact that the World Trade Organisation, whose task it is to guide

${ }^{25}$ In addition, a widespread opinion - in truth one not well-supported by economic studies of an empirical nature - has it that stringent environmental regulations, especially common in the wealthier nations, wind up being a factor in decisions of companies, especially the multinationals, to relocate in developing countries owing to the more favourable environmental law "offered" there. For a recent treatment, cf. S. Nespor, "La globalizzazione danneggia l'ambiente?”, Riv. giur. ambiente, 2002, p. 1 and following, which also includes valuable bibliographical references to the economic literature on the subject.

${ }^{26}$ Among others, interesting considerations are found in L. Wallach and M. Sforza, Whose Trade Organization?, Public Citizen Foundation, 1999; Italian translation, WTO - Tutto quello che non vi hanno mai detto sul commercio globale, Feltrinelli, Milano, 2000.

${ }^{27}$ By this time the literature on the effects produced by economic and trade integration is indeed vast. For a general treatment, as well as numerous bibliographic references, cf. H. Nordstrom and S. Vaughan, "Trade and Environment”, WTO Special Studies, 1999.

${ }^{28}$ G. Cocco, A. Marzanati, R. Pupilella and A. Russo, "Ambiente”, ed. M.P. Chiti and G. Greco, Trattato di diritto amministrativo comunitario, op. cit., p. 104.

${ }^{29}$ For observations concerning a parallel between the European Communities and the World Trade Organisation, cf. M.P. Chiti, Diritto amministrativo europeo, op. cit., pp. 9-10. In Chiti's view both constitute "what we might define as second-generation organisations", and represent the most recent and innovative examples of tendency "that seems to definitively supersede the model of international community as a community of States". 
and regulate the process, is increasingly called upon to deal with problems that pertain to national policies other than the trade policies of the States, once considered a strictly domestic matter ${ }^{30}$. Consequently, pressures multiply to broaden the competencies of the WTO to the extent of including matters such as the safeguarding of working conditions, the environment and health, whose connection with international trade presents diverse, complex aspects ${ }^{31}$.

Nevertheless, it is difficult to imagine an evolution of the WTO that retraces that of the European communities, which is to say one giving rise to a progressive broadening of the competencies, including outside the strictly economic sphere. Such a course in fact would end up by altering the WTO's very nature; also, more generally, it appears incompatible with the structure of international relations and with the institutional order which is a reflection of it, which is based on a plurality of regimes: policies for the safeguarding of labour, of health and of the environment in fact already have their own appointed seat for international co-ordination distinct and separate from the WTO.

In a similar context, the need to integrate the diverse policies for specific sectors caused by the rise of global markets seems destined to be met in a different way, meaning though institutional mechanisms for linkage among the various international regimes, and among the international organisations which are an expression thereof.

A significant exemplification of the success of such mechanisms for linkage is contained in the international accords on the application of sanitary and phytosanitary measures (the so-called SPS Agreement), that form an integral part of the establishing treaties of the WTO.

The overall objective of this discipline is to strike a balance between conflicting needs: the need to recognise the right of a State to safeguard

\footnotetext{
${ }^{30}$ In his so-called Millennium Summit Report (We the Peoples, op. cit., p. 11), United Nations Secretary General Kofi Annan, indicates this phenomenon as one of the most obvious signs of the changes caused by globalisation: "The post-war institutional arrangements were premised on a world made up of separate national economies, engaged in external transactions, conducted at arm's length. Globalization contradicts each of these expectations. It is hardly surprising, therefore, that the trade regime is under such stress - it increasingly deals with traditionally "domestic" matters rather than border barriers". For considerations along this same line about the effects of globalisation on international law, cf. P. Sands, "Turtles and Torturers", op. cit., pp. 537-538: "Simply put, it means that activities which were previously treated as local (a matter of domestic concern only, to take the language of the U.N. Charter) are internationalized. This, in turn, provides conditions for new level of lawmaking beyond the state".

31 "The trade and ... industry is booming", as observes D.W. Leebron in "Linkages: The Boundaries of the WTO", American Journal of International Law, n. 96, 2002. The reference is to the fact that, in Leebron's view, trade is now developing in tandem with other industries, such as trade and environment, trade and health, trade and labour, etc.
} 
the health of its citizens through the application of whatever standards it deems appropriate, such as in the interest of food security ${ }^{32}$, against the need to safeguard the interests of the commercial enterprises of other States whose comparative advantage in a given productive sector might be nullified by the application to their export products of standards designed not so much to safeguard the health of the first State's citizens as to protect its domestic companies from international competition ${ }^{33}$.

As is evident, in this case the weighing of potentially conflicting interests - promotion of trade and the safeguarding of human health cannot but take place at the international level, since what is involved is striking a balance between the health of the citizens of one State and the profits of the companies of another State.

In the discipline of the SPS accords this aim is pursued, among other things, by encouraging the harmonisation of national regulations, which, however, is accomplished through the recognition of standards elaborated outside the WTO, within the framework of various regimes and international organisations. More particularly, pursuant to Section 3, par. 2 of the SPS accords, only those national measures consistent with international standards enjoy a presumption of compatibility with the discipline of international trade ${ }^{34}$. Instead, those national disciplines that set higher standards of protection than international standards, while admissible in theory, are nonetheless subjected to rigorous, penetrating scrutiny by the WTO bodies for the resolution of controversies ${ }^{35}$. This scrutiny is designed in

32 Section 2, par. 1: "Members have the right to take sanitary and phytosanitary measures necessary for the protection of human, animal or plant life, provided that such measures are not inconsistent with the provisions of this Agreement".

${ }^{33}$ To that end, the subsequent paragraphs of Section 2 define the limits of the right recognised in par. 1 . The sanitary or phytosanitary measures introduced by the States must first of all observe the principle of proportionality, being applied "only to the extent necessary to protect human, animal or plant life". Second, they must comply with scientific principles, meaning that such measures must be "based on scientific principles and ... not maintained without sufficient scientific evidence". Third, the principle of non-discrimination comes into play: "Members shall ensure that their sanitary or phytosanitary measures do not arbitrarily or unjustifiably discriminate between members where identical or similar conditions prevail including between their own territory and that of other members". Finally, the national measures must observe the principle of good faith: "measures shall not be applied in a manner which would constitute a disguised restriction on international trade".

${ }^{34}$ Section 3, par. 2: "Sanitary or phytosanitary measures which conform to international standards, guidelines or recommendations shall be deemed to be necessary to protect human, animal or plant life or health, and presumed to be consistent with the relevant provisions of this Agreement and of GATT 1994".

${ }^{35}$ For a significant exemplification, cf. "EC Measures Concerning Meat and Meat Products (Hormones)", Report of the Appellate Body, WT/DS26/AB7R, WT/DS48/ $\mathrm{AB} / \mathrm{R}$, January 16, 1998. 
particular to ensure that such higher national standards have a "scientific justification" (Section 3.3.), and were adopted on the basis of appropriate techniques for the evaluation of the risk (Section 5) ${ }^{36}$.

As concerns food security, the international standards recognised by the WTO based on the SPS accords are those elaborated by the Codex Alimentarius Commission" ${ }^{37}$, which constitutes a "second-generation" 38 international organisation. It is also a mixed organisation, having been established not by an international agreement, but as a result of a joint decision by the top intergovernmental organs of two international organisations, the FAO and the WHO, the Member States of which then also became members of the Commission simply by giving notice to the directors general of the two organisations.

The Commission is an intergovernmental or political organ ${ }^{39}$, meaning composed of the representatives of the States ${ }^{40}$, which nevertheless

${ }^{36}$ In the event that scientific knowledge about the existence of the risk to health is insufficient, the States may, based on available information, adopt sanitary orf phytosanitary measures on a temporary basis pursuant to the so-called principle of precaution contained in the Declaration of Rio (principle 15). However, the SPS accords contain a restrictive interpretation of the principle, by requiring that, within a reasonable time, any State resorting to it shall obtain the additional information necessary for making a more objective assessment of the risk, and consequently control and review the measures adopted. More recently, the Protocol of Cartagena on biodiversity has provided for a further application of the principle of precaution with specific reference to the matter of genetically modified organisms, about which cf. J.S. Applegate, "The Prometheus Principle: Using the Precautionary Principle to Harmonize Regulation of Genetically Modified Organisms", Indiana Journal of Global Legal Studies, n. 9, 2001, p. 265 and following.

${ }^{37}$ The standards elaborated by the Commission are expressly cited in the preamble of the SPS accords, along with the standards set by the International Office of Epizootics for safeguarding the health of animals, and by the International Plant Protection Convention for safeguarding the health of plants.

${ }^{38}$ As observed by A. Caffarena, Le organizzazioni internazionali, Il Mulino, Bologna, 2001, p. 50, beginning in the 1980s the majority of international organisations have no longer been created by the States, but by other international organisations. According to a study of the 1981-1992 period, this type of organisation constitutes approximately $70 \%$ of the total (C. Shanks, H.J. Jacobson and J.H. Kaplan, "Inertia and Change in the Constellation of International Governmental Organizations, 19811992”, International Organization, 4, 1996, p. 593 and following).

${ }^{39}$ It should also be noted that the Commission is assigned the function of submitting proposals and advising the directors general - that is, the top administrative officials - of the FAO and the WHO, who in addition have important powers in the matter of the running of the Commission itself. The typical relationship between the political and bureaucratic organs of international organisations are thus in certain respects reversed in this case, since here it is the intergovernmental organ - the Commission - that serves the administrations of the FAO and the WHO.

${ }^{40}$ It should further be noted that the delegations that participate in the work of the Commission, although headed by functionaries appointed by their respective govern- 
adopts standards on the basis of proceedings dominated by the administrations: on the one hand, by the secretariat of the Commission, which has the power to undertake initiatives and make proposals; and on the other hand, by the national administrations for specific sectors, whose functionaries participate in the meetings of the numerous committees ${ }^{41}$, hosted by the Member States, whose task it is to examine and amend the normative proposals elaborated by the secretariat prior to their submission to the Commission for final approval as a standard contained in the Codex Alimentarius ${ }^{42}$.

As with the case of the Agenda 21 discipline, the discipline contained in the SPS accords is inspired by the need to strike a balance

ments, may, and in fact do, also include representatives of industry and consumer organisations. Consequently, on the international level in addition to the interests of the States, the viewpoints of private interest groups are directly represented by their delegates.

${ }^{41}$ The committees are subsidiary organs created by the Commission and composed of members of the Commission who have indicated to the Director General of the FAO or the WHO their intention to participate on such committees, or else of members selected by the Commission itself. The by-laws state that the representatives of the subsidiary organ shall be "specialists in the subject matter of such organ" and must participate on a regular basis in the work of that same organ (Section IX. 4. of the by-laws). In practice, it is mainly functionaries of the national administrations for a particular sector who fill this role. With but few exceptions, each committee is hosted by a Member State, which assumes the running expenses and appoints the Chairman thereof. At present the Codex committees are 25 in number. Nine of them are the so-called General Subjects Committees or Horizontal Committees, which concern themselves with issues regarding all categories of food products; for example, the committee on general principles is hosted by France, that on labelling by Canada, that on methods of analysis by Hungary, that on pesticide residues by the $\mathrm{Ne}$ therlands, etc. The remaining 16 are the so-called Commodity Committees or Vertical Committees, which concern themselves with standards referring to individual food categories; for example, the committee on milk is hosted by New Zealand, that on cocoa and chocolate is hosted - obviously - by Switzerland, that on fruit and vegetables by Mexico, etc.

${ }^{42}$ The procedure for the elaboration of standards is highly complex and at times requires several years for completion. It is articulated in eight phases, as follows: (1) the Commission decides to elaborate a standard for inclusion in the Codex Alimentarius, and designates the competent committee; (2) the secretariat elaborates a proposed draft standard or avant-projet de norme; (3) the proposed draft standard is referred by the secretariat to members of the Commission and to the other interested international organisations in order to have the benefit of their views; (4) the observations received are communicated to the competent committee, which is empowered to examine them and to amend the secretariat's proposed draft standard; (5) after giving due consideration to the observations made by its members, the Commission elevates the proposed draft standard, as modified by the committee, to the status of draft standard or projet de norme; (6) the secretariat now conveys the draft standard to the Member States and to the interested international organisations for their observations; $(7)$ the observations received are communicated to the competent committee for the examination and eventual amendment of the draft standard; (8) the Commission gives its final approval to the draft standard, at which point it becomes a standard in the Codex Alimentarius. In 
between interests (international trade and the safeguarding of health) and among States which may assign a different value to them. In this case as well, the purpose of the discipline is reflected in the institutional mechanisms it provides for, which hinge on the interconnections linking different international regimes and organisations, as well as their respective administrative systems.

In the case of the SPS accords, linkage takes the form of norms, in the sense that the norms elaborated within the framework of an administrative system coming under an international organisation the Codex Commission - likewise produce effects outside the organisation, inasmuch as they also get "adopted" by a different international regime - the WTO - whose organs afterwards apply them. Through this connection technique, defined in the literature as borrowing regimes ${ }^{43}$, both organisations increase their own power. The WTO avails itself of the work of the Codex Commission to harmonise national regulations susceptible of jeopardising international free trade, which is what the organisation is for. The Codex Commission instead borrows from the greater institutional effectiveness of the WTO system for the purpose of ensuring food security: the standards approved by the Commission are not, in fact, mandatory per se for the States, but the level of observance of them is appreciably increased owing to the effect of their application on the part of the WTO organs for settling controversies.

Perhaps the most interesting aspect is the following: just as in organisational terms the international administrations - such as those which participate in the IACSD - tend to become part of a system that goes beyond the confines of the single international organisations, so in functional terms the norms adopted by the international administrations - such as those elaborated by the Codex Commission - tend to constitute a law no longer referable to the system of a definite international organisation.

It seems useful to undertake a more general treatment of the phenomenon in our concluding remarks.

\section{Conclusions. Toward administrative globalisation?}

As initially observed, to a great extent the traditional arrangement of the organisation of international public authorities presupposes and

consideration of the lengthiness of the ordinary procedure just described, the regulations provide for certain instruments for flexibility, such as recourse to an accelerated procedure or a decision by the Commission to skip certain phases of the process, or directly assign them to the committee.

${ }^{43}$ Cf. D.W. Leebron, "Linkages", op. cit., p. 14. 
reflects a structure of international relations which, at least in the dominant realist ${ }^{44}$ and neorealist ${ }^{45}$ approach, are viewed exclusively as a confrontation of interests of States ${ }^{46}$.

This may involve a "political" confrontation, which primarily pertains to the theme of security and the balance of power among the States as such, considered unitarily; for example, this is what occurs within the framework of the United Nations Security Council.

Otherwise, the confrontation, and the co-operation, may regard certain specific circumscribed sectors, signally in the economic and social field. Especially concerning the latter, a set of separate and distinct international "regimes" come into play, with differing degrees of institutional stability. At times these give rise to true and proper international organisations endowed with international legal status and their own bureaucratic structures (secretariats). Based on special "relationship agreements," some such organisations constitute UN specialized agencies, with respect to which, however, they jealously defend their autonomy - which is deeply rooted in history - due to the fact that they answer exclusively to their member States ${ }^{47}$.

In this way, numerous separate seats come into being for the coordination of State policies pertaining to a specific sector, as therefore do places for a confrontation of the States over interests touching on a given subject matter. As a consequence, in each such appointed place direct relations come to be entertained among the administrations by sector of

${ }^{44}$ The text of reference, the first edition of which was published 1948, is H.J. Morgenthau, Politics among Nations. The Struggle for Power and Peace, McGraw-Hill, New York, 1985 (Italian translation, Politica tra le Nazioni, Il Mulino, Bologna, 1997).

${ }^{45}$ In particular, cf. K.N. Waltz, Man, the State and War, Columbia University Press, New York, 1959 (Italian translation, L'uomo, lo Stato e la guerra, Giuffrè, Milano, 1998); and especially, by the same author, Theory of International Politics, Newbery Award Records, New York, 1979 (Italian translation, Teoria della politica internazionale, Il Mulino, Bologna, 1987).

${ }^{46}$ This approach rests on four basic assumption, as has recently been observed by P.J. Katzenstein, R.O. Keohane and S.D. Krasner, "International Organization and the Study of World Politics", International Organization, 52, 4, Autumn 1998, p. 658: (a) "states are the key actors in world politics"; (b) "states can be treated as homogeneous units acting on the basis of self-interest"; (c) "analysis can proceed on the basis of the assumption that states act as if they were rational"; (d) "the absence of any legitimate authority in the international system means that conflict between self-interested states entails the danger of war and the possibility of coercion."

${ }^{47}$ A classic on the theme is C.W. Jenks, "Co-ordination: A New Problem of International Organization", Académie de droit international, Recueil des Cours, 1950, II, p. 151 and following. Also, cf. E. Luard, International Agencies: The Emerging Framework of Interdependence, Royal Institute of International Affairs, 1977, especially p. 264 and following. 
the different States. These administrations create links and integrate among themselves and - facilitated in this by the international secretariats - form networks and coalitions that avoid the control of the States ${ }^{48}$. The States disaggregate from within into a plurality of administrative bodies, which then reaggregate on the international level by integrating with the corresponding administrative bodies of the other countries ${ }^{49}$.

The outcome of the process is the phenomenon of administrative internationalisation, characterised by a confrontation of the interests expressed by various national bureaucracies competent in a given sector. The phenomenon is nurtured by institutional pluralism and by the relative autonomy of the infra-State points of reference for public interests, simultaneously feeding it by accentuating the division of public policies by sector.

The phenomena previously described appear to show a change visà-vis the above arrangement, which may be summed up as a passage from internationalisation to administrative globalisation. The change quite likely represents the institutional reflection of a change in the structure of international relations, which are no longer exclusively connoted by a confrontation involving the interests of States or of more or less autonomous national administrations operating in a given sector.

As we have seen, the concept of sustainable development itself is the result of a balancing of differing, potentially conflicting interests environment and economic development - which takes place directly on the international scene. In other words, what this means is that the function of balancing different collective interests ceases to be exercised unilaterally by the States within their borders ${ }^{50}$.

A consequence of this change is the growing inadequacy of an institutional model based on the totality of single non-communicating international regimes. As a result, the need is increasingly felt for a new system which neither negates nor replaces the previous system, but instead uses it as a starting point for creating new forms of linkage between sectors among the different regimes and organisations of which they

48 The literature on transgovernmental relations, which by now is highly developed, initially took its cue from R. Keohane and J. Nye, "Transgovernmental Relations and International Organizations", World Politics, October 1974, vol. 27, p. 39 and following.

${ }^{49}$ On this point, cf. A.M. Slaughter, "The Real New World Order", Foreign Affairs, 76 (1997), 183; and, by the same author, "The Accountability of Government Networks", Indiana Journal of Global Legal Studies, vol. 8 (2001), p. 347 and following, which includes numerous bibliographical references of interest.

${ }^{50} \mathrm{~A}$ recent contribution in this sense is the paper by G. Della Cananea, "I pubblici poteri nello spazio giuridico globale", delivered at the meeting of the "S. Martino" group on globalisation, Pescara, April 12, 2002. 
are an expression.

One example of what such need entails in terms of organisation is the creation of networks to bring together parts of the secretariats of various international organisations, such as that presiding over the implementation of Agenda 21. Under these circumstances the international administrations assume a twofold function. As has been clear for some time, one such function is to facilitate the creation of international coalitions of national administrations for specific sectors, which thus acquire further autonomy with respect to the States of which they are a structural component. The second such function, which has received less attention, is, in then acting as an expression of said coalitions on an international level, to operate as centres of reference for a specific collective interest with international or global dimensions.

The recognition of the rules adopted within the framework of other international organisations likewise corresponds to the same need under the normative profile, with an example being the WTO's recognition of the standards contained in the Codex Alimentarius. In such cases the purpose of the acts of the international administrations is not to induce the States to maximise a certain interest (e.g., the safeguarding of health), but instead to determine what level of protection of that interest is compatible with the achievement of other collective interests (e.g., the promotion of international trade) assigned to other international organisations.

It is in this sense, then, that the emergence of a trend to administrative globalisation can be observed, which compliments and surpasses the long-standing trend to administrative internationalisation.

The latter consists of the international confrontation and linkage among national administrations for a particular sector, and puts to the test the capacity of the State to co-ordinate the relevant policies.

The former instead consists confrontation and linkage among international centres of reference for national administrations for specific sectors, which tend to become, more simply, centres of reference for collective interests with global dimensions.

In contrast to administrative internationalisation, administrative globalisation accentuates neither the public policy approach in terms of sector nor the autonomy of the administrative bodies charged with attending to different interests. On the contrary, it marks a recovery by the public authorities - first and foremost the States - of a capacity to perform on a higher level their proper function of balancing economic and social interests, which is a political function par excellence.

If this vision of the international system progressively moving away from the institutional fragmentation that has long characterised it is correct, then the contribution that Italian public law culture can make 
is important for an understanding of phenomena presently still in embryonic form. In fact, as early as the second decade of the twentieth century Italian public law culture was prescient enough to react against the State positivism then dominant, which denied the existence of a legal organisation proper to international society and concluded by reducing international law to a mere sum total of many separate accords produced by the will of the States, thus conceiving international law "akin to Penelope's web, the weaving of which begins anew with each agreement." Instead, maintained Romano, "from its earliest phase international law asserts itself as an institution, as a necessary result of inter-State organisation - of the structure with which, in fact and in law, it is taking shape" 51 . 



\title{
Conclusions: Material on the Concept of Sustainability
}

\author{
Giuseppe Cogliandro*
}

The main topic of the Meeting is sustainable development. It forms the vantage point of three of the four papers, concerning information technology, public ethics and globalisation.

According to the definition elaborated by the World Commission for Environment and Development, development is sustainable when "it satisfies the needs of the present without compromising the capacity of future generations to satisfy theirs", meaning development that ensures to future generations living standards no lower than today's.

The noun "development" is used in conceptual opposition to "growth", with the intention of indicating qualitative variations with the former term and quantitative variations with the latter.

But the popularity of the locution in Italian is due to the English adjective "sustainable" (susceptible to being maintained), whence derive the Italian "sostenibile", the French "durable" and the Canadian French "soutenable", all three of which are improper or at any rate not cogent.

Sustainable development is located at a midpoint between a maximum, which optimises the current value of utility, and a minimum not below the threshold of survival. It thus does not imply the blocking of productive activity, but rather the transformation of the production model in order to pass from quantity to quality, from growth to development.

The term sustainability is very widespread in normative, administrative and jurisprudential sources in the Italian system. Here we shall limit ourself to citing the minimum material necessary for identifying a semantic sampling which, if not complete, is sufficiently broad to make it possible to infer the meaning or meanings of the term (in the normative, administrative and jurisprudential passages that follow, the words "sustainability", "sustainable" and "sustain" will appear in italics):

ENVIRONMENTAL SUSTAINABILITY. It is precisely the need to safeguard the environment as a limit to growth that, as we have seen, is at the origin of the elaboration of the concept of sustainable development. The most important sectors for which observance of the principle of sustainability is required are as follows:

* Corte dei Conti, Università degli Studi di Firenze. 
- the safeguarding of waters. One of the objectives pursued by the general discipline (Legislative Decree n. 152/1999) for the protection of surface, marine and subsurface waters is "to pursue the sustainable and lasting use of water resources, with priority given to potable water";

- land management policy. A 1997 law provides for premiums for the "environmental sustainability of urban areas", including for the purpose of strengthening and directing the spread of innovative intervention in urban areas for a sustainable and conscious management of particularly degraded territories" (Section 2, Law n. 344/1997);

- fisheries policy. Policies pertaining to fisheries and fish farming are inspired, among other things, "by the principles of sustainability and responsibility toward the environment and toward consumers" (Section 1, Legislative Decree n. 226/2001);

- the realisation of public works. Among other things, feasibility studies in the matter of public works must provide an analysis of the situation for each such project "in terms of environmental sustainability" (Section 14, Law n. 109/1994);

- Structural Funds. Through the Funds, the European Community contributes to promoting the harmonious, balanced and lasting development of economic activities (a periphrasis of the concept of sustainable development), the development of employment and of human resources, the safeguarding and improvement of the environment, the elimination of inequalities and the promotion of equal opportunity between men and women (sections 1 and 12, EC Regulation n. 1260/ 1999, Council of June 21, 1999);

SUSTAINABILITY OF THE ECONOMIC AND MONETARY POLICIES OF THE European Union. Section 2 of the Treaty establishing the European Community (known hereafter as the EC Treaty), as amended by Section 2, par. 2 of the Treaty of Amsterdam, assigns the Community the task of promoting, among other things, "harmonious, balanced and sustainable development of economic activities" and "sustainable, noninflationary growth". The concept of sustainability is taken up once again in sections 4 and 121 of the EC Treaty. Section 4 provides that the actions of the Community and of the Member States pursuant to the objectives indicated in Section 2 above, "imply the observance of the following guiding principles: stable prices, sound public finances and monetary conditions, as well as a sustainable balance of payments". Section 121 provides that the reports by the Commission and by the European Monetary Institute (the forerunner of the European Central Bank) addressed to the Council, must among other things examine the "realisation of a high degree of sustainable convergence in reference to 
the observance by every Member State of the following criteria": price stability, "sustainability of the public financial situation", absence of devaluations for no less than two years in the regards of the currency of any other Member State, stable interest rates.

DIDACTIC SUSTAINABILITY. Programming pertaining to the university system for the three-year period 2001-2003 must among other things (Decree of the Ministry of Education, Higher Education and Research n. 115 of May 8, 2001), be inspired by the principles of "didactic sustainability and stability", which imply the existence of the required minimum resources (number of teaching staff, number and size of classrooms, libraries, laboratories, etc.);

SUSTAINABILITY IN THE MATTER OF CO-OPERATION FOR DEVELOPMENT. Among the tasks assigned by Law n. 46/1994 to the Parliamentary Investigating Commission on Italian Policy for Co-operation with Developing Nations was that of ascertaining "the economic and social results of the measures ... with particular reference to the sustainability, to the profitability and to the effective continuity of the functioning of the facilities or of the initiatives";

FISCAL SUSTAINABILITY. One of the selective criteria for controls in the matter of income and value added taxes is the "degree of sustainability of the taxes and the degree of solvency of the taxpayer" (Decree of the Ministry of Finance, December 21, 1990);

HEALTH CARE SUSTAINABILITY. Among the guidelines contained in the delegation to the Government to issue legislative decrees for the reordering of the health care sector is a provision stating that "the exemption of citizens from contributing to expenses is determined in relation to its sustainability vis-à-vis the consumer, taking into account the economic condition of the same, the size of the family, the age of the patient and the need for health-related services in connection with particular pathologies" (Section 50, par. 50, Law n. 449/1997);

SCHOLASTIC SUSTAINABILITY. Measures adopted by public education authorities for the suppression of schools must take into account (in addition to the specific demographic, orographic, economic and sociocultural characteristics of the territory when the school is located, and the distance from other schools and roadways) "the sustainability of the time required to cover the distance in relation to the age of the pupils" (Decree of the Ministry of Public Education, March 15, 1997);

FinANCIAL SUSTAINABILITY. Pursuant to Section 47, par. 4, of Legislative Decree n. 165/2001, the State Audit Court must certify the compatibility of the costs deriving from collective labour contracts undersigned by the administrations and the unions with the instruments for programming and the budget as provided under Section 1-bis, Law n. 468/1978. The certification by the State Audit Court takes the form of 
a resolution and addressed to the special Agency responsible for the representation of the public administrations at the bargaining table during the process of negotiating labour contracts, to the interested Administrations, to the Government and - in some cases - to the Parliament. The certification of the compatibility of contractual costs resulting from collective bargaining agreements postulates: (a) a verification of the reliability of the quantification of the costs, (b) an evaluation of the financial compatibility and (c) an evaluation of the economic compatibility. With reference to the evaluation of the financial compatibility, the Court has declared that for public administrations other than national the mere quantification of the resources allocated for cost coverage does not suffice; rather, precise documented assurances must be furnished as to the sustainability of the financial burden, including through budgetary analysis, statistical data, and elaboration and projections (resolutions 33/01, 49/01, 62/01).

From an examination of these materials it emerges that the term "sustainability" has a twofold lexical significance depending on whether it is used in reference to resources (natural, economic, financial, didactic, scholastic, etc.) or in reference to the impact it produces (e.g., the impact of a policy or public programme on the environment, of taxation or public health contributions on citizens, of a new university course on the facilities, of an outlay on the national budget).

From the standpoint of resources, sustainable means enduring or lasting, but even more not excessive, moderate, congruous, proportionate, balanced, rational, adequate to meet the need, compatible with the destination of the asset. From the standpoint of impact, it means supportable, absorbable, respectful of the proper limits. The exploitation of a forest must not exceed the rate of regeneration; the recurrent outlays budgeted must not exceed ordinary revenues.

Two questions. One: Why is it that such a common term has not been the object of study? Why is it that sustainability, unlike, for example, subsidiarity, has not produced literature? Two: Can the concept of sustainability be applied to human resources (in addition to physical resources), to intellectual assets (in addition to material assets), and specifically to the management of public personnel (the topic of the fourth paper)?

The answer to the first question probably is a matter of semantics. Unlike subsidiarity, sustainability is not an autonomous concept. True, subsidiarity is not an univocal phenomenon, since it can take different forms and directions: horizontal subsidiarity and vertical subsidiarity, which latter can in turn operate on a higher or lower plane. The point here, though, is that whereas subsidiarity is a clear and distinct term pertaining to a phenomenon, the term sustainability involves a specifier, 
a predicate, an attribute. Unlike subsidiarity, sustainability involves not essence, but incidental circumstances.

As for the second question, if it regards prior administrations, the answer has to be no. In the past the management of public personnel was a matter almost wholly apart from the policies pursued by the administrations: it was completely disciplined by law (and therefore constituted a sub-topic of administrative law); the only professional requirement was a generic law background (which was bolstered by the relevant case studies); it was assigned to a special administrative structure (distinct from the appointed structures for the achievement of institutional objectives); it made reference to an autonomous aggregate ("rubric") contained in the budget (which precluded knowing the effective cost of the functions and products of the administrations); it was subjected to formal controls.

The administrative reform approved in the 1990s radically changed the way public sector personnel are managed. Today the matter is regulated by collective bargaining contracts (and thus comes within the framework of labour law); it requires managerial skills and, therefore, knowledge of subjects outside the field of law (including economics, to which we owe the concept of "human capital"); it is assigned to special managers responsible for the structures charged with reaching the institutional goals of the administrations (who therefore are provided with ways of rewarding or punishing staff based on results); it makes reference to the budget aggregates corresponding to the various administrative structures (which makes it possible to know the overall costs of the functions and products of the administrations, including staff-related costs); it is subjected to controls aimed at ascertaining (in addition to the legitimacy) the effectiveness, the efficiency and the economy of administrative action.

In the new context the evaluation of management personnel assumes particular importance, since it constitutes the fundamental mechanism for the passage from an administration for producing documents to an administration for producing results. Section 5 of Legislative decree n. 286/1999 establishes that the public administrations shall evaluate their managers non only on the basis of job performance, but also in terms of behaviour in relation to the "development of professional, human and organisational resources". What this means is that the modern public manager is asked to not only achieve the short-term objectives assigned him or her by the political leadership, but also to use human resources to best long-term advantage by actions fostering sensitivity, stimulation, involvement, motivation and training - all in the perspective of none other than sustainable development. 